\title{
WestVirginiaUniversity
}

THE RESEARCH REPOSITORY @ WVU

Graduate Theses, Dissertations, and Problem Reports

2006

\section{A model of stabilizer roll bearing for a continuous hot-dip galvanizing line}

Vishnu V. Rachamalla

West Virginia University

Follow this and additional works at: https://researchrepository.wvu.edu/etd

\section{Recommended Citation}

Rachamalla, Vishnu V., "A model of stabilizer roll bearing for a continuous hot-dip galvanizing line" (2006). Graduate Theses, Dissertations, and Problem Reports. 3265.

https://researchrepository.wvu.edu/etd/3265

This Thesis is protected by copyright and/or related rights. It has been brought to you by the The Research Repository @ WVU with permission from the rights-holder(s). You are free to use this Thesis in any way that is permitted by the copyright and related rights legislation that applies to your use. For other uses you must obtain permission from the rights-holder(s) directly, unless additional rights are indicated by a Creative Commons license in the record and/ or on the work itself. This Thesis has been accepted for inclusion in WVU Graduate Theses, Dissertations, and Problem Reports collection by an authorized administrator of The Research Repository @ WVU. For more information, please contact researchrepository@mail.wvu.edu. 


\title{
A Model of Stabilizer Roll Bearing for a Continuous Hot-dip Galvanizing Line
}

\author{
VISHNU V. RACHAMALLA
}

Thesis submitted to the

College of Engineering \& Mineral Resources at West Virginia University in partial fulfillment of the requirements for the degree of

\author{
Master of Science \\ In \\ Mechanical Engineering \\ John Loth, PhD, Chair \\ Kenneth Means, PhD, \\ Victor Mucino, PhD \\ Department of Mechanical and Aerospace Engineering \\ Morgantown, West Virginia \\ 2006
}

Keywords: Galvanizing Line, Pot Hardware, Zinc Pot Roller, Conveyor Rollers 


\section{ABSTRACT}

\section{A Model of Stabilizer Roll Bearing for a Continuous Hot-dip Galvanizing Line}

\section{VISHNU V. RACHAMALLA}

The short service life of the hardware inside the molten zinc pot is often the cause for the unscheduled shutdown of a galvanizing line. The lifetime of the hardware used in these lines is not only a function of materials used but also on factors such as line speed, sheet tension, bearing contact pressure, bearing alignment, zinc pot temperature, corrosion as a function of pot chemistry, and surface finish of the materials used. Dr. James Snider has developed a comprehensive data file on the wear rate and corrosion properties of currently available bearing materials. Dr. Snider's dissertation research as well as this thesis work was funded under DOE Project Award Number DE-FC36-01D14042. Snider's research advisor Dr. John Loth designed a new roller bearing configuration which reduces bearing contact pressure by a factor of three without increase in bending moment. It assures bearing alignment and loading uniformity on line. As wear rate is proportional to contact pressure squared, this new configuration has the potential for increased roller bearing life by up to $3^{\wedge} 2=9$ fold. West Virginia University owns the patent rights to Loth's US Patent No: 7,040,482, issued May 9, 2006 and titled: "Bearing Life Extender for Conveyor Type Rollers". This thesis contains detailed and dimensioned components for a redesigned roller for Weirton Steel galvanizing Line No: 5. It uses an 8" diameter by 59.25" long roller, complete with mounting hardware. This thesis describes the features of the new design and their required component tolerances. All components and assemblies were drawn and dimensioned using CAD software Pro-Engineer. The structural finite element analysis performed in ANSYS 10.0. 


\section{ACKNOWLEDGEMENTS}

Firstly I would like to thank my parents and my brother for their great support and encouragement without which none of this would have been possible.

I am very much grateful to my research advisor, Dr. John Loth for his guidance all throughout the course of this project. His significant contributions would never be forgotten. His invaluable knowledge in the field of design inspired me a lot. I would like to thank Dr. Kenneth Means, Dr. Victor Mucino for serving as my committee members.

I would also like to thank all my friends who have played their part in helping me directly or indirectly in all my efforts and lending their support for the successful completion of this project.

Finally, I express my gratitude to god for providing me an opportunity to pursue a higher education. 


\section{TABLE OF CONTENTS}

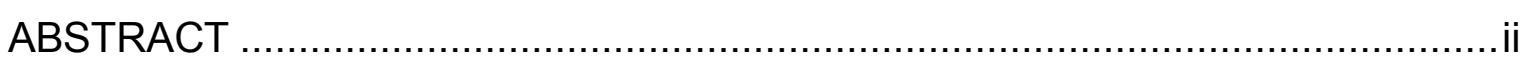

ACKNOWLEDGEMENTS .................................................................ii

LIST OF FIGURES ..............................................................................vi

LIST OF TABLES ...........................................................................................

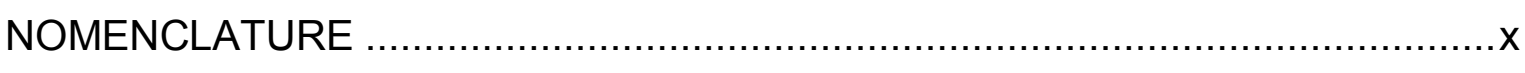

CHAPTER 1- INTRODUCTION............................................................. 1

1.1. The Continuous Hot Dip Galvanizing Process....................................... 1

1.2. Problems faced by galvanizers.............................................................. 4

CHAPTER 2 - LITERATURE REVIEW ......................................................

2.1. Metallurgy of the galvanize coating ............................................... 6

2.2. Metallurgy of Aluminum with the Steel............................................ 10

2.2.1. Percentage of Aluminum in the coating .................................... 11

2.3. Selection of Bearing Type .......................................................... 13

2.3.1. Stresses acting on the Bearing................................................ 14

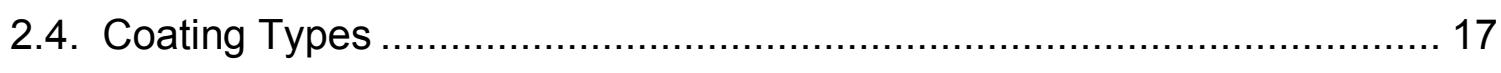

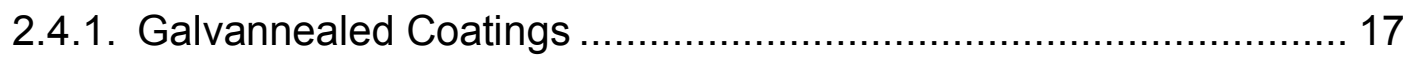

2.4.2. Galvalume Coatings .......................................................... 18

2.5. Control of Coating thickness \& its significance ..................................... 22

2.5.1. Coating Weight Range (Minimum/Maximum Thickness) ............... 23

2.5.2. ASTM Coating Designations.................................................. 26

2.6. Material Optimization - 316L Stainless Steel ....................................... 29 


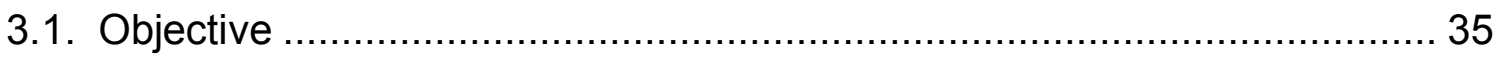

3.2. Wear Characteristics of Bearing Materials ..................................... 37

3.3. New Design for roll bearing to reduce wear-rate ............................... 42

3.4. Stabilizer Roll Design ....................................................... 49

3.5. Dimensioned Drawing Views ................................................... 59

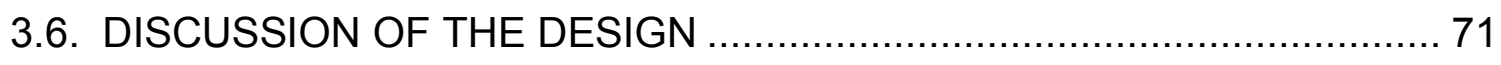

CHAPTER 4 - SUMMARY AND RECOMMENDATIONS ......................... 72

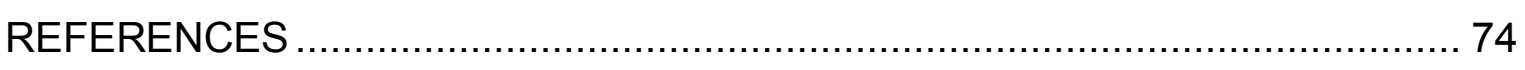

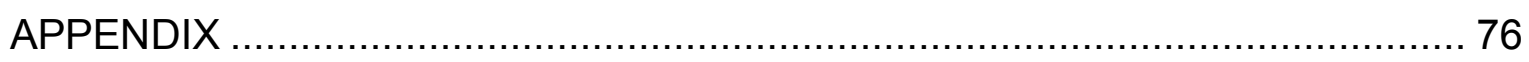




\section{LIST OF FIGURES}

Fig 1.1: Zinc Pot Diagram ......................................................................

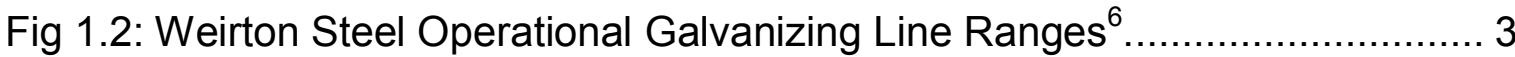

Fig: 2.1 Cross-Section of an Aluminum free galvanizing bath. ${ }^{1}$.......................... 7

Fig: 2.2 Cross-section of a galvanize coating with aluminum containing bath. ${ }^{1} \ldots 11$

Fig: 3.1 Stabilizer roll of about 8-inch diameter with cantilever shaft welded at

each end arms. ${ }^{5}$.................................................................... 35

Fig: 3.2. Roll bearing sleeve and thrust plate shown welded to bridle support

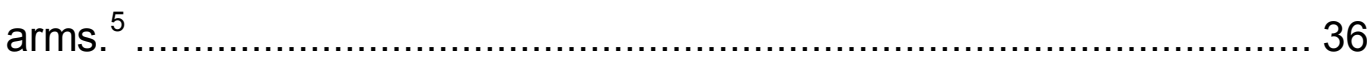

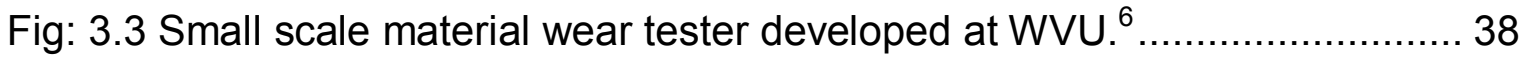

Fig. 3.4 Wear rate of 316 Stainless Steel seat by a 316 Stainless steel ball sample

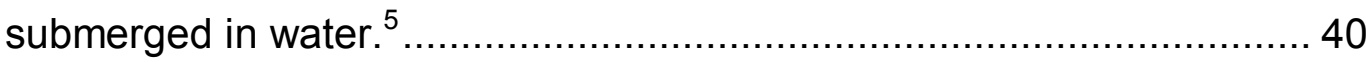

Fig.3.5 Wear rate of Stellite 6 seat by Stellite 6 Ball sample at $460^{\circ} \mathrm{C} .^{5} \ldots \ldots \ldots \ldots . . .41$

Fig.3.6 Conventional roll designs with short stubby shafts welded into roll and

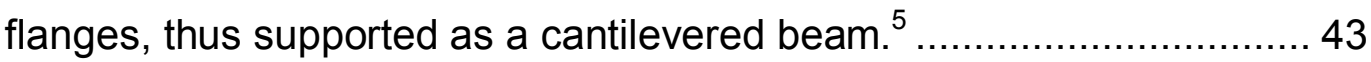

Fig: 3.7 Bearing Life Extender Assembly (Roll display is made transparent) ...... 46

Fig: 3.8 Stabilizer Roll (Exploded View)...................................................... 49

Fig: 3.9 Stabilizer Roll Assembly ....................................................51

Fig: 3.10 Side View of the Roll Assembly without Clamping.......................... 52

Fig: 3.12 Fixed Non-rotating Shaft....................................................... 53

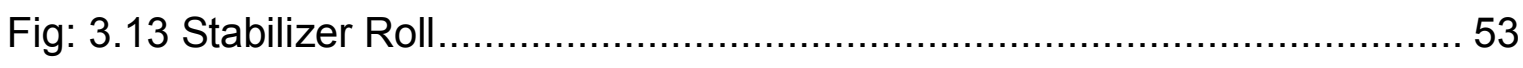

Fig: 3.14 Coated Bearing Sleeve ............................................................... 54 
Fig: 3.15 Ceramic Insert ..................................................................... 54

Fig: 3.16 Insert Clamp ..................................................................... 55

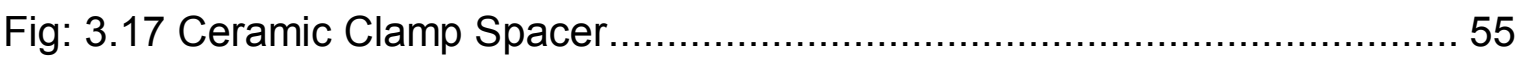

Fig: 3.18 Hangar ........................................................................... 56

Fig: 3.19 Collar to fit Hangar .......................................................... 56

Fig: 3.20 Welds Bearing to the Roll $\ldots \ldots \ldots \ldots \ldots \ldots \ldots \ldots \ldots \ldots \ldots \ldots \ldots \ldots \ldots \ldots \ldots \ldots \ldots \ldots \ldots . .57$

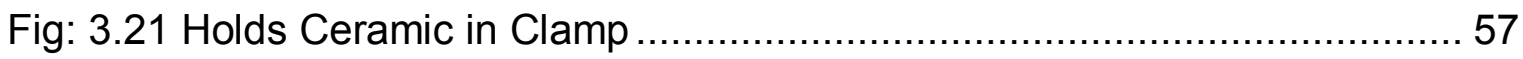

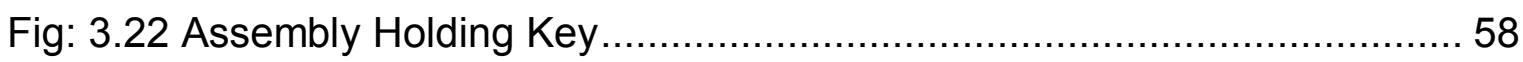

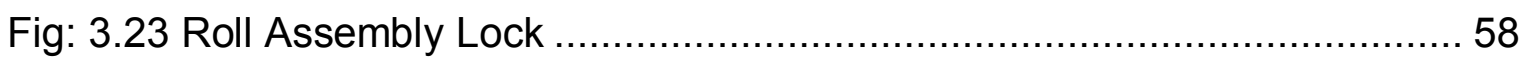

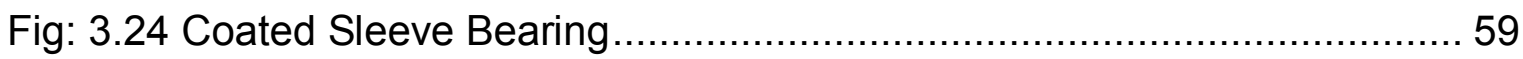

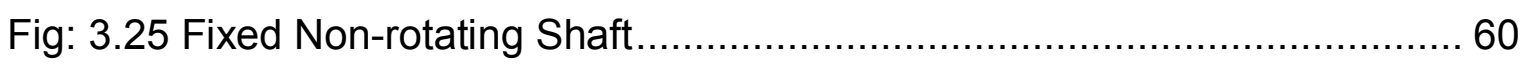

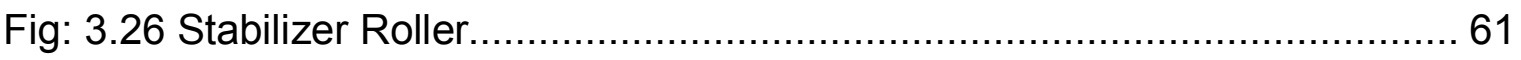

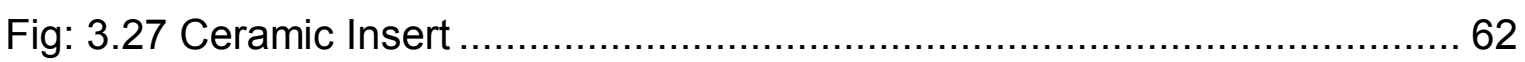

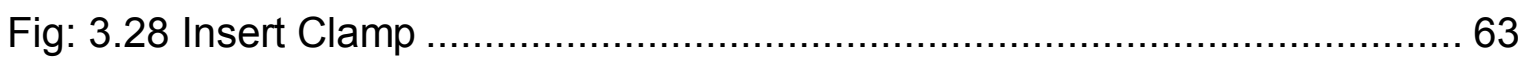

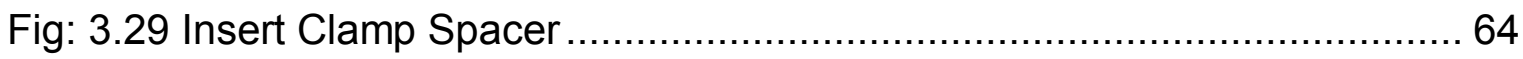

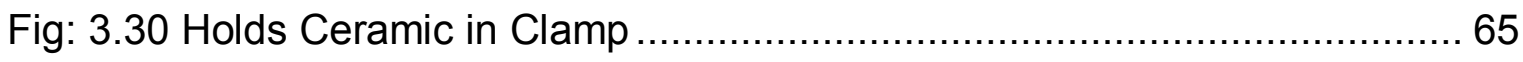

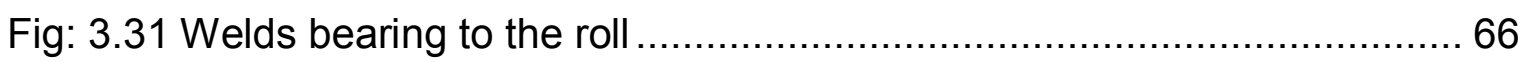

Fig: 3.32 Collar to fit Hangar.............................................................. 67

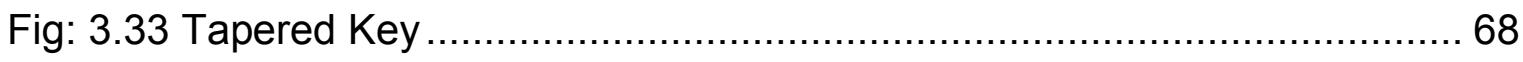

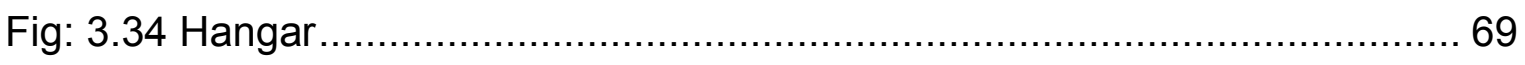

Fig: 3.35 Roll Assembly Lock .......................................................... 70

Fig: 3.36 Uniform Load acting on the Stabilizer Roll................................. 76

Fig: 3.37 Free body Diagram (Shear Force \& Bending Moment Diagram) ......... 77 
Fig: 3.39 Maximum deflection in ANSYS (beam elements) at $\mathrm{X}_{2}=0$ (in $\mathrm{mm}$ ) $\ldots \ldots . .80$

Fig: 3.40 Maximum deflection in ANSYS (beam elements) at $\mathrm{X}_{2}=5.625$ (in $\mathrm{mm}$ ) 81

Fig: 3.41 Comparison of Maximum Deflection values in ANSYS \& Theoretical

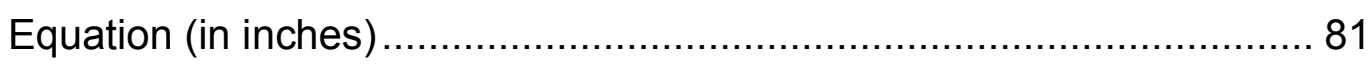




\section{LIST OF TABLES}

Table: 2.1 Percentage of Aluminum in different coatings. ${ }^{1}$............................ 9

Table 2.2 ASTM Standards for Coated Steel Sheet Products. ${ }^{1}$........................ 20

Table: 2.3 Coating Descriptions for Hot-dip Galvanized Sheet Products. ${ }^{1}$.......... 27

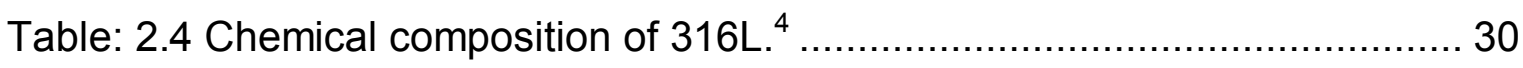

Table: 2.5 Mechanical Properties of $316 \mathrm{~L}$ at room temperature ${ }^{4} \ldots \ldots \ldots \ldots \ldots \ldots \ldots . . \ldots 11$

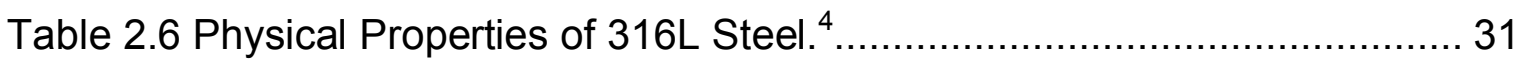

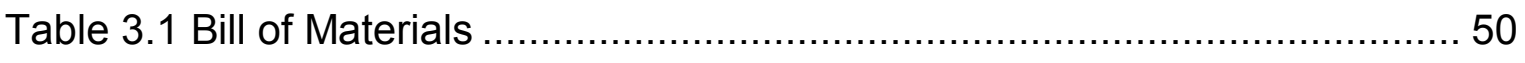




\section{NOMENCLATURE}

$\begin{array}{ll}W_{\text {inch/hour }} & \text { Wearing rate of the seat material } \\ \mathrm{p}_{\mathrm{c}} & \text { Laboratory ball on seat contact pressure } \\ \mathrm{V}_{\mathrm{c}} & \text { Laboratory ball on seat contact velocity } \\ \mathrm{M}_{\max } & \text { Uniformly distributed load on the shaft } \\ \mathrm{F} & \text { Span of the shaft } \\ \mathrm{L} & \text { Maximum deflection of the shaft } \\ \mathrm{Y}_{\max } & \text { Diameter of the roll } \\ \mathrm{D} & \text { Young's Modulus of the shaft } \\ \mathrm{E} & \text { Moment of Inertia of the shaft } \\ \mathrm{I} & \text { Length of the roll between the two supports } \\ \mathrm{X}_{1} & \text { Free length of the roll beyond the supports } \\ \mathrm{X}_{2} & \text { Acceleration due to gravity } \\ \mathrm{g} & \text { Density of } 316 \mathrm{~L} \text { Stainless Steel } \\ \mathrm{P} & \end{array}$




\section{CHAPTER 1- INTRODUCTION}

\subsection{The Continuous Hot Dip Galvanizing Process}

The working of a continuous hot-dip galvanizing line involves immersing the steel in a bath of molten zinc where in the molten zinc is applied onto a continuous ribbon of steel sheet passing over different rollers at high speeds. The melting point of zinc is $419^{\circ} \mathrm{C}\left(786^{\circ} \mathrm{F}\right)$ and hence the bath must be heated further to a temperature of approximately $455^{\circ} \mathrm{C}\left(842^{\circ} \mathrm{C}\right)$ or higher for the galvanizing process to be more effective.

The pre-treated steel sheet dips into the molten zinc bath by means of a snout over the sink roll which rotates with a sheet contact velocity up to $200 \mathrm{~m} / \mathrm{min}$ and then travels vertically upwards. To maintain the desired uniform sheet thickness, two opposing gas knives (usually air) are employed. One or two submerged stabilizer rolls are installed below the gas knives for sheet stability and flatness. Usually, the steel sheet remains in the bath for 2 to 4 seconds and during this short duration the strong metallurgical bonding of the zinc coating with the steel sheet takes place by diffusion. After wiping to the desired coating thickness the zinc is cooled by air jets to solidify prior to reaching the upper roll. The resulting bonding region formed is an inter-metallic compound called the alloy layer whose thickness is 1 to 2 micrometers. This thin alloy bonding zone is critical to allow recoiling and shipping for forming it into the product. In order to get the forming operation done successfully, the steel and zinc have to be well bonded to each other. If the bond zone is not formed or not 
formed properly, the steel and zinc would not stick together during the many critical forming steps the coated sheet undergoes.

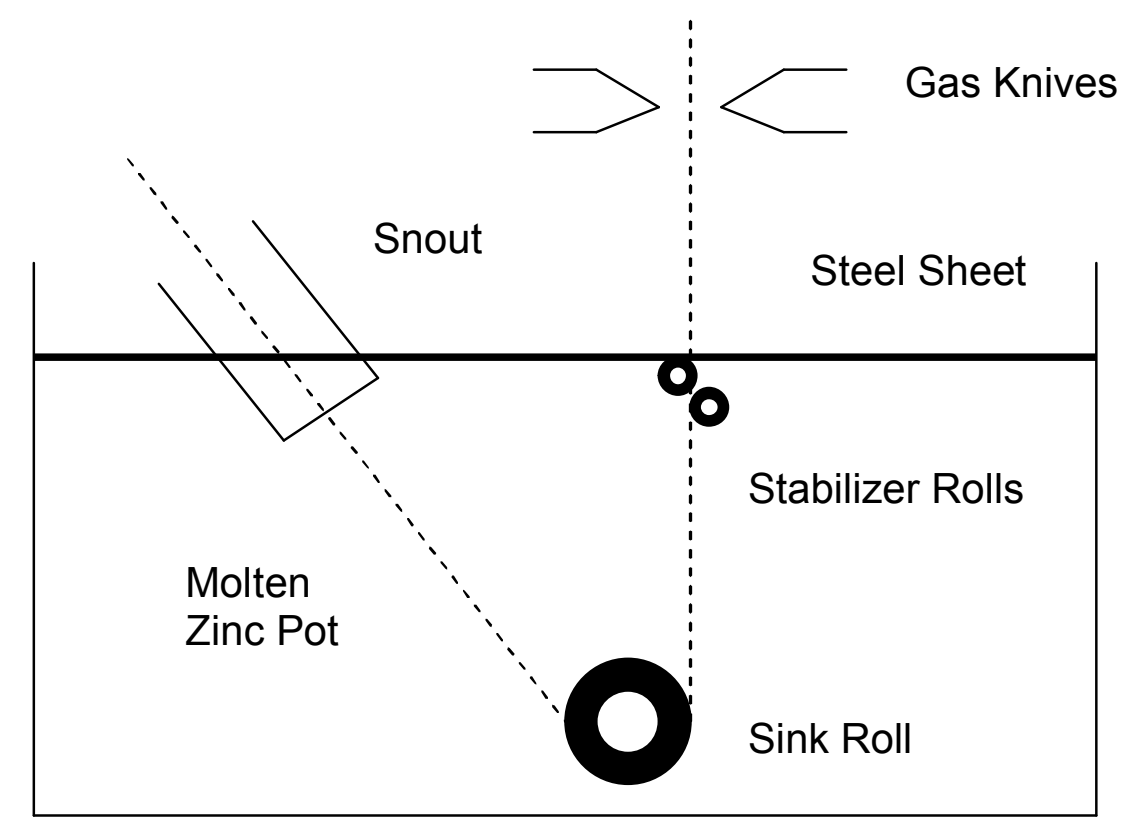

Fig 1.1: Zinc Pot Diagram

An adherent and formable bond zone requires that the alloy layer be thin and of the correct composition. The reason is that the inter-metallic compound that the bond layer consists of is very hard and brittle, an inherent characteristic of such alloy layers. There is no metallurgical process that will make the bond zone soft and ductile. By producing a thin alloy layer of the correct composition, the coated steel sheet can be formed into many intricate shapes without loss of adhesion between the steel and zinc coating. If the alloy layer becomes too thick, or is of the wrong composition, cracks develop in it during forming and the steel and zinc coating may disband during product manufacture. A thin alloy layer of the correct composition can be bent and 
stretched without cracking and debonding. For the steel and zinc to form a proper bonding zone, it is very important that the zone is thin. This can be accomplished by focusing on the two major control points as follows:

1. The addition of controlled amount of aluminum ( 0.15 to $0.20 \%)$ to the molten zinc bath and

2. Control of the steel sheet temperature at the point where it enters into the molten zinc bath.

3. Control of the zinc bath temperature.

\begin{tabular}{|c|c|c|c|}
\hline & Line \#3 & Line \#4 & Line \#5 \\
\hline Pot liner & Ceramic Brick & Ceramic Brick & Ceramic Brick \\
\hline Zinc pot chemistry & $0.08-0.22 \% \mathrm{Al}$ & $0.15-0.22 \% \mathrm{Al}$ & $0.08-0.22 \% \mathrm{Al}$ \\
\hline Temperature & $880-1100^{\circ} \mathrm{F}$ & $900-940^{\circ} \mathrm{F}$ & $880-900^{\circ} \mathrm{F}$ \\
\hline Sheet width & $24-49$ inch & $24-42$ inch & $24-49$ inch \\
\hline Sheet thickness & $.028-.165$ inch & $\begin{array}{l}.0094-.028 \\
\text { inch }\end{array}$ & $.012-.045$ inch \\
\hline Sheet tension $\left(T_{s}\right)$ & $3200-5000 \mathrm{lbf}$ & $1000-2000 \mathrm{lbf}$ & $3200-4800 \mathrm{lbf}$ \\
\hline Sheet velocity & $50-300 \mathrm{ft} / \mathrm{min}$ & $100-410 \mathrm{ft} / \mathrm{min}$ & $110-550 \mathrm{ft} / \mathrm{min}$ \\
\hline \multicolumn{4}{|c|}{ Bottom Roller Characteristics } \\
\hline Bearing life & $7-14$ days & $7-14$ days & $7-30$ days \\
\hline Bearing materials & 316L S.S. & 316L S.S. & 316L S.S \\
\hline Outside diameter $\left(D_{R}\right)$ & 24 inch & 20 inch & 20 inch \\
\hline Shaft diameter $\left(D_{B}\right)$ & 5.25 inch & 3.875 inch & 3.875 inch \\
\hline Bearing length & 4 inch & 4 inch & $\begin{array}{l}4 \text { inch, three 1- } \\
\text { inch inserts }\end{array}$ \\
\hline $\begin{array}{l}\text { Each bearing has } \\
\text { projected area }\left(A_{B}\right)\end{array}$ & 21 inch $^{2}$ & 15.5 inch $^{2}$ & 9.65 inch $^{2}$ \\
\hline
\end{tabular}

Fig 1.2: Weirton Steel Operational Galvanizing Line Ranges ${ }^{6}$. 
Coating thickness control can only be accomplished if the steel sheet is held under tension while being blown by the gas knives. Tension needs to be applied to pull the ribbon of steel through the coating line and to maintain the flatness of the sheet. The distortion of the sheet can occur during exposure to high annealing temperatures. Tension prevents distortion, and allows a controlled, even application of zinc onto sheets of various thicknesses, which otherwise would not be possible.

\subsection{Problems faced by galvanizers}

The zinc-pot is the only section of the galvanizing line for continuous hot dipping which requires frequent line shutdown for maintenance. The stability and flatness of the steel sheet in the region between the air-knives, is crucial for achieving accurate and uniform coating thickness. For this purpose, the small diameter stabilizer and reflector rolls are installed just below the pot surface. Coating thickness uniformity has a major impact on the product cost and profit margin. The roll drive torque is usually derived from sheet contact friction for most of the galvanizing lines. The roll continues to turn as long as the sheet friction torque exceeds the bearing friction torque. The surface finish of the sheet 
is damaged once the roll stops and therefore requires immediate line stoppage. Stopping the line for other than scheduled maintenance, such as dredging the dross out of the zinc pot, is highly expensive. The production cost loss is at least $\$ 1400$ per hour. Moreover, the steel sheet remaining inside the furnace may have to be discarded due to loss of carbon content. The total heat-loss cost must also be added to production-loss cost. It has been observed that some of the stabilizer rolls have a lifetime as short as 1 week while others lasts up to 4 weeks. The roll endurance depends on the bearing wear rate. This is a complex function of materials used, contact velocity, contact pressure, pot chemistry, temperature, load-distribution and line vibrations. All these aspects have their own negative influence on the operation of a galvanizing line. 


\section{CHAPTER 2 - LITERATURE REVIEW}

\subsection{Metallurgy of the galvanize coating}

Continuous hot-dip galvanized sheet is made by immersing steel sheet, as a continuous ribbon into the molten zinc pot. Both sides of the steel sheet have to be very clean and free of surface oxides when introduced into the coating bath. Typically, the sheet is cold rolled steel and is on-line annealed at temperatures above $1200^{\circ} \mathrm{F}\left(650^{\circ} \mathrm{C}\right)$. Then it is cooled to approximately 875 $925^{\circ} \mathrm{F}\left(470-490^{\circ} \mathrm{C}\right)$ before entering the bath. The zinc which melts at $787^{\circ} \mathrm{F}$ $\left(419^{\circ} \mathrm{C}\right)$ is usually at a temperature of $870^{\circ} \mathrm{F}\left(465^{\circ} \mathrm{C}\right)$. Steel sheet has sufficient high temperature strength so that it can be pulled through both the annealing furnace and the zinc bath without distortion. ${ }^{1}$

The metallurgical reaction between the steel and the molten zinc can be explained as follows. The surface atoms of the steel sheet, which are in the solid state, interact with the zinc atoms in the bath, which are in the molten state. This interaction is called diffusion. Zinc atoms move in the direction of the steel and iron atoms in the steel migrate towards the molten zinc. The result is the formation of a solid mixed layer between the steel and the molten zinc. This layer contains zinc and iron atoms in specific proportions and is call an intermetallic compound. The mixing of atoms of different metals is known as alloying and the diffusion zone that is formed during galvanizing is an inter-metallic alloy. It is this alloy zone, when properly formed, provides the excellent bond between the steel and the zinc coating. 
Surface tension forces cause an outer layer of molten zinc to adhere to the sheet when it leaves the molten bath. After excess zinc is wiped off, the remaining liquid solidifies when it cools below $787^{\circ} \mathrm{F}\left(420^{\circ} \mathrm{C}\right)$. The final product (galvanized sheet) consists of the steel core, with an inter-metallic alloy layer and outer zinc layer on both surfaces.

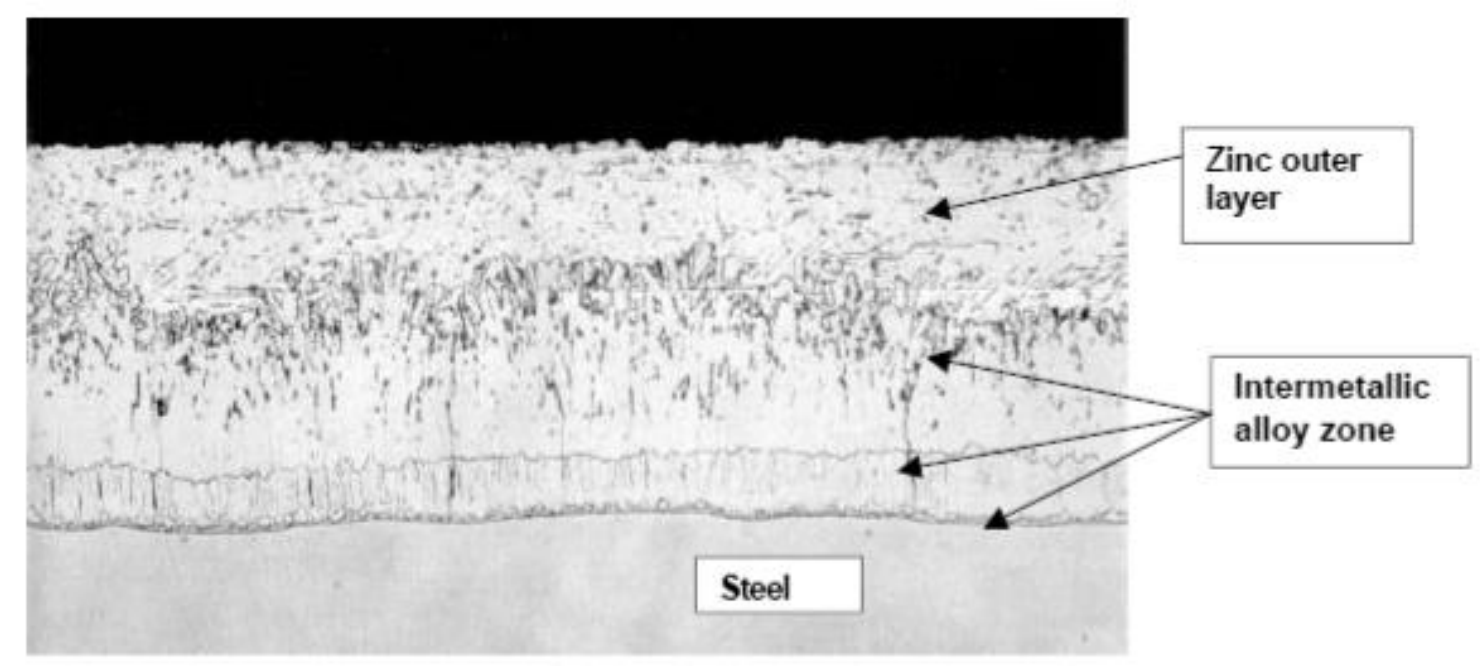

Fig: 2.1 Cross-Section of an Aluminum free galvanizing bath. ${ }^{1}$

The cross-section of an aluminum-free galvanizing bath consists of an outer zinc layer, the core steel metal and in between lays the inter-metallic alloy. But in absence of aluminum these alloys have very poor ductility, i.e. they are very hard and brittle. It is highly likely that shear cracks may develop when the sheet is formed into a shape and the zinc coating flaking off as well thereby drastically limiting the potential of the sheet to form into various shapes such as drawn cups, roofing panels, tight lock seams, or highly stretched automotive fenders. 
In order to overcome the drawbacks of this brittle layer, a small amount of aluminum is added to the coating bath. Having aluminum made the alloy layer very thin compared to that from an aluminum-free bath. Aluminum greatly slows down the zinc-iron reaction rate, acting as an inhibitor. Also, aluminum makes the alloy more thinly and hence more ductile, allowing the coated sheet to be formed into many complex shapes without loss of coating adhesion, since it is not prone to the development of large internal shear cracks.

The standard percentage of aluminum used in the galvanizing baths nowadays is approximately $0.15 \%$. There is much better understanding of the metallurgy of aluminum in zinc however; with the aluminum concentration is more closely controlled. A few manufacturers use as much as 0.20 to $0.25 \%$ of aluminum, but the standard practice involves the use of about of 0.15 to $0.19 \%$. The percentage of aluminum varies with the coating type chosen, which is explained in Table 2.1. ${ }^{1}$ 


\begin{tabular}{|l|c|}
\hline Coating Type & \% Aluminum \\
Galvanized & $0.2 \%$ \\
Galvalume & $55 \%$ \\
Galfan & $5 \%$ \\
\hline Galvanneal & $0.12 \%$ \\
\hline
\end{tabular}

Table: 2.1 Percentage of Aluminum in different coatings. ${ }^{1}$

Although the addition of such a small amount of aluminum has well pronounced effect on the ability to form galvanized sheet, it does not have much effect on the other attributes of the product. For instance, it has an insignificant influence on bulk corrosion behavior. The reason is the aluminum tends to concentrate in the alloy layer and to some extent at the surface of the zinc; its effect is adverse especially involving issues such as spot welding, soldering and white rust occurrence. All these drawbacks are insignificant in comparison with the beneficial effect which the aluminum has on the ability to form the sheet without loss of coating adhesion. 


\subsection{Metallurgy of Aluminum with the Steel}

When a small percentage of aluminum is added to a coating bath, the normal zinc-iron alloy compound FeZn that forms on the steel surface and grows at a faster rate is no longer the most stable compound. Aluminum has greater affinity for iron than zinc; so that within 0.15 seconds after the steel enters the coating bath, the stable inter-metallic compound that forms is not a zinc-iron compound but an aluminum-iron compound i.e. $\mathrm{Fe}_{2} \mathrm{Al}_{5}$. This alloy layer so formed is very thin and retards the zinc-iron reaction. By the time the strip leaves the bath some 2-4 seconds later, some amount of zinc is taken into the layer but its nature is completely different from that which occurs in the absence of aluminum. The layer now obtained is a ternary alloy layer composed of approximately $45 \% \mathrm{Al}$, 35\% Fe and $20-35 \% \mathrm{Zn}\left(\mathrm{Fe}_{2} \mathrm{Al}_{5-\mathrm{x}} \mathrm{Zn} \mathrm{n}_{\mathrm{x}}\right)$. Had it been liquid zinc and solid iron only, the diffusion rate that occurs would have been very high and a binary FeZn $\mathrm{n}_{7}$ alloy in aluminum-free bath had been obtained. Instead, the diffusion rate is now dependent on the transport characteristics of zinc through the barrier created by the aluminum-iron compound. The reaction between the zinc and iron is delayed, and the net result is that the final thickness of the alloy layer is much less than when it is dependent on the diffusion rate across a growing zinc-iron alloy zone. ${ }^{1}$ 


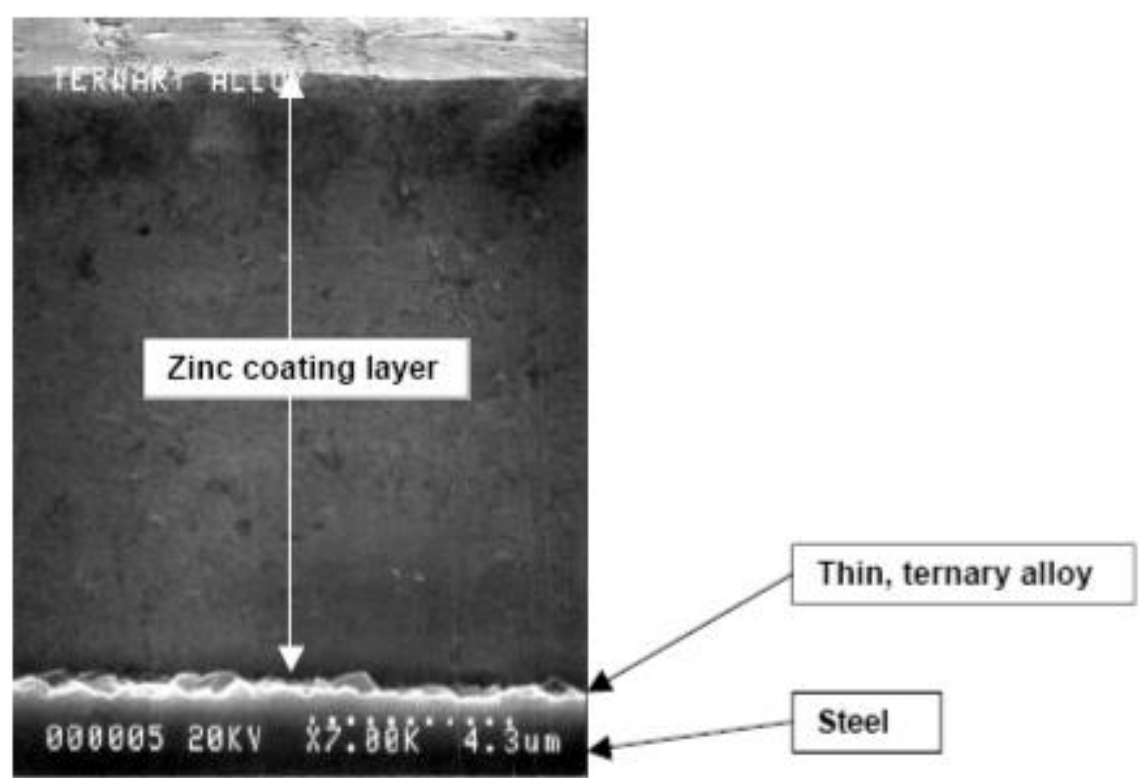

Fig: 2.2 Cross-section of a galvanize coating with aluminum containing bath. ${ }^{1}$

The figure above describes the nature of the alloy layer, when aluminum is added to the galvanizing bath. The alloy layer is thin layer seen near the bottom of the figure. With this thin and hence ductile alloy layer, it can be formed into many useful shapes without any cracking and loss of coating adhesion.

\subsubsection{Percentage of Aluminum in the coating}

For a typical galvanize coating bath, which contains $0.15-0.17 \%$ $\mathrm{Al}$, upon analyzing later, it was found to have a bulk aluminum content of 0.25 $0.40 \%$ Al. The answer lies in the strong affinity aluminum has for iron. The initial alloy that forms is $\mathrm{Fe}_{2} \mathrm{Al}_{5}$ - by weight over $55 \%$ aluminum. Aluminum actually concentrates at the steel-zinc interface and is taken out of the bath with the strip. The thickness of the inhibition layer is independent of coating weight (mass). This 
is why a lighter coating weight (mass) contains a higher overall percentage of aluminum. The rate and method of aluminum addition to the bath must take into account situations that cause its removal rate to vary, e.g. coating light gauge sheet (high surface area) with a thin zinc coating removes aluminum at a much higher rate than running heavy gauge sheet with a thicker coating. There are other factors which have control over the amount of aluminum in the coating such as immersion time, aluminum addition rate, zinc bath temperature and steel type. One must take all these factors into account when planning how to replenish the aluminum in the bath. Most galvanize producers, with the assistance of their zinc suppliers; have developed aluminum addition algorithms for their zinc pots. These prediction models forecast aluminum levels depending on product mix and stipulate how to add aluminum bearing zinc to keep the aluminum in the bath at the desired concentration.

In addition to the high percentage of aluminum in the inhibition layer, the outermost atomic layers at the zinc surface contain a significant amount of aluminum. This occurs due to solute rejection during freezing of the zinc coating, which forces aluminum to the surface. In order that they can bond to the zinc, chemical passivation and pre-painting treatments are designed to remove the few high aluminum containing atomic layers at the surface. ${ }^{1}$ 


\subsection{Selection of Bearing Type}

For moderate speeds, plain sleeve bearings with boundary lubrication serve reasonably well for longer periods without failure. They are the best alternative to rolling element bearings. In case of the galvanizing lines, the sleeve bearings do not need further lubrication since the whole bearing setup is immersed in the galvanizing solution. The sleeve bearings do not pose the danger of unexpected fatigue failures as in case of the roller bearings. The major advantage of the sleeve bearings is that it is possible to continue the machine running for a longer period of time even when they wear out. They can be replaced online at a much convenient time. Hence, to a great extent all the financial, energy, production and time losses involved in a line shutdown can be

prevented. It is much easier to mount and replace the sleeve bearings without even removing the shaft. However, they cannot carry higher loads because the sleeve bearings support the load at a single point unlike the roller bearings. Moreover, the sleeve bearings are less sensitive to dust, slurry and corrosion. However, the sleeve bearings require higher maintenance costs as compared to roller bearings. They are comparatively expensive to manufacture as well. Considering the advantages and disadvantages as well as the long-term effects on the life of the galvanizing line, most of the manufacturers opt for the sleeve bearings to minimize the overall production losses in the long run. ${ }^{2}$ 


\subsubsection{Stresses acting on the Bearing}

Bending is the most common shaft stress. It is the deflection of the shaft as a result of the load applied to it. Torque loading or twisting of a shaft is directly influenced by the drive ${ }^{3}$ and the driven machinery connected to it. Both torque and bending loads must be considered for any shaft design. But as in this case, the shaft is fixed, there is no torque load associated with it. The sleeve bearings are affected by torque and offer more resistance if the shaft is rotating. Axial loading also has its effect on the bearing. The sheet steering causes an axial load which can cause horizontal or lengthwise movement of the shaft. The amount of axial deflection varies with the size, length, and temperature encountered. The maximum load would be at the centre which in case of two fixed bearings which can cause fair amount of damage.

A bearing manufacturer for the galvanizing line has to consider the following criteria while designing the bearing:

1. Load capacity - the weight and pressure exerted on the bearing.

2. Speed - the rotational speed at which the bearing would operate.

3. Life Expectancy - which the bearing must fulfill.

4. Fatigue factor - the extent to which it must be subjected for it can withstand extreme loading conditions.

5. Mounting, replacement \& maintenance - the ease with which the bearing could be mounted, replaced \& maintained without affecting the above factors. 
6. Bath Chemistry - as the whole setup is immersed in a galvanizing line, the bearing life depends upon the bath chemistry as well.

The following is an assumption of factors affecting roll:

- Load Capacity - The contact load or contact pressure acting on the bearing is a prime design parameter. The load capacity of a bearing is its ability to withstand a given amount of weight or pressure. It varies with the different shapes and sizes of the bearing. The speed of operation of a galvanizing line and the bearing life expected play a significant role. In comparison to anti-friction bearings, the sleeve bearings can take up relatively smaller loads. But as the surface area is much larger than the anti-friction bearings, they are not easily subjected to fatigue stresses.

- Speed - The sleeve bearings have some sort of limitation over their operating speed. The speeding rate is in inverse proportion to the loading rate. Higher speeds imply smaller loading rate to ensure proper functioning of the bearing.

- Life - The bearing in a galvanizing line is designed for a long life. As stated before, the bearing life is directly affected by contact pressure and velocity. The longer the life, the less contact pressure it can support for any given velocity, or the less velocity at which it can operate for any given contact pressure. Going for a bearing which has a longer life is preferred to buying less expensive bearings and 
replacing them more often. The cost of repairing the equipment is based more on the cost of labor and the inconvenience of taking the unit out of service. It is preferable to replace a very old setup that has been running on for several years rather than paying for its repair keeping in view the cost savings that can be expected from future repair costs.

- Fatigue - The sleeve bearings used in a galvanizing line have a larger surface contact area when compared to anti-friction bearings. Hence, the problem of fatigue can be almost overlooked. ${ }^{3}$

- Bath Chemistry - The bath chemistry contributes to the wear of the bearing. The galvanizing solution at a temperature of about $850^{\circ} \mathrm{F}$ wears away the surfaces of the hardware used in the zinc pot. 


\subsection{Coating Types}

\subsubsection{Galvannealed Coatings}

Applying a galvanneal coating involves combining of zinc atoms with iron atoms in a steel surface at high temperatures. First, the steel sheet is immersed in a liquid zinc bath at about $842^{\circ} \mathrm{F}\left(450^{\circ} \mathrm{C}\right)$. Then it is made to pass through a cascade of furnaces, the temperature raised to as high as $1292^{\circ} \mathrm{F}$ $\left(700^{\circ} \mathrm{C}\right)$. During the heat treatment process, the iron atoms from the molten steel sheet drift into the zinc coating to form the zinc-iron alloy. The protective interatomic layer of zinc-iron alloy prevents the steel from corrosion through. However, the most significant aspect involving in this process is to ensure that the molten steel surface is at the right temperature, which eventually leads to the formation of the best galvanneal coating. Making galvanneal involves growing zinc-iron alloy compounds throughout the coating, so that it has approximately 9 to $10 \%$ bulk iron content. The presence of aluminum restricts the growth of alloy layer, affecting the production of galvanneal. The reheating of the steel, which is necessary to produce galvanneal, restarts the zinc-iron diffusion reaction. Within seconds the heat breaks down the aluminum-iron inhibition layer. For this to happen consistently require aluminum control that was not possible in the early days of continuous galvanizing. Producing galvanneal depends on the zinc and steel alloying at a rate high enough so that complete diffusion of iron throughout the coating can be accomplished in a reasonable timeframe (allowing production to be done at economical rates). Inhibition layers formed in galvanneal zinc baths are generally thinner than those formed in galvanizing baths. In fact, the inhibition 
layer formed in higher aluminum galvanizing baths may not allow the galvanneal reaction to proceed properly in the time allowed. When the aluminum concentration in the bath is reduced to less than $0.15 \%$ (in the range of $0.12 \%$ to $0.14 \%$ ), the ternary alloy layer ${ }^{1}$ is sufficiently thin, and of the right composition, that reheating allows the required amount of diffusion to occur in a matter of seconds. After the coating has been converted to galvanneal the aluminum-iron alloy interface layer no longer exists. This layer and the small amount of extra

aluminum at the surface become diffused into the zinc-iron coating. For a producer making both galvanize and galvanneal products on the same coating line initially uses $0.15 \%$ to $0.19 \%$ aluminum for galvanized production and then allows the aluminum level to drop below $0.15 \%$ to make galvanneal. In practice, it is as difficult as it appears, since there is very less time for the transition to take place. For this, precise aluminum control is needed requiring accurate measuring capabilities. $^{1}$

\subsubsection{Galvalume Coatings}

A Galvalume coating comprises of $55 \%$ aluminum, $43.5 \%$ zinc and $1.5 \%$ silicon. It finds its primary use in metal building roofing, long-life roofing sheets especially low slope roofing on industrial buildings. It has been widely applied as unpainted sheet with the coating being directly exposed to the atmosphere. Galvalume steel sheet is also used a substrate for pre-painted sheet when a more decorative finish is desired and the use has recently shown significant rates of growth. When used for low slope roofing, Galvalume has 
performed extremely well for over 25 years and in many cases over 30 years, without failure. Often the roofs retain their bright metallic finish for over 25 years in areas where the atmosphere does not contain too much particulate matter. The term 55AI-Zn is the most well known trade name used. In the manufacture of $55 \mathrm{Al}-\mathrm{Zn}$, the inclusion of $1.5 \%$ silicon is significant. The major purpose of inclusion of silicon is to suppress the growth of the brittle inter-metallic layer that would otherwise form during manufacture of the product. ${ }^{1}$ Thus, addition of silicon is essential and the 55Al-Zn product cannot be manufactured without it. The interaction between the steel sheet and the molten coating during the manufacture process is vital to achieve good adhesion of the coating during eventual forming operations in case of the hot-dip galvanized sheet. Even so, the inter-metallic alloy layer formed is hard and brittle and it is therefore important for this layer to be kept as thin as possible. Inclusion of silicon takes care of this aspect. It restricts growth of the alloy layer, allowing the product to be readily formed after manufacture. Silicon does not play any role in preventing corrosion. In some applications, especially those that involve deep drawing, the coating adhesion of the as-produced product is not as good as that of a galvanized coating. The inhibition of the alloy layer growth is not as effective with the addition of silicon to a 55Al-Zn bath as it is when aluminum is used in a galvanizing bath. A galvanized sheet is often the preferred product for this reason and also for reduced galling (abrasion) behavior. The recent developments in coating technologies though, in particular the use of acrylic coatings facilitate 55Al-Zn for some deep drawing and other forming operations. Despite better 
corrosion performance than galvanized steel depending on the environment, there are several notable exceptions. The most important one is that in closed animal confinement buildings. Buildings that house the intensive farming activities of certain animals, especially pigs, can present problems for $55 \mathrm{Al}-\mathrm{Zn}$ coated sheet. The animal waste and waste decomposition by-products have been found deleterious towards 55AI-Zn coated sheet. Also, unpainted galvalume sheet cannot come in direct contact with wet concrete. Concrete's high alkalinity attacks the aluminum, causing the coating to become porous and prone to corrosion. ${ }^{1}$

\begin{tabular}{|c|c|c|}
\hline Soating Method & ASTM Standard & Comments \\
\hline Hot-dip galvanized & A 653/A 653/M & Zinc coated sheet \\
\hline Hot-dip galvannealed & A 653/A 653/M & Zinc-iron alloy coated sheet \\
\hline Electro galvanized & A 879/A 879/M & Electroplated zinc coated sheet \\
\hline Galvalume & A 792/A 792/M & $55 \%$ Al $45 \% \mathrm{Zn}$ alloy coated sheet \\
\hline Galfan & A $875 / A ~ 792 / M$ & $95 \%$ Zn $5 \%$ Al alloy coated sheet \\
\hline Aluminized & A 463/A 463/M & 2 types of Aluminum coatings \\
\hline & & $\begin{array}{l}\text { - } \quad \text { Pure Al coated sheet } \\
\text { - } 5 \% \text { Al } 11 \% \text { Si alloy coated sheet }\end{array}$ \\
\hline Teme & А $308 / A$ 308/M & Lead-Tin alloy coated sheet \\
\hline Electroplated Zn/Ni & A 918 & $\begin{array}{l}9 \% \mathrm{Zn} 16 \% \mathrm{Ni} \text { alloy electroplated } \\
\text { coated sheet }\end{array}$ \\
\hline
\end{tabular}

Table 2.2 ASTM Standards for Coated Steel Sheet Products. ${ }^{1}$ 


\section{Interpretation of ASTM Standards}

The ASTM Standard number A 653/A 653M means a dual standard and allows the product to be ordered in either "inch-pound" (English) units, or SI (Metric) units. The two sets of units are to be regarded separately as standard units. In the text the SI units are shown in brackets. One has to keep in mind that the values stated in each system are not exact equivalents and each system must be used independently of the other. In this example, when ordering galvanize to inc-pound units, specify A 653 . When ordering to SI units, one needs to specify A 653M. However, there are exceptions for some of the electrogalvanize products in that the ASTM numbers do not imply dual specifications for instance A 917 and A918. These standards which don't have an M after the number specify only SI units. ${ }^{1}$ 


\subsection{Control of Coating thickness \& its significance}

It is the coating thickness that determines coating life in any given application; the normal practice is to specify and manufacture to coating weight (inch-pound system) though. Since the density of zinc is well known, it is easy to calculate the thickness of a galvanized coating once the coating weight (mass) is determined.

It becomes highly important that the coating thickness is properly controlled. Most of the coating lines employed in various industries today have highly potential coating thickness controlling equipment to meet end-user needs. These coating lines, which operate at 600 feet/minute and higher use very specialized equipment to ensure the correct coating thickness applied to the sheet.

In a typical arrangement, the steel sheet exits the bath at high speeds, and as it exits, it drags out more zinc than is needed for coating. The higher the line speed, the more zinc is dragged out of the bath. The thickness of zinc on the sheet is then controlled by using gas knives to wipe off excess zinc while allowing the desired amount to pass through the knives. A typical gas knives setup employs low-pressure/ high volume gas streams (usually air, rarely nitrogen) that impinge against the sheet surfaces. The pressurized air is generated by blowers. The air flows from the blower through piping up to a position parallel and adjacent to the strip. It is then allowed to escape through a precisely designed and machined slot opening or orifice that is placed about 0.5 
inch or less from the traveling strip. The resulting air jet acts a knife, stripping the excess molten zinc and forcing it back in the direction of the coating bath surface. Pressure/volume is the principal control parameter, although height above the bath, distance to the strip, angle of the knives, and knife orifice gap are also controlled.

Of late, automatic coating weigh (mass) control systems using artificial intelligence technology have been installed on many lines to produce consistent coating thickness with low standard deviation. The degree of control required depends on the thickness that is being applied. The thinner the coating, the more is the control required. The producer can use a set of small rolls located immediately beneath the zinc bath surface to keep the sheet uniformly distant from each knife orifice. This kind of arrangement is quite significant to obtain the desired uniform thickness of coating on both sides of the sheet. ${ }^{1}$

\subsubsection{Coating Weight Range (Minimum/Maximum Thickness)}

\section{Minimum Coating Thickness}

The minimum thickness is primarily limited by the amount of air (pressure and volume) that is practical to use during the production. More is the air intensity blowing onto the sheet, less is the coating thickness. The rate of decrease in the coating thickness as the knife parameters are adjusted becomes limiting when the coating thickness gets down to about 0.00025 inch (about 6 microns). This is not an absolute number as the design of the air knives and the 
processing speed govern the lowest coating thickness that is achievable. If the air pressure and volume are increased further, or the knives are moved too close to the strip, the zinc exhibits a tendency to freeze at the air knife location. If this occurs, there is obviously no further wiping action. The speed of the sheet when it exits the coating bath has a large influence on the volume of zinc that needs to be wiped off. The higher the sheet speed, the higher the air pressure and volume needed to obtain the specific coating thickness, therefore the thinnest coating achievable is influenced by line speed. As the processing speeds used on coating lines are usually dictated by the annealing furnace design, it is common for thin gauge sheet to be processed at high speeds and for thick gauge sheet to be processed at lower speeds. It is reasonable to expect that the thinnest coatings might only be possible on heavier gauge strip. This is true except for one offsetting factor. The sheet and coating metal react to form an alloy layer during the time that the sheet is immersed in the coating bath. This alloy layer is solid and cannot be wiped off by the air knives. The longer the sheet is immersed in the bath, the thicker is the alloy layer. Hence, heavy gauge sheet being processed at lower speeds is immersed in the coating bath longer than light gauge sheet and typically has a thicker alloy layer. Since the alloy layer is a part of the final total coating thickness, it is not necessarily true that heavy gauge sheet can be coated with the thinnest coatings. ${ }^{1}$ 


\section{Maximum Coating Thickness}

The maximum coating thickness is limited by a number of issues, but the primary one is the amount of zinc that can be dragged from the bath. Since it is governed by the property of the surface tension of the liquid zinc, the amount of zinc being dragged at low speeds is less than at high speeds, so it is difficult to achieve a thick coating on heavy gauge sheet. Heavy gauge sheets are usually processed at lower line speeds because of the limitations of the annealing furnace. A heavy gauge sheet is often a product that is intended to have a thick coating since it is used for long times in service. In order to achieve this, the galvanized sheet manufacturers apply special practices to heavy-gauge sheet to achieve thicker coatings like for instance increasing the surface roughness of the steel substrate. A rougher surface results in more zinc being dragged out any given speed. In addition to being limited by the amount of zinc that is dragged out of the coating bath, there is another practical limitation. There arises a tendency for the molten coating metal to sag due to gravity if the coating is too thick after it passes through the air knives towards the Stabilizer roll above the coating pot. The coating immediately adjacent to the steel surface is held in place by surface tension between the molten coating and the solid alloy layer. Also, the outer surface of the molten coating has a solid but very thin layer of oxide. This oxide layer attempts to hold the molten coating in position until it has fully solidified. But, as the thickness of the molten layer increases, the coating may break through the oxide layer and thereby causing local sagging. This causes formation of a non-uniform thickness on the sheet surface, one that can 
be unsightly as well as affecting the time before rusting of the steel begins. It is highly necessary that the coating is uniformly thick to avoid localized early onset of red rust. The practical maximum thickness depends on many specifics of the particular coating line, but realistically, coatings thicker than about 0.002 inch often have coating sags. ${ }^{1}$

\subsubsection{ASTM Coating Designations}

The ASTM standard specifications such as A 653/A 653M cover continuous hot-dip galvanized sheet products taking into account the minimum/maximum coating thickness limitations. The following table contains the coating designations that are recognized in A 653/A 653M. 


\begin{tabular}{|c|c|c|}
\hline Units & Coating Designation & $\frac{\text { Minimum Coating }}{\left.\text { Weight (oz/ft }{ }^{2}\right)}$ \\
\hline Inch-Pound & G360 & 3.60 \\
G300 & 3.00 \\
G235 & 2.35 \\
G210 & 2.10 \\
G185 & 1.85 \\
G165 & 1.65 \\
& G140 & 1.40 \\
& G115 & 1.15 \\
& G90 & 0.90 \\
& G60 & 0.60 \\
& G30 & 0.30 \\
& G01 & No minimum \\
& & \\
& &
\end{tabular}

Table: 2.3 Coating Descriptions for Hot-dip Galvanized Sheet Products. ${ }^{1}$

The maximum coating thicknesses, G360 and G300, cannot be applied to all thicknesses of sheet. Also, the tendency for sags to develop in coatings this thick is high. On the other end of the range, the thinnest coating, G01 has no specified minimum thickness. This designation clearly recognizes that there is a physical limit to the thinnest achievable coating thickness. Even a G30 coating at approximately 0.0003 inch thick is beyond the thinnest 
designation that is achievable on some coating lines when processing the sheet at high speeds.

The galvanizing industries today have been trying to enhance the quality of the coating applied owing to the increased use of galvanized sheet as exposed automobile panels. Deterioration of the submerged pot hardware causes excessive strip vibration and poor surface quality. 


\subsection{Material Optimization - 316L Stainless Steel}

The type 316 is an austenitic chromium stainless steel alloy containing molybdenum. The addition of molybdenum causes increase in the general corrosion resistance particularly higher resistance to pitting and crevice corrosion in chloride environments. It also exhibits increased strength at elevated temperatures. Hence grade 316 shows greater corrosion resistance in both acidic and alkaline environments, especially against sulfuric acid, formic acid besides alkaline chlorides. The austenitic structure gives it great toughness, even down to cryogenic temperatures. ${ }^{4}$

It has outstanding forming and welding characteristics. It can be readily brake or roll formed into a wide variety of parts for applications in the industrial, architectural and transportation fields. It also has excellent welding characteristics. Moreover, for welding thin sections, even post-weld annealing is not necessary.

The extensive use of $316 \mathrm{~L}$ includes furnace parts, exhaust manifolds, heat exchangers, jet engine parts, pharmaceutical and photographic equipment besides weldments. $316 \mathrm{~L}$ is an extra-low carbon version of 316 . The low carbon content helps minimizing harmful carbide precipitation due to welding assuring optimum corrosion resistance.

The table 2.4 gives the information regarding the composition of 316L. 


\begin{tabular}{|l|c|}
\hline Element & Percentage (\%) in 316L \\
Carbon & 0.03 \\
Manganese & 2.00 \\
Phosphorus & 0.045 \\
Sulfur & 0.03 \\
Silicon & 0.75 \\
Chromium & $16-18$ \\
Nickel & $10-14$ \\
Molybdenum & $2-3$ \\
Nitrogen & 0.10 \\
\hline Iron & Rest \\
\hline
\end{tabular}

Table: 2.4 Chemical composition of 316L. ${ }^{4}$

Usually, $316 \mathrm{~L}$ sheets are available up to a thickness of 0.01 " to 0.25 " with widths up to 50 ". The mechanical properties of $316 \mathrm{~L}$ at room temperature are shown in table 2.5 . 


\begin{tabular}{|l|l|}
\hline Property & $\underline{\text { Units }}$ \\
UTS & $580 \mathrm{MPa}$ \\
Rockwell Hardness & $300 \mathrm{MPa}$ \\
& 95 \\
\hline Modulus of elasticity & $200 \mathrm{GPa}$ (in tension) \\
& $80 \mathrm{GPa}$ (in torsion) \\
\hline
\end{tabular}

Table: 2.5 Mechanical Properties of $316 \mathrm{~L}$ at room temperature. ${ }^{4}$

The ASTM standard specifications for the three types of 316L steel are AMS 5507, ASTM A 240, and ASTM A 666.

\begin{tabular}{|l|l|}
\hline Property & \multicolumn{1}{c|}{$\underline{\text { Units }}$} \\
Density & $0.29 \mathrm{lb} / \mathrm{in}^{3}$ \\
Electrical Resistivity & $29.4 \mu \Omega-$-in at $68^{\circ} \mathrm{F}$ \\
Specific Heat & $0.12 \mathrm{BTU} / \mathrm{lb} /{ }^{\circ} \mathrm{F}$ at $32-212^{\circ} \mathrm{F}$ \\
Thermal Conductivity & $12.4 \mathrm{BTU} / \mathrm{hr} / \mathrm{ft}^{2} / \mathrm{ft} /{ }^{\circ} \mathrm{f}$ at $932^{\circ} \mathrm{F}$ \\
Mean Coefficient of Thermal Expansion & $9.7 * 10^{6} \mathrm{in} / \mathrm{in} /{ }^{\circ} \mathrm{F}$ at $32-1000^{\circ} \mathrm{F}$ \\
\hline Melting Point range & $2500-2550^{\circ} \mathrm{F}$ \\
\hline
\end{tabular}

Table 2.6 Physical Properties of 316L Steel. ${ }^{4}$ 


\section{$\underline{\text { Corrosive Resistance }}$}

316 L has outstanding corrosion resistance. It remains unscathed in a range of atmospheric environments and many corrosive media. Above $140^{\circ} \mathrm{F}$, it is subject to pitting and crevice corrosion in warm chloride environments and to stress corrosion cracking. It is considered resistant to potable water with up to about $.0101 \mathrm{lb} /$ gal chlorides at room temperature reducing to about 0.005 $\mathrm{lb} / \mathrm{gal}$ at $140^{\circ} \mathrm{F}$.

Grade 316 steel is usually regarded as the standard marine grade stainless steel, but it has been found that it shows not resistance to warm sea water. It is subject to surface corrosion usually visible as brown staining associated with crevices and rough surface finish in many marine environments.

\section{$\underline{\text { Heat Resistance }}$}

Grade 316 shows good oxidation resistance in fitful service at $1598^{\circ} \mathrm{F}$ and in continuous service at $1697^{\circ} \mathrm{F}$. It is not recommended to use 316 continuously in the range of $797-1580^{\circ} \mathrm{F}$ to prevent aqueous corrosion resistance. Grade $316 \mathrm{~L}$ is more resistant to carbide precipitation and can be used in the above temperature range.

\section{$\underline{\text { Heat Treatment }}$}

To improve the hardness of 316 steel, it is subjected to Annealing. It is heated to a temperature range of $1850-2048^{\circ} \mathrm{F}$ and is cooled rapidly. However, it is quite difficult to harden these grades by thermal treatment. 
Welding

It shows excellent weldability by all standard fusion methods, both with and without filler metals. Heavy welded sections in grade 316 require postweld annealing for maximum corrosion resistance. This is not required for $316 \mathrm{~L}$. Grade $316 \mathrm{Ti}$ may also be used as an alternative to 316 for heavy section welding. $316 \mathrm{~L}$ steel is generally not weldable using oxyacetylene welding methods. Special attention is necessary to prevent weld hot cracking by formation of ferrite in the weld deposit. Grade 316 and $316 \mathrm{~L}$ generally have poorer weldability than grades 304 and $304 \mathrm{~L}$. The prime factor here is the percentage composition of nickel. The high nickel content in these alloys requires slower arc welding speed and more consideration to avoid hot cracking.

\section{Machining}

It tends to work harden if it is machined too quickly. For this reason low speeds and constant feed rates are recommended. It is also easier to machine compared to grade 316 due to its lower carbon content.

\section{Hot and Cold Working}

Grade 316L steel can be hot worked using most common hot working techniques in the range of $2102-2300^{\circ} \mathrm{F}$, and certainly should not be less than $1706^{\circ} \mathrm{F}$. Post work annealing should be carried out to induce maximum corrosion resistance. Some of the most common cold working operations such as shearing, drawing and stamping can be performed on 316L. Post work annealing is carried out in order to get rid of the internal stresses. ${ }^{4}$ 


\section{Applications:}

$316 \mathrm{~L}$ finds its use in some of the following applications:

- Marine applications.

- Pharmaceutical applications.

- Architectural applications.

- Food preparation equipment particularly in harmful chloride atmospheres.

- Medical implants such as pins, screws.

- Orthopedic implants such as hip and knee replacements.

- Fasteners. $^{4}$ 


\section{CHAPTER 3 - DESIGN ASPECTS OF POT ROLLERS}

\subsection{Objective}

The research objective is to find the best material for the zinc pot bearing that can withstand the stresses and the misalignments and design an appropriate bearing-housing system for the stabilizer roll. Most of the galvanizing lines use the sleeve type bearings, with or without ceramic inserts. These inserts incorporate for the large bearing clearances and misalignments simultaneously to minimize the chance for roll stoppage. The Fig.3.1 shows the end of a hollow stabilizer roll of about 8-inch diameter. The openings at the end of each roll play a significant role allowing for the proper inflow and outflow of the molten zinc from the roll causing uniform heat flow and reducing thermal stresses. The roll is usually made of centrifugal cast low carbon stainless steel, with its surface machined to maximize sheet traction. A hemispherical button at the shaft end, is used for the thrust bearing, and is shown welded to the end of the shaft. ${ }^{5}$

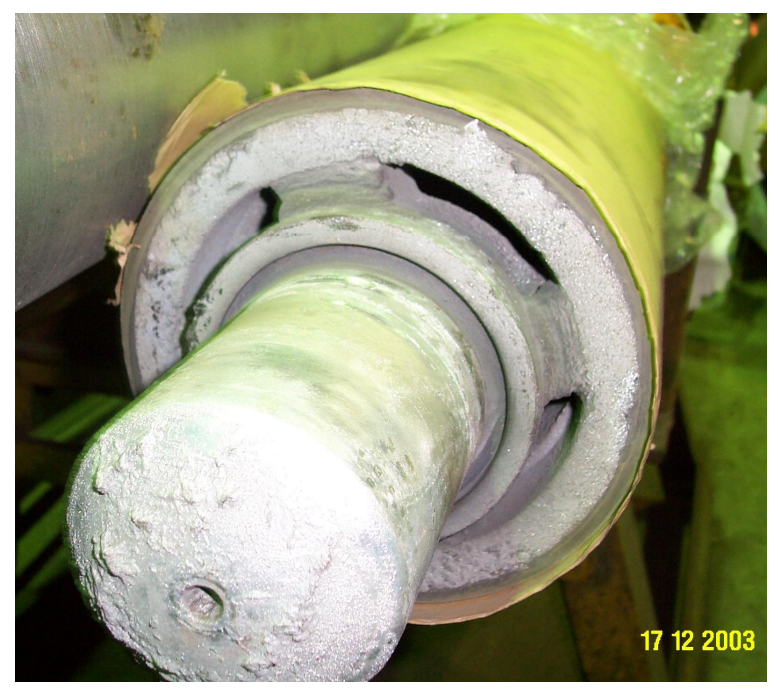

Fig: 3.1 Stabilizer roll of about 8-inch diameter with cantilever shaft welded at each end arms. ${ }^{5}$ 


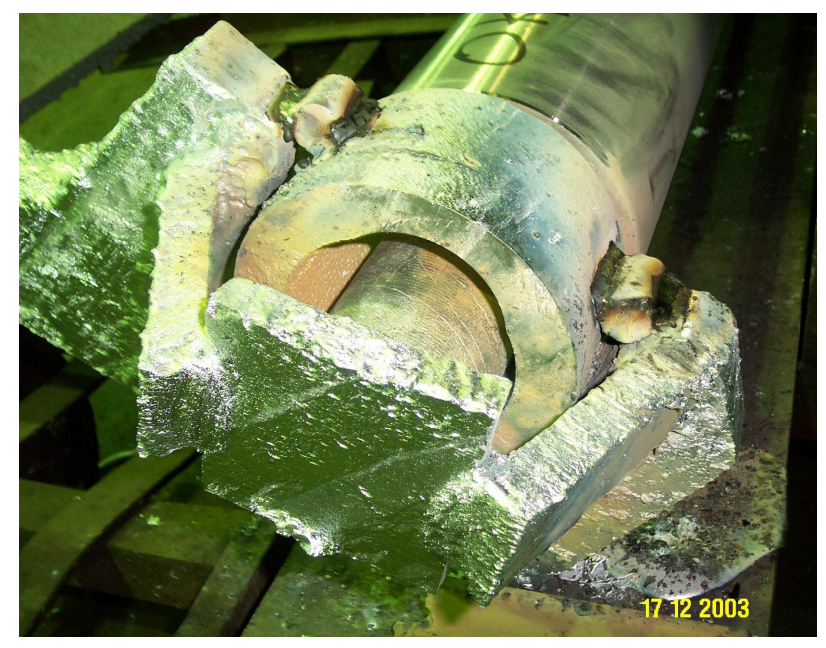

Fig: 3.2. Roll bearing sleeve and thrust plate shown welded to bridle support arms. ${ }^{5}$

As shown in Fig 3.1 and Fig 3.2, a resurfaced stabilizer roll is shown, ready for installation. It uses $316 \mathrm{~L}$ stainless steel for bearing sleeves. They are welded to the roll support bridle together with a thrust plate to limit axial movement. The point of focus here would be the gap between the shaft and the sleeve, which is allowed to get quite large prior to replacing sleeve and shaft. A gap such as this cannot support any hydrodynamic lubrication though, but this is of no concern, since with liquid zinc it is not an occurrence even with a very narrow clearance. The bearing material selection is done based on taking into account both the cost and resistance to wear characteristics of different materials tested. Hence, the wear of the shaft and sleeve is caused by sliding friction on a small contact area and also at very high contact pressures. Galvanizing lines that operate without a hot bridle must operate inside the zinc-pot with the same high sheet tension as is needed inside the furnace. Without the hot bridle, the 
stabilizer roll must also be able to steer the sheet by moving the bearing sleeves, one in and the other one out. This alters the bearing sleeve alignment resulting in an increased wear. Sheet steering produces axial thrust loading which may cause failure of the thrust buttons. High and non-uniform bearing loading is believed to be mainly responsible for short bearing life. From all the above aspects, the following conclusions can be drawn:

- The usage of improved bearing materials, which are better able to cope with this type of bearing load, is desirable.

- Contact pressure and the sleeve/shaft misalignment during the sheet steering are the considered to be the main contributors to the short bearing life. ${ }^{5}$

\subsection{Wear Characteristics of Bearing Materials}

"The four sectors: West Virginia University, Oak Ridge National Labs, International Lead-Zinc Research Organization, industrial partners such as steel makers, their materials suppliers and equipment producers all have been involved in finding better materials for the continuous hot-dip galvanizing lines. The effort was funded by the U.S. Department of Energy through the Office of Industrial Technology. The research was to improve the performance of the bearing materials supporting rotating components such as sink, stabilizer and reflector rolls; minimizing corrosion of materials subjected to sliding contact, nucleation and dross formation on molten metal bath hardware, especially on the surface of the roll were it may cause cosmetic defects in the finished product. ${ }^{7}$ 
West Virginia University developed a new material wear tester as shown below in order to quickly compare the wear characteristics of new bearing materials produced by steel company suppliers. It is an improved version of the conventional pin on disc type material wear tester. It comprises of a one-inch diameter ball rotating on a stationary narrow seat at a 45-degree mean contact angle. This ensures self-centering and keeps the test sample cost low as well. To maintain a constant load, the seat is mounted inside a zinc filled cup. The cup is suspended from a disc, which rests on an airbag. As the ball lowers onto the seat, the cup pushes the disc down on the airbag increasing its contact area and thus spindle load. This eliminates vibrations and the otherwise needed dead weights to load down the rotating spindle ${ }^{6}$.

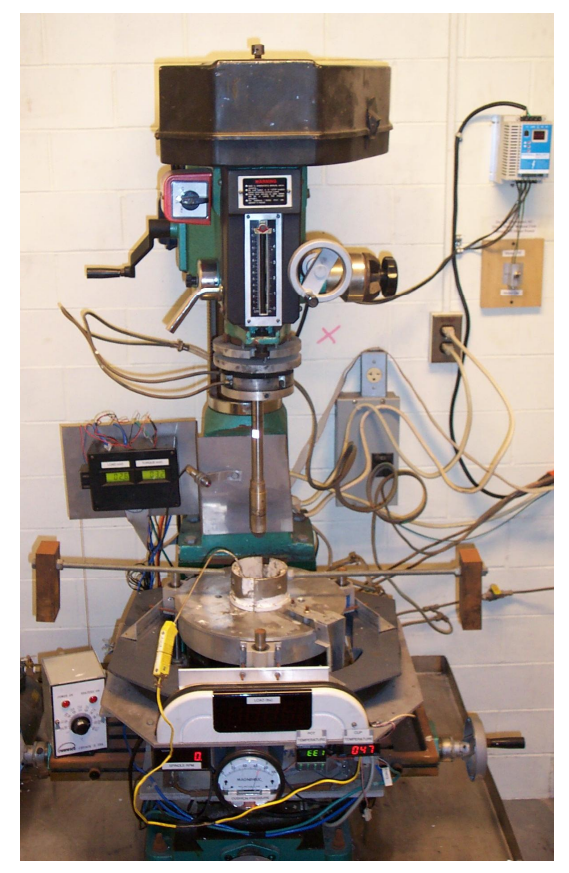

Fig: 3.3 Small scale material wear tester developed at WVU. ${ }^{6}$ 
An automated data acquisition system allows evaluating any material sample of interest within a 24-hour day span. Jay Snider ${ }^{1}$ developed the test procedure, which has become a routine operation. All the conventional roll bearing materials have been tested such as 316 stainless steel and Stellite 6 in addition to dozens of novel bearing materials supplied by steel company vendors which includes MSA 2020 and ACD Ceramic Wearguard and coatings such as laser-clad tungsten carbide in cobalt and nickel based alloy matrix composites. Some of these new materials showed a significant improvement in their respective wear performances under high contact pressures and velocities as well. However, no one material provided orders of magnitude better performance than the next best one. One series of tests performed with a 316 stainless steel ball on a 316 stainless steel seat, covered a range in contact pressures from 25 to $100 \mathrm{psi}$ and a range in contact velocities from 5 to 15 inch per second. These series of tests were conducted with the test samples submerged in water to eliminate the time required for sample heating, cooling and cleaning, as is normally required to measure wear in molten zinc. The test data shown in Figure 4 all appear to fit a simple empirical equation as given below for wear rate, $w$, in (inches per hour) as a function of contact pressure, $p_{c}$, in (psi) and contact velocity, $V_{c}$, in (inches per second) with wear rate equal:

$$
\mathrm{w}_{\text {inch / hour }}=4 * 107 * \mathrm{p}_{\mathrm{c}}^{2} * \mathrm{~V}_{\mathrm{c}}^{0.5}
$$


A similar exponential wear rate sensitivity to contact pressure, $p_{c}$, was found using Stellite 6 on Stellite 6 test samples. Those tests were conducted while submerged in a $460^{\circ} \mathrm{C}$ zinc-pot. The resulting wear-rate as a function of contact pressure is shown in Figure: 3.4 and fits the empirical equation:

$$
\mathrm{w} \approx \mathrm{p}_{\mathrm{c}}^{1.6}
$$

These two equations give an insight into the sensitivity of bearing material wear rate to contact pressure, pc. It is observed that wear-rate is not proportional to friction work done, as it is not proportional to the product of contact pressure times contact velocity times the friction coefficient. The test results on all other bearing materials clearly confirmed this observation.

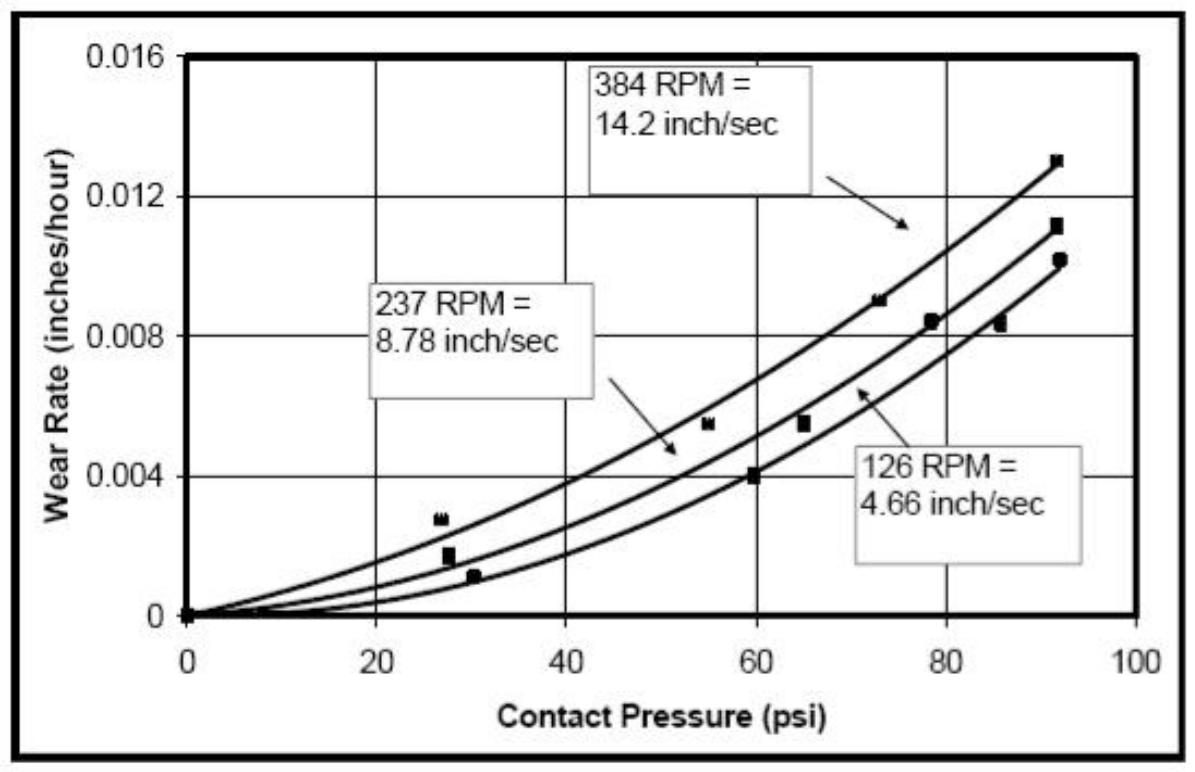

Fig. 3.4 Wear rate of 316 Stainless Steel seat by a 316 Stainless steel ball sample submerged in water. $^{5}$ 


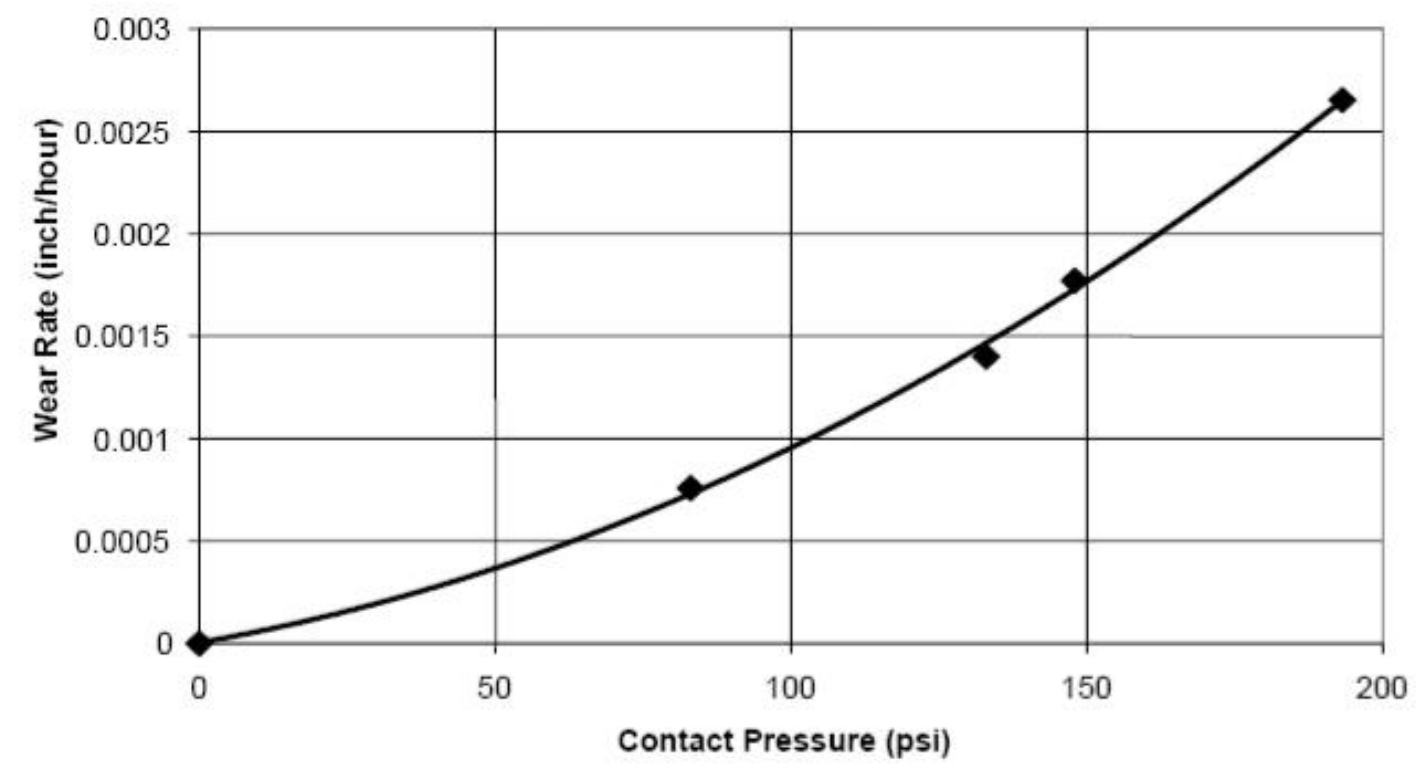

Fig.3.5 Wear rate of Stellite 6 seat by Stellite 6 Ball sample at $460^{\circ} \mathrm{C} .^{5}$

From the above mentioned test results, apparently high bearing contact pressure is the most controlling parameter on bearing life. Therefore developing a technique to decrease bearing contact pressure and simultaneously preventing bearing miss-alignment with its associated point pressure may be equally productive as the search for new materials". ${ }^{6}$ 


\subsection{New Design for roll bearing to reduce wear-rate}

The test results conducted on various sample materials, it is apparent that decreasing the bearing contact pressure by making the bearings longer will have a significant impact on bearing life, provided one can assume that the bearings remain perfectly aligned during all operations, including sheet steering. An obvious way to reduce the contact pressure is by increasing the shaft diameter and thus length. However, this decreases the ratio between the sheet friction roll driving torque to the bearing friction roll stopping torque and is therefore unacceptable. ${ }^{5}$

A recently filed patent application named "Bearing Life Extender for Conveyor Type/Zinc-Pot Rolls" provides an apt solution for this problem. According to it, the bearing length could be increased up to three fold without increasing the shaft diameter and root bending moment. Moreover, it decreases the shaft deflection, which itself also contributes to bearing wear, assures optimum bearing alignment during sheet steering and allows using the bearing sleeve itself to serve also as a thrust bearing. The figures used in the patent application clearly depict the difference between the previously used configuration (Figure: 3.6) and the modified design (Figure: 3.7).

In contrast, the conventional roll design comprised of a rotating shaft attached to the roller and held in place by a stationary bearing housing at each end. The cylindrical roll $\mathbf{5}$ is often hollow and therefore only a section of the 
roll has been shown. End plug $\mathbf{1 0}$ is welded to both the cylinder and a shortcantilevered shaft 15 . The sheet/belt tension or the weight of the conveyor load produces a force, $F$, on the roll as indicated by arrow 20. This force, F, is transmitted via the roll to shaft 15 , which deflects inside the bearing. The reaction to force, $F$, by the bearing housing is indicated by arrow 25. Each of the two bearing housings is mounted on a stationary support 30 . Since the two end bearing housing supports are not rigidly connected, when the roll is used for sheet steering, the resulting misalignment and non-uniform loading on the bearing contact surface causes increased wear.

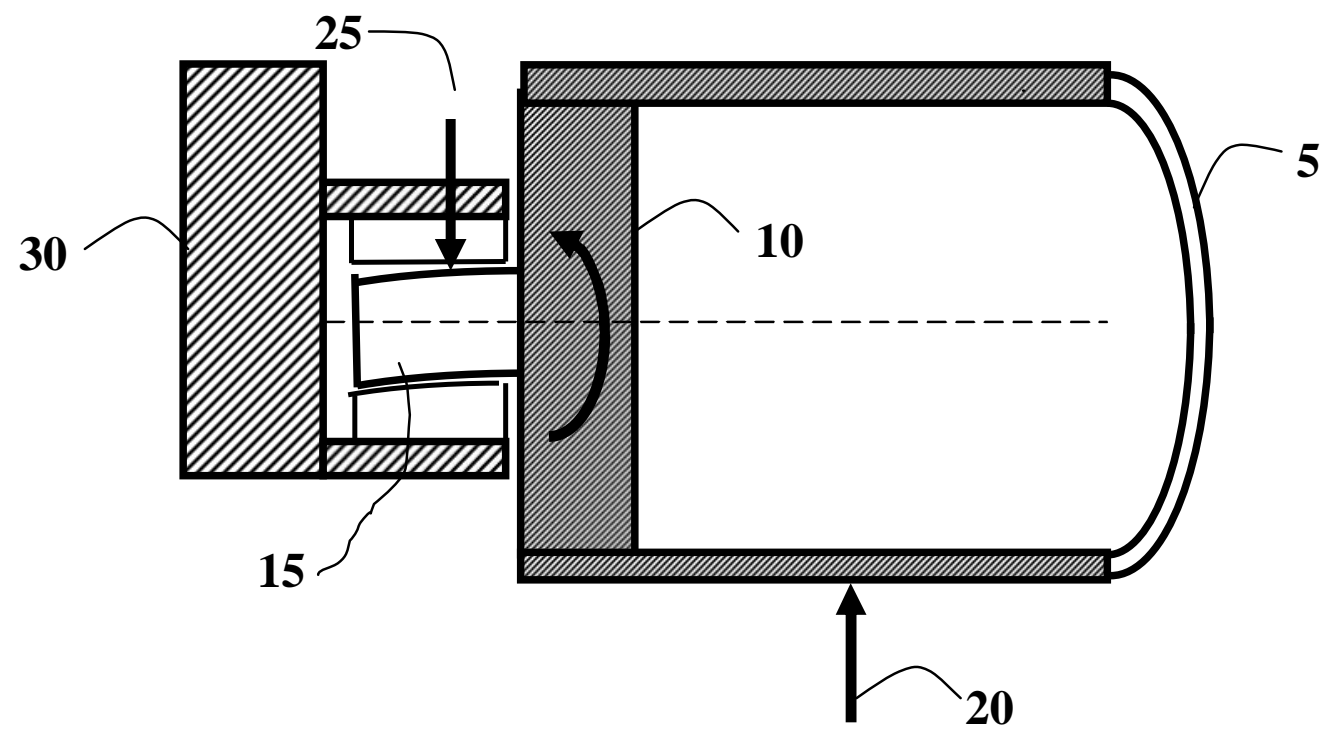

Fig.3.6 Conventional roll designs with short stubby shafts welded into roll and flanges, thus supported as a cantilevered beam. ${ }^{5}$

Such a rotating shaft deflects like a cantilevered beam of length, L, with a uniformly distributed load, $F$, resulting in maximum bending moment: 


$$
M_{\max }=\frac{F^{*} L}{2}
$$

and maximum deflection:

$$
\Delta y_{\max }=\frac{F^{*} L^{3}}{8 E l}
$$

The "Bearing Life Extender for Conveyor Type/Zinc-Pot Rolls" patent application provides a solution for this crisis. It is based on using of a stationary shaft, clamped at each end into the arms of the roll-supporting bridle. If the center portion of the shaft between the two bearings were made thick and thus essentially rigid, the bearing section would be loaded like a beam clamped at each end. The resulting maximum bending moment in the shaft should be similar to that of a beam, fixed at both ends, with a uniformly distributed load, F, and length, L, as shown in Fig. 3.7.

$$
\mathrm{M}_{\max }=\frac{\mathrm{F}^{*} \mathrm{~L}}{6}
$$

and of maximum deflection:

$$
\Delta y_{\max }=\frac{5 * F^{*} L^{3}}{384 E I}
$$

Depending on the rigidity achieved at the end of each bearing, the maximum bending moment might be reduced up to $6 / 2=3$ fold, and the shaft deflection up 
to $384 / 8=48$ fold. Therefore a fixed shaft roller may be designed with bearings that are both smaller in diameter and longer in length to improve their performance. Reducing shaft deflection eliminates high pressure points and contributes to increased bearing life.

The 3D Fig.3.7 illustrates the differences between the conventional and the modified roll equipment design. The major distinguishing factor is that the $591 / 8$ " long 4 " diameter roll 1 rotates about a stationary 72 " long 3" diameter shaft 2, which has been rendered rigid on either side of the two bearings as shown above. The display of the roll is made transparent. The roll 1 therefore has to be hollow, to accommodate such an internal shaft $\mathbf{2}$. Therefore, again a sectioned view of the roll has been shown. The roll is a stepped one on the inside to block the sliding of the inserts on the bearing sleeve. The sheet 


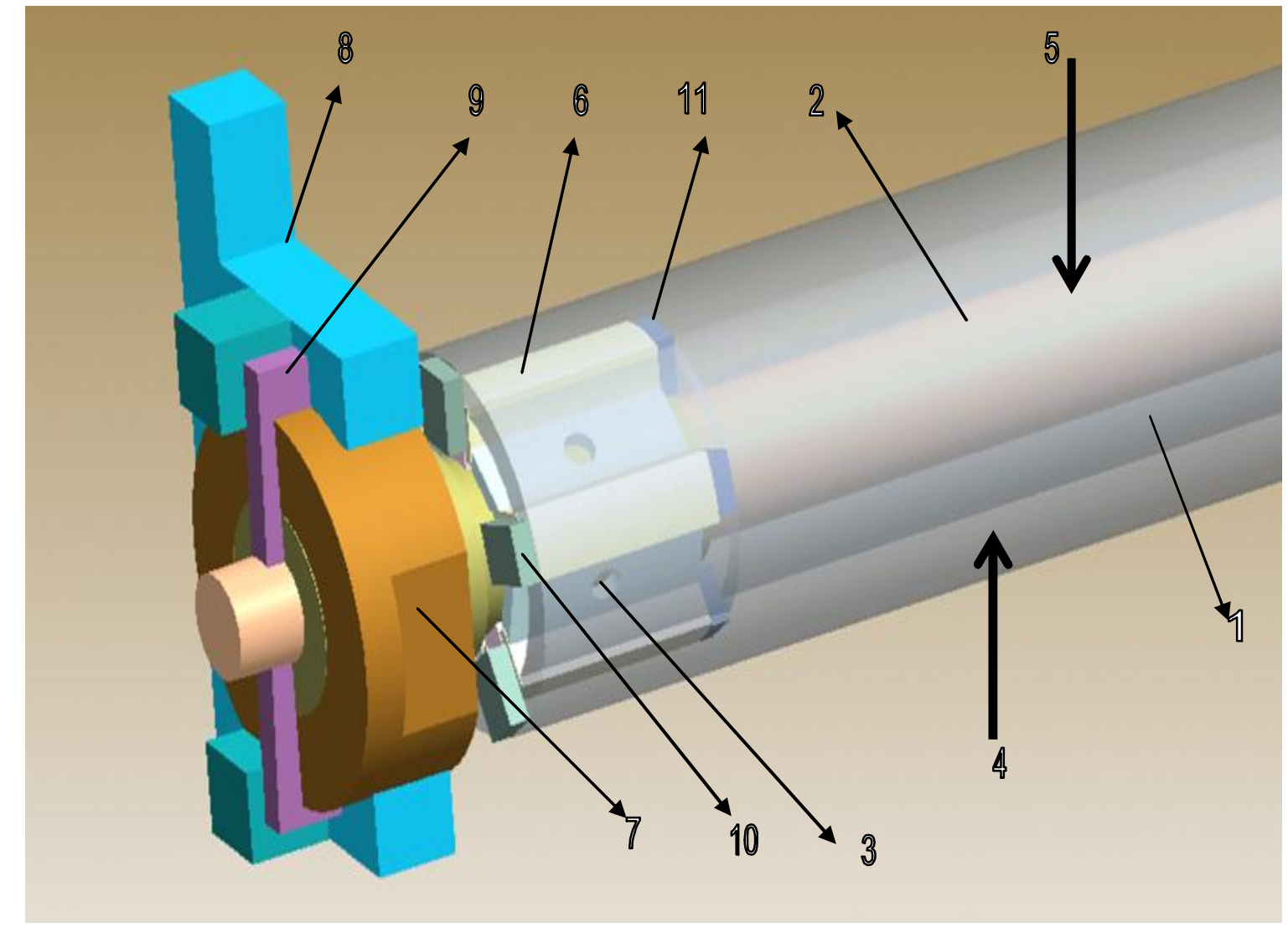

Fig: 3.7 Bearing Life Extender Assembly (Roll display is made transparent)

tension or the weight of the conveyor load produces a force 4 on the roll as indicated. This force 4 is transmitted via the rotating bearing housing 6 to the shaft 2 . The force $\mathbf{4}$ on the roll creates reaction force $\mathbf{5}$ by the stationary shaft. The bearing housing 6 at each end of the roll is welded to roll 1 and thus rotates with it. The housing comprises of 5" long ceramic inserts placed at equal angular distance about the axis of the shaft. The ceramics are held by means of insert clamps which are same in number as the inserts. The space between them is occupied by the 5 " long insert clamp spacers which are 5 in quantity as well. The spacers are interference fitted in between the insert clamps. A vent hole of $3 / 4 "$ 
diameter is drilled through the centre of gravity of each spacer which enables equal heat conduction throughout. This bearing housing accounts for the large bearing-roller clearances. The stationary shaft 2 must be rendered rigid on either side of the bearings. Therefore in between the two bearings, its diameter is tapered along the bearing length. Outside the two bearings the shaft is clamped securely to the roll support, such clamps are needed to render the shaft rigid outside the two bearings. For maintenance purposes, the bearing housing 6 have to be removable thus must be attached temporary to the roll. The bearing clamping hardware consists of an 8.5" diameter 3" thick collar 7 placed over the bearing. A lip of 1 " thickness and $3 / 8$ " depth is made on the collar on four sides as shown for an over hangar $\mathbf{8}$ which exactly sits on this collar lip. A keyway runs through the shaft, bearing and the collar as shown. A tapered key 9 of 10" long with a taper of $3 / 8$ " taper on one side prevents the relative motion between the shaft, the bearing and the collar. Further to hold the tapered key 9 in its place the over hangar 8 is installed. To prevent the over hangar from falling off, ceramic blocks of 2" thick are welded on to the hangar as shown. There are 4 blocks altogether which act like roll assembly locks on either side of the roll. The shaft 2 should be stiffer and thus must be thicker in between the bearings, as indicated by the taper it can also serve as a thrust bearing. Such a dual function applies to most bearing types. Hence the bearing now accommodates for both the radial and axial loads. By mounting the bearing housings 6 into the roller cylinder by means of the inserts with the spacers in between, they will act like vanes of a centrifugal pump and move liquid zinc radially through the holes $\mathbf{3}$ in them. This 
provides bearing cooling and improves the bearing lubrication. For holding the ceramic inserts in the clamp, a 0.5 " thick rectangular block 10 is welded onto the roll and the bearing while mating the surface of the insert. There are 5 such blocks stopping the inserts from sliding on the bearing on one side. On the other side, we have another set of rectangular blocks 11 of different cross-section, 0.5 " thick though which are welded to the bearing radially on the inside and the insert surface as well. There is a clearance of $1 / 16$ " between the stepped down roller radial surface and the insert stopping rectangular block, also between the first set of rectangular blocks and the stepped up bearing radial surface. 


\subsection{Stabilizer Roll Design}

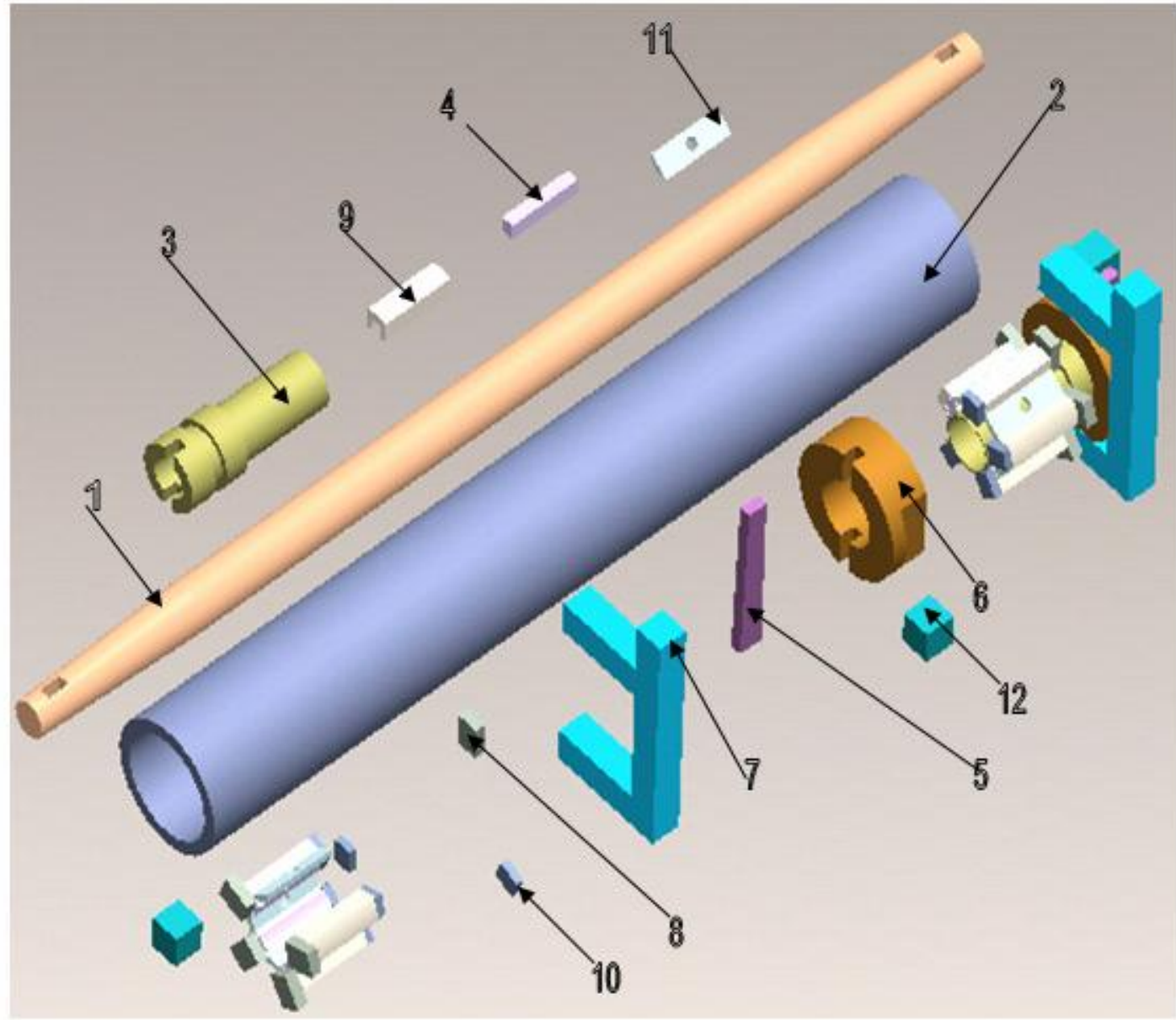

Fig: 3.8 Stabilizer Roll (Exploded View) 


\begin{tabular}{|l|l|l|c|}
\hline S.NO & PART DESCRIPTION & MATERIAL & QTY \\
\hline 1. & NON-ROTATING SHAFT & 316 L STAINLESS STEEL & 1 \\
\hline 2. & STABILIZER ROLL & 316 L STAINLESS STEEL & 1 \\
\hline 3. & COATED BEARING SLEEVE & 316 L STAINLESS STEEL & 2 \\
\hline 4. & INSERT & CERAMIC & 10 \\
\hline 5. & ASSEMBLY RETAINING KEY & 316 L STAINLESS STEEL & 2 \\
\hline 6. & COLLAR TO FIT HANGAR & 316 L STAINLESS STEEL & 2 \\
\hline 7. & HANGAR & 316 L STAINLESS STEEL & 2 \\
\hline 8. & WELDS BEARING TO ROLL & 316 S STAINLESS STEEL & 10 \\
\hline 9. & INSERT CLAMP & 316 L STAINLESS STEEL & 10 \\
\hline 10. & HOLDS INSERT IN CLAMP & 316 L STAINLESS STEEL & 10 \\
\hline 11. & INSERT CLAMP SPACER & 316 L STAINLESS STEEL & 10 \\
\hline 12. & ROLL ASSEMBLY LOCK & 316 STAINLESS STEEL & 4 \\
\hline
\end{tabular}

Table 3.1 Bill of Materials 




Fig: 3.9 Stabilizer Roll Assembly 


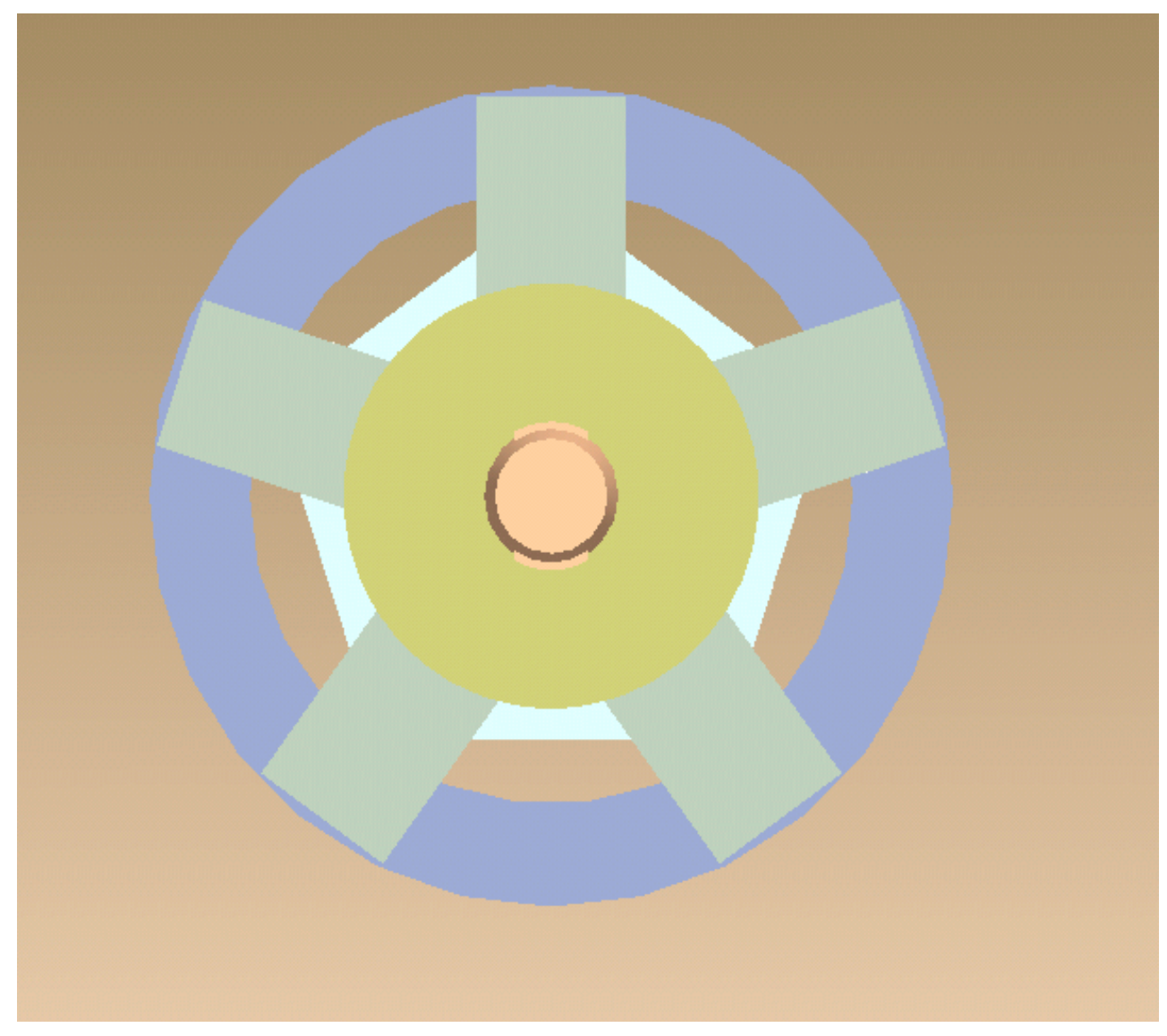

Fig: 3.10 Side View of the Roll Assembly without Clamping 
Fig: 3.12 Fixed Non-rotating Shaft

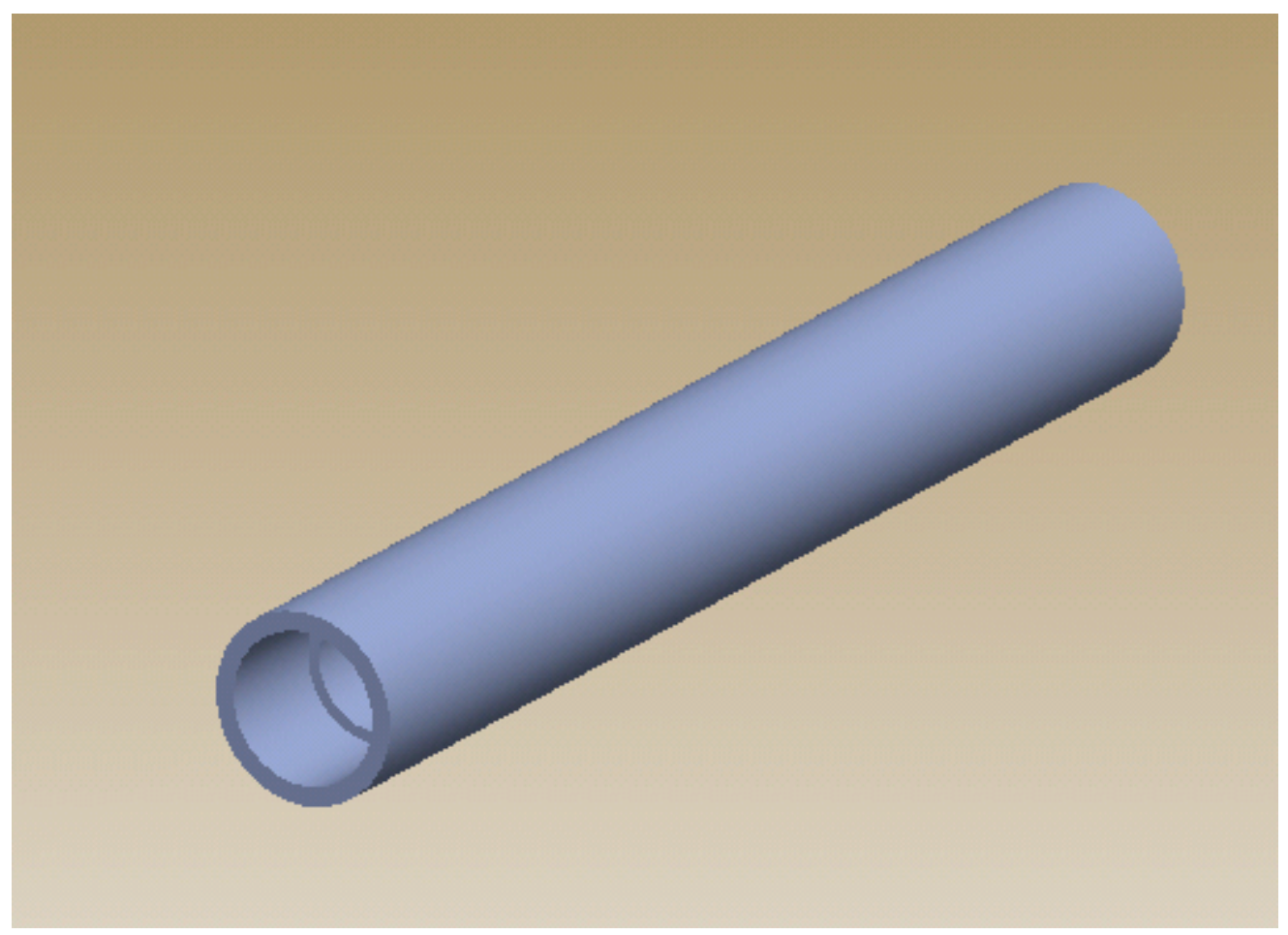

Fig: 3.13 Stabilizer Roll 


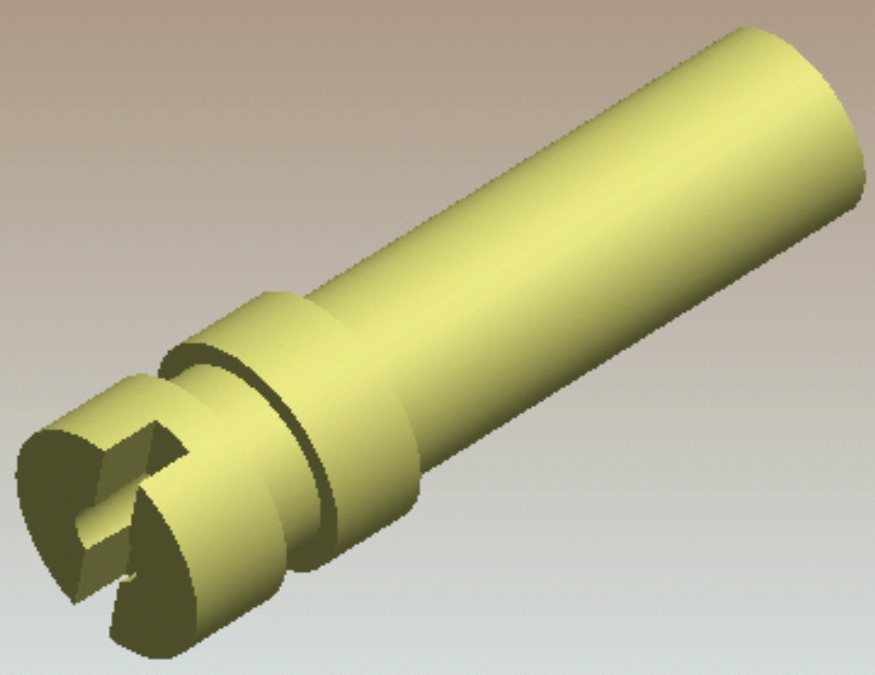

Fig: 3.14 Coated Bearing Sleeve

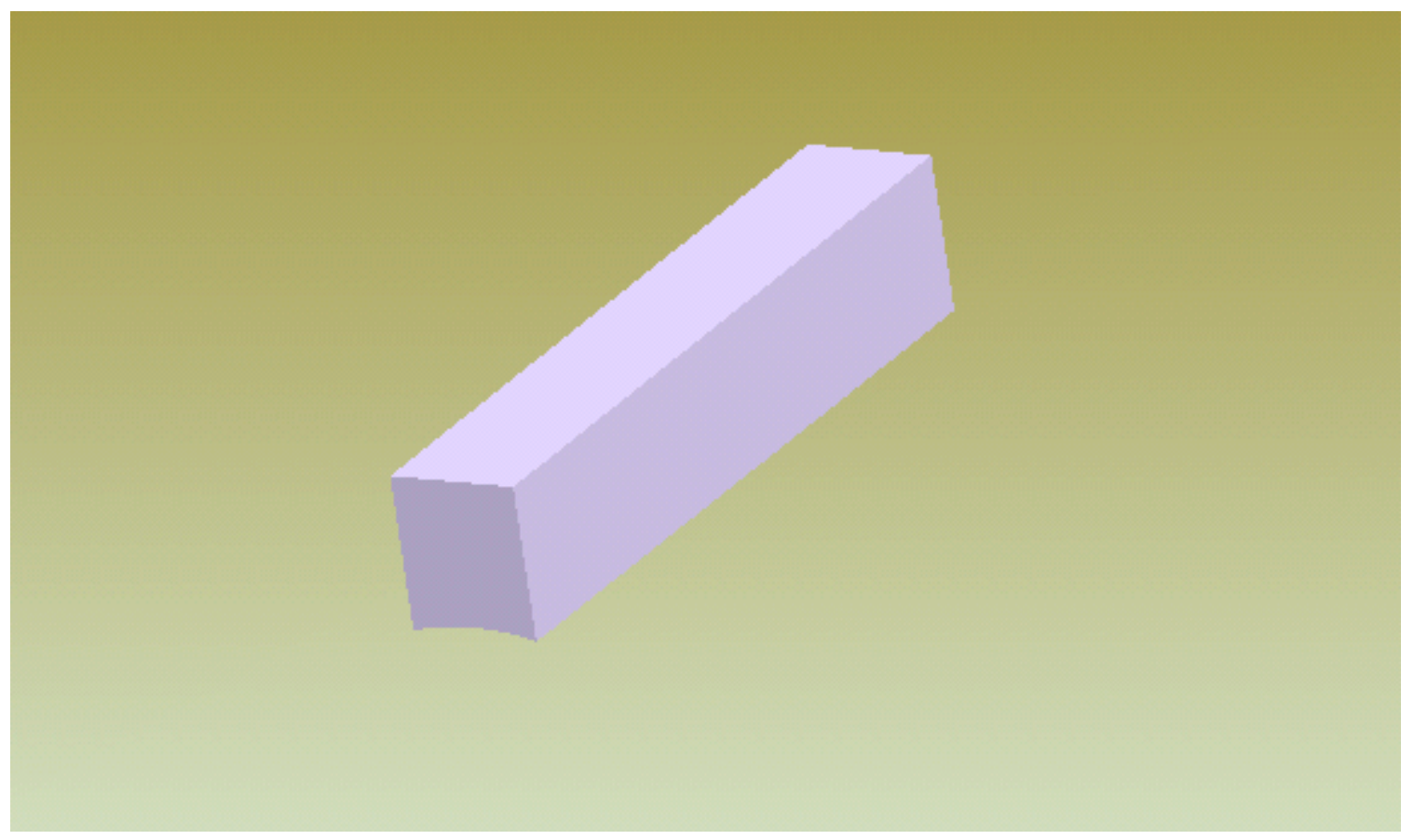

Fig: 3.15 Ceramic Insert 


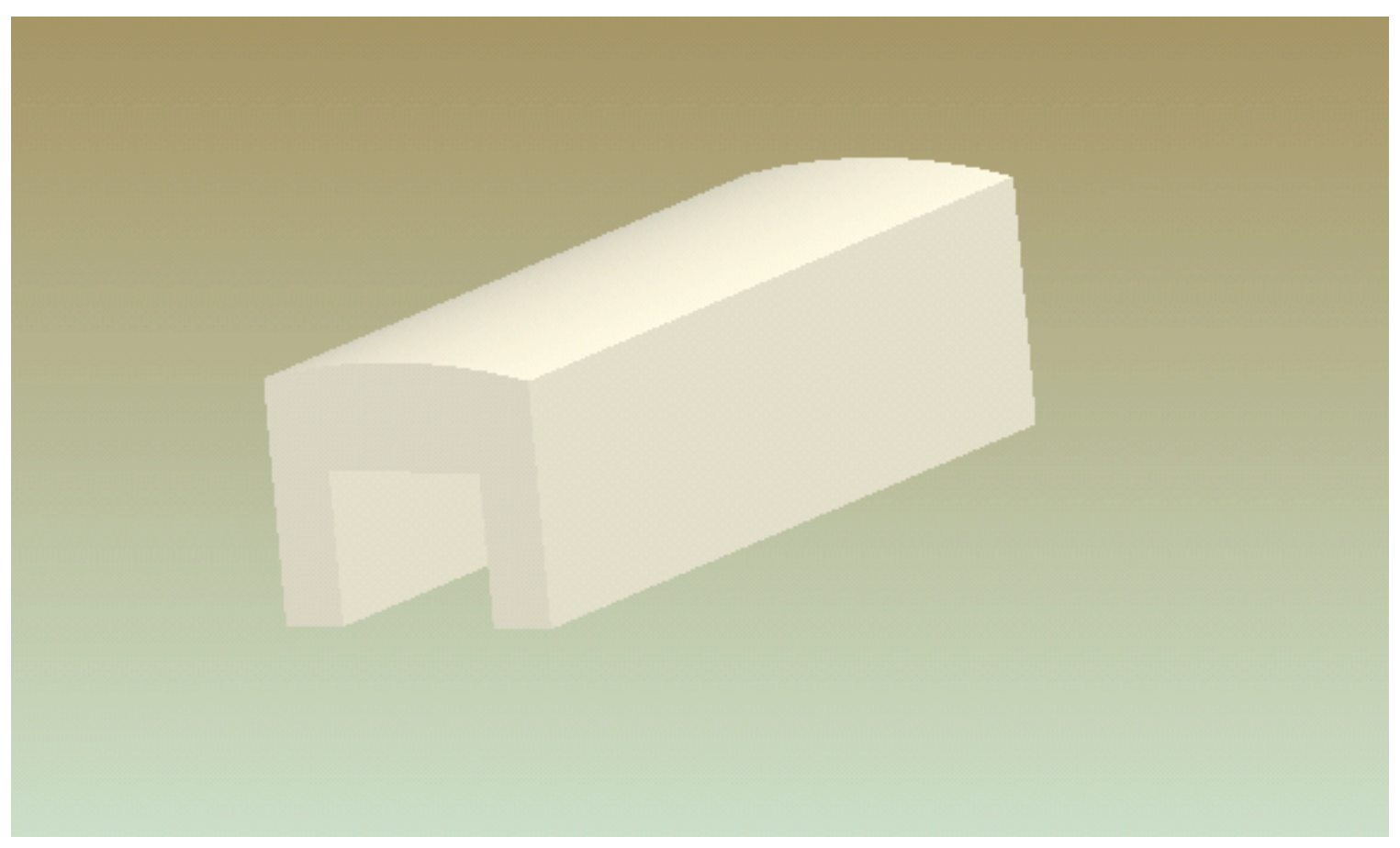

Fig: 3.16 Insert Clamp

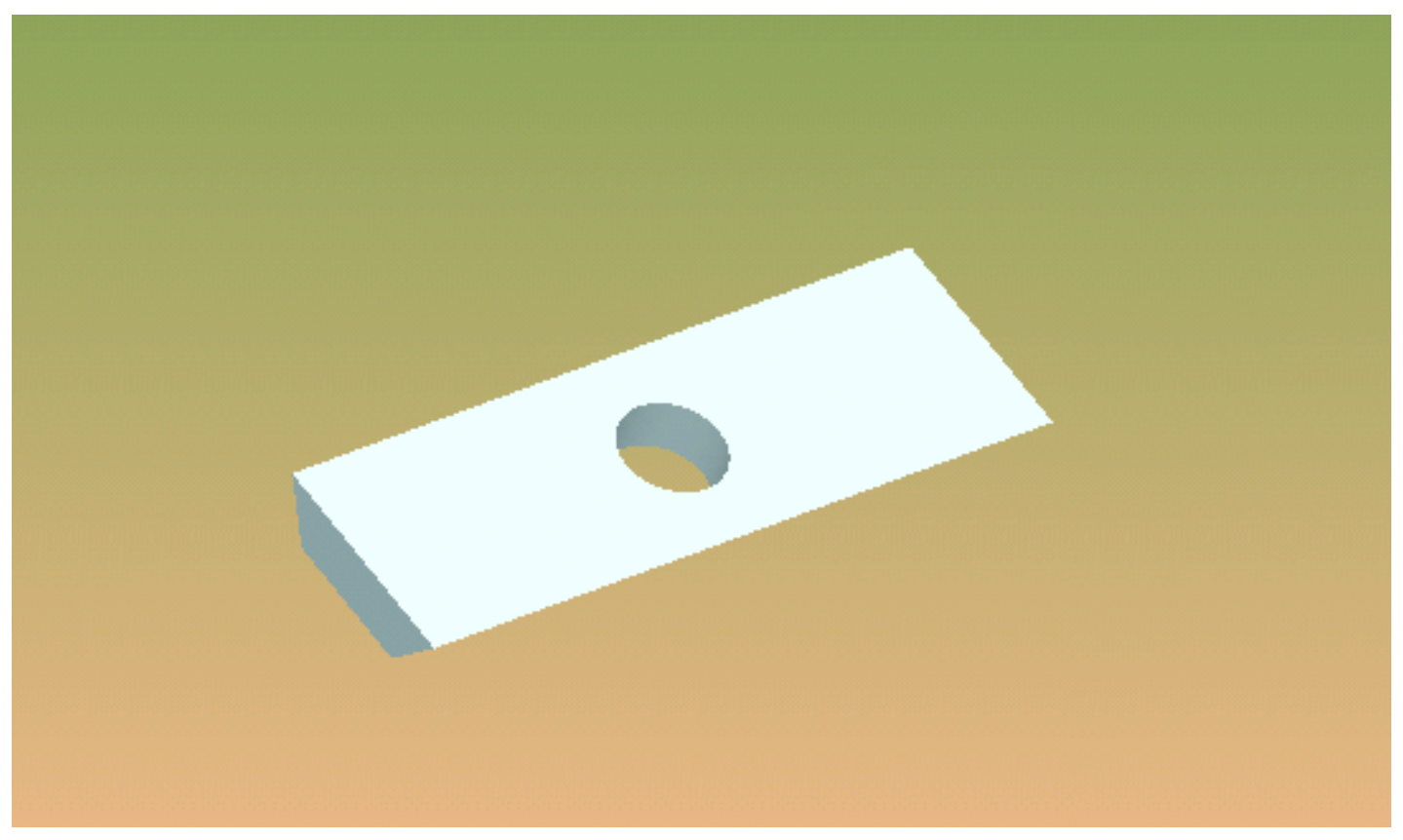

Fig: 3.17 Ceramic Clamp Spacer 


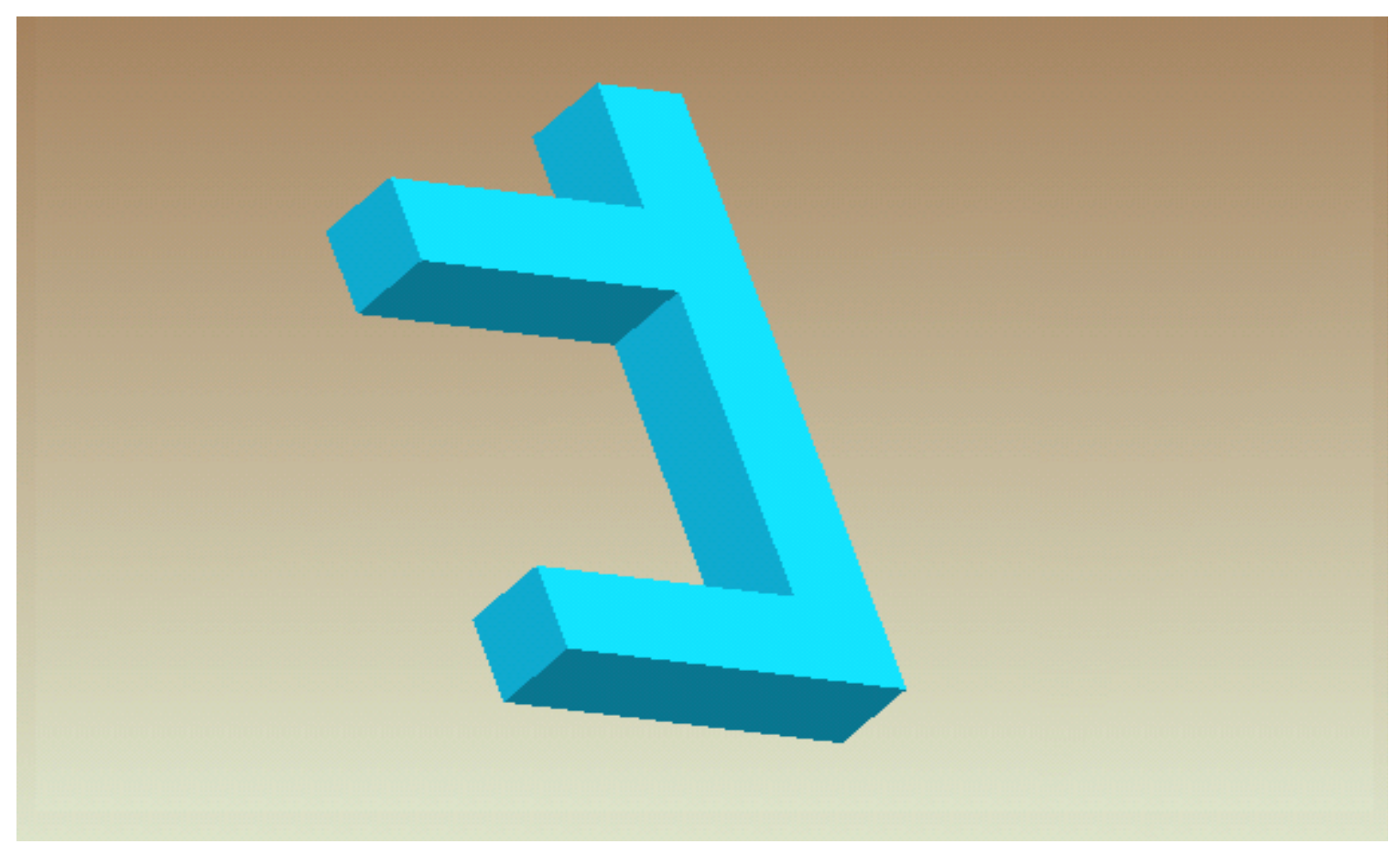

Fig: 3.18 Hangar

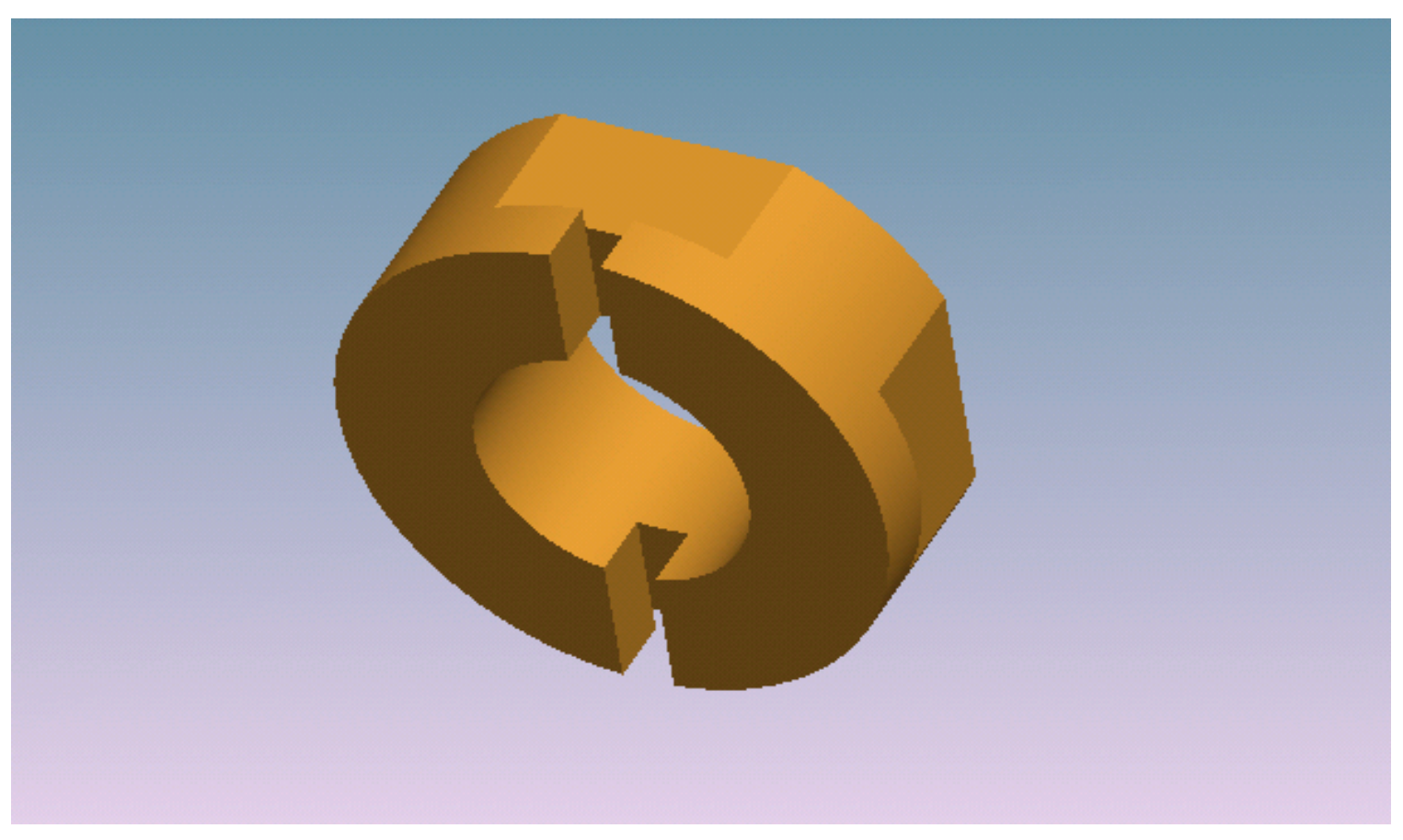

Fig: 3.19 Collar to fit Hangar 


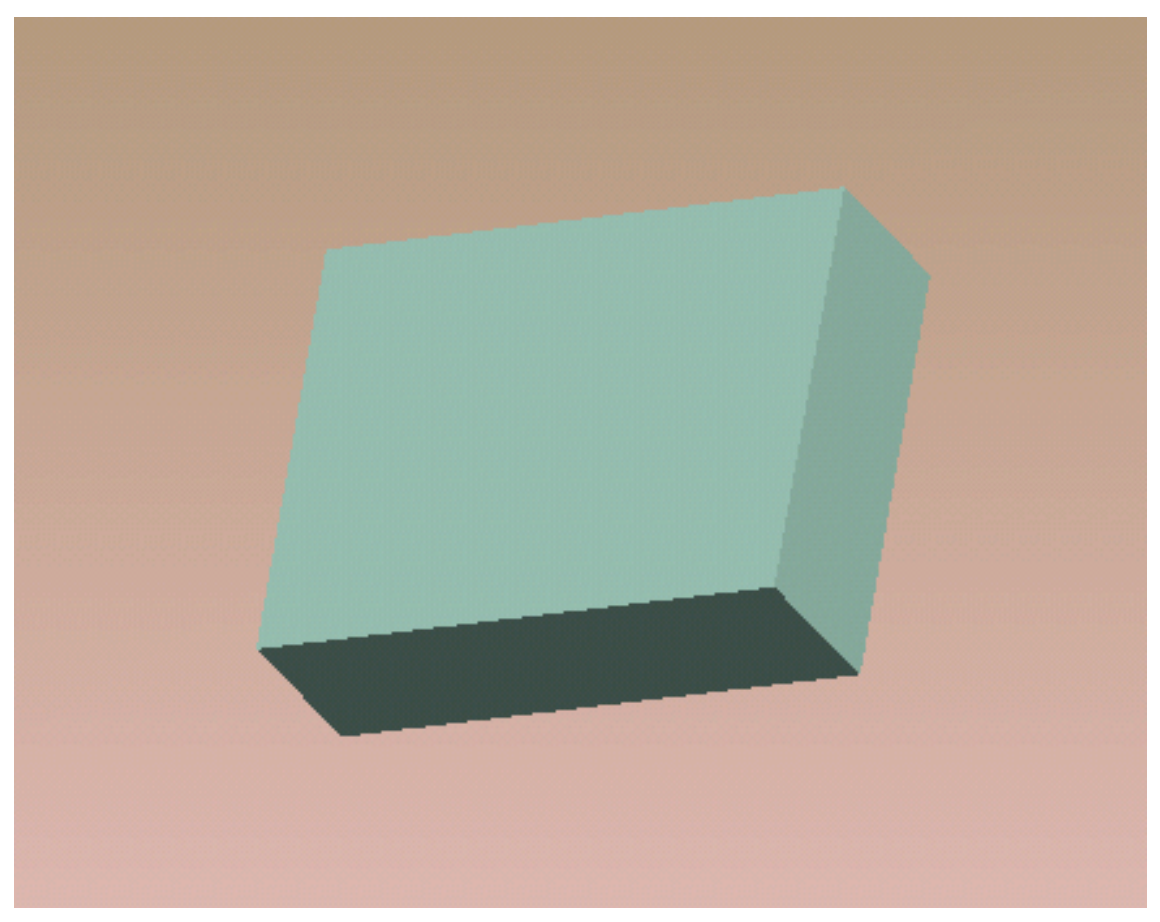

Fig: 3.20 Welds Bearing to the Roll

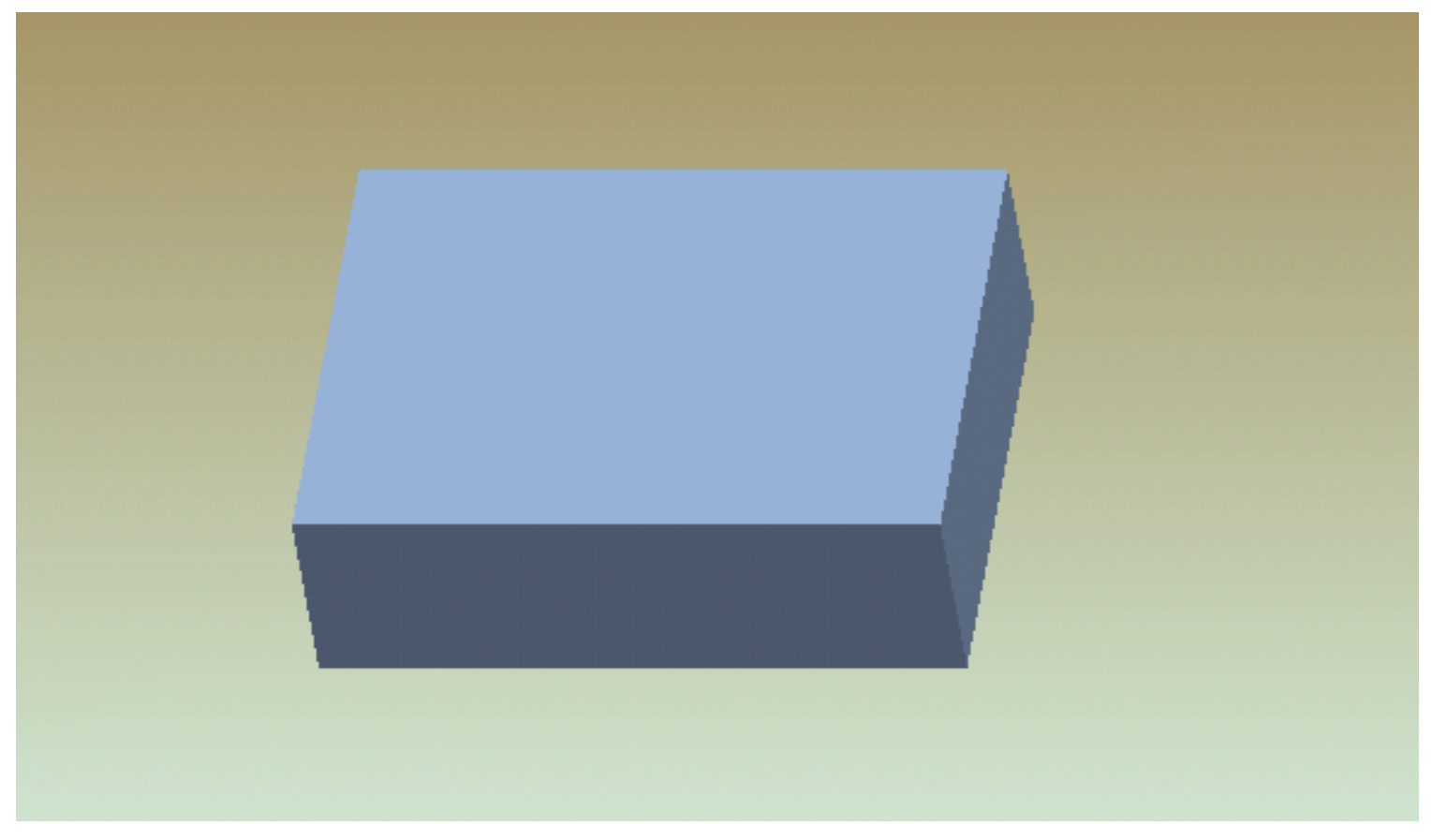

Fig: 3.21 Holds Ceramic in Clamp 


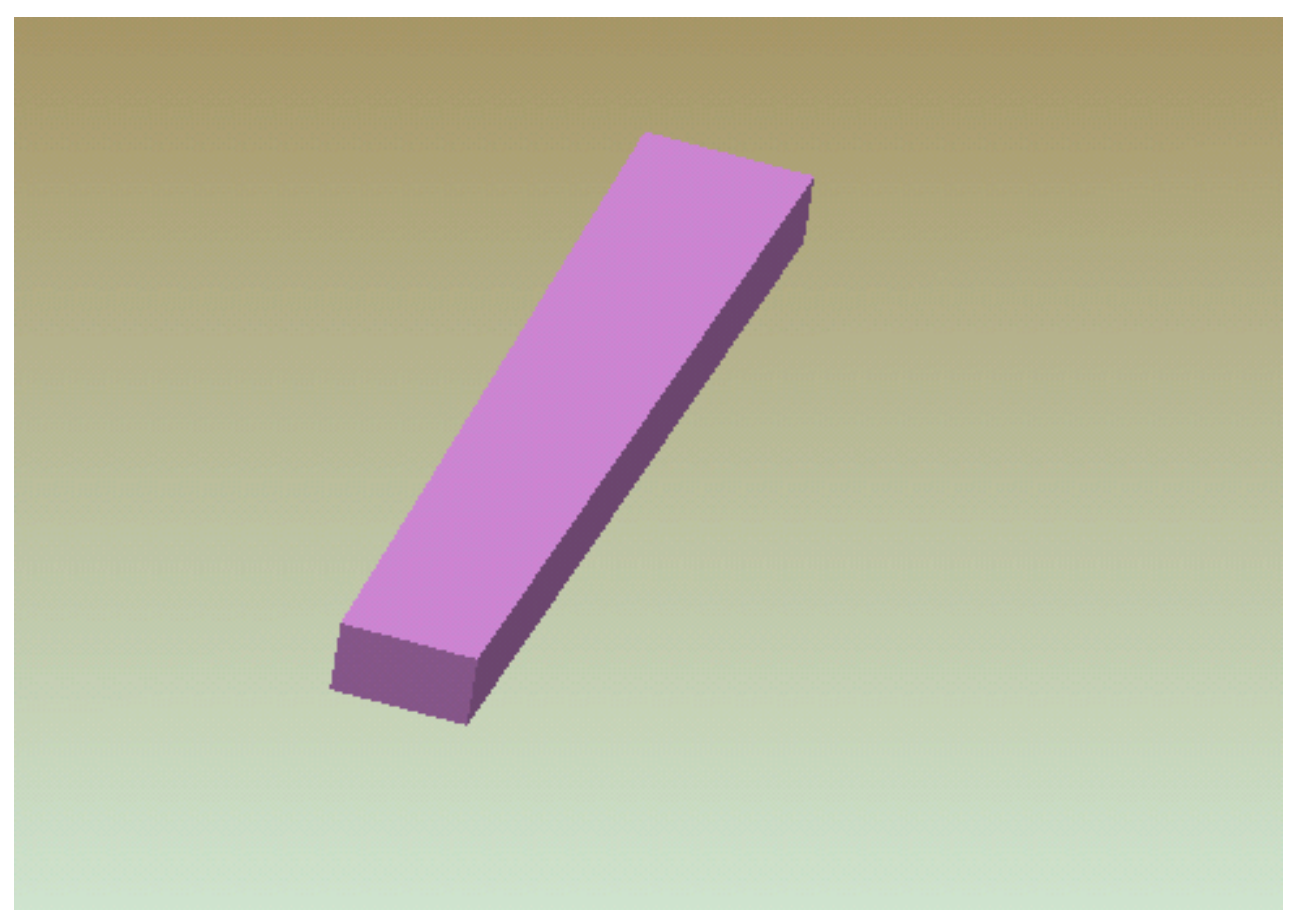

Fig: 3.22 Assembly Holding Key

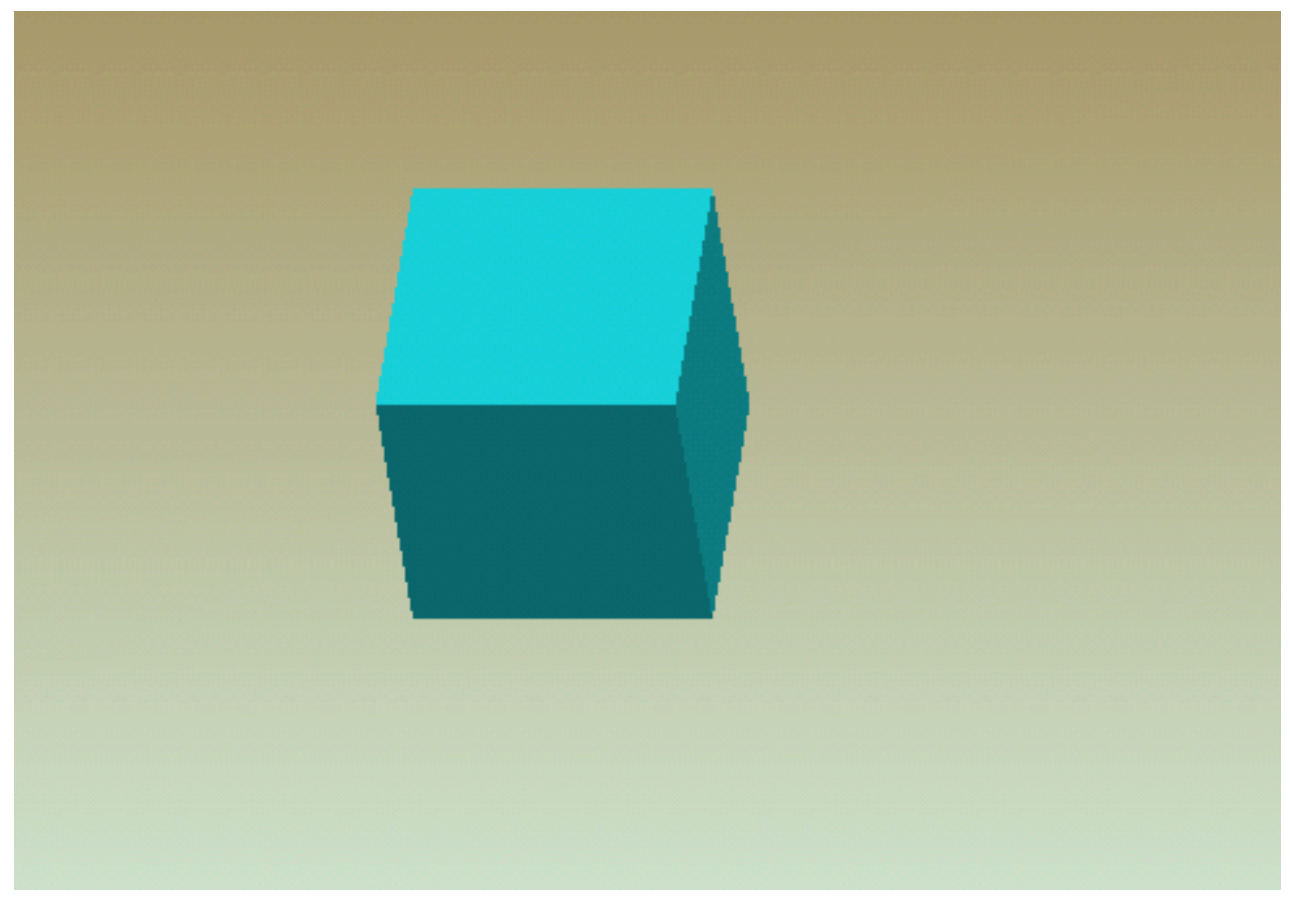

Fig: 3.23 Roll Assembly Lock 


\subsection{Dimensioned Drawing Views}

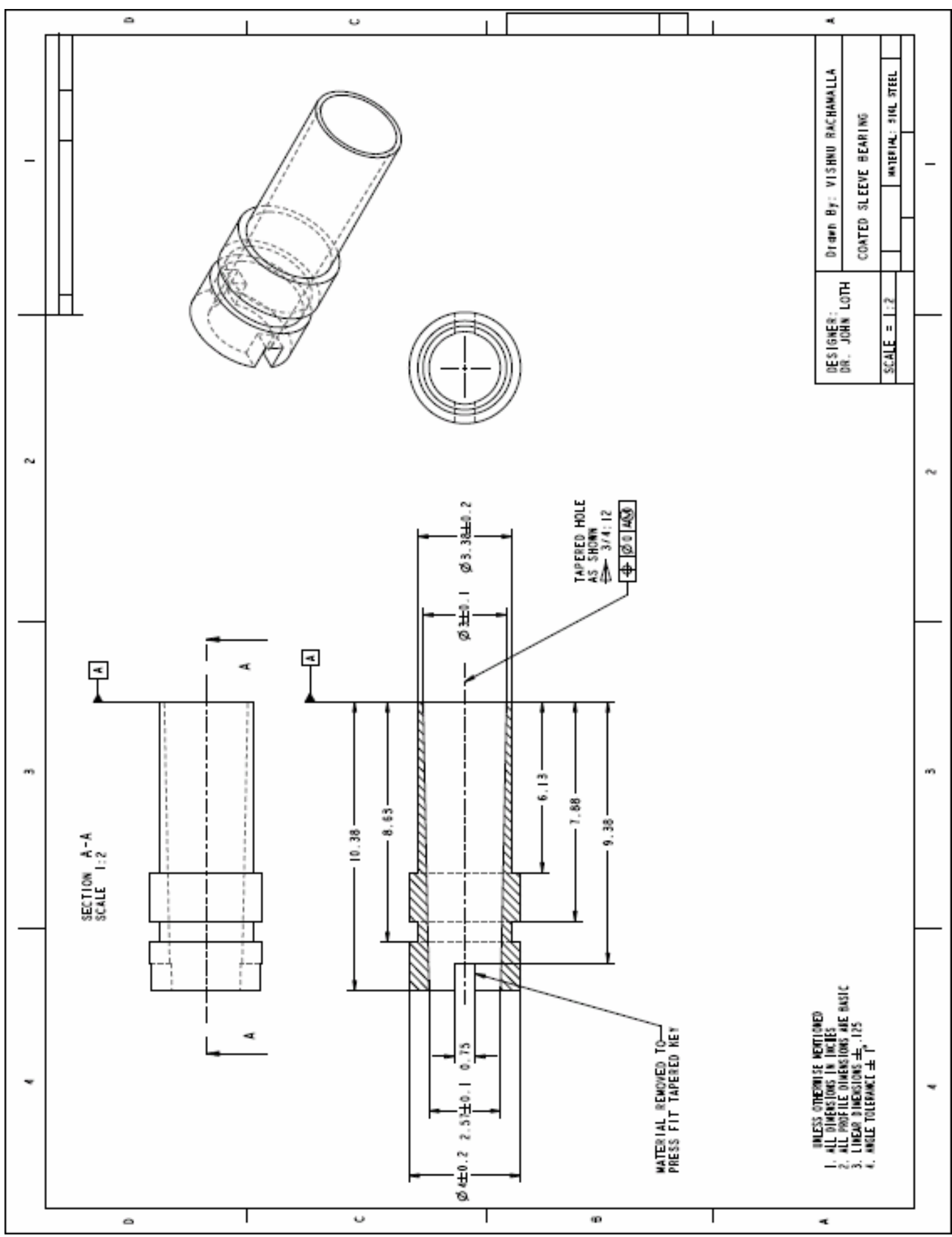

Fig: 3.24 Coated Sleeve Bearing 


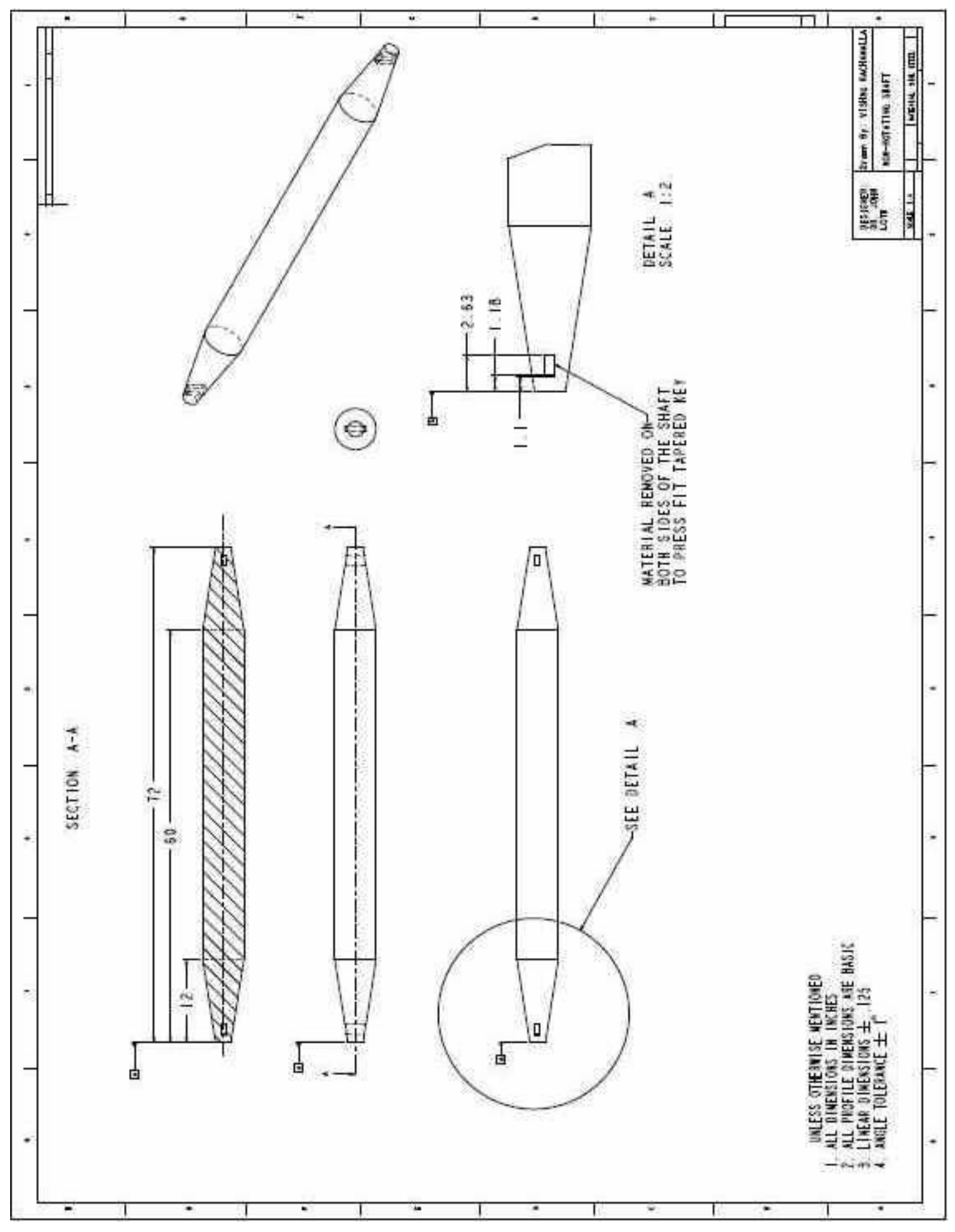

Fig: 3.25 Fixed Non-rotating Shaft 


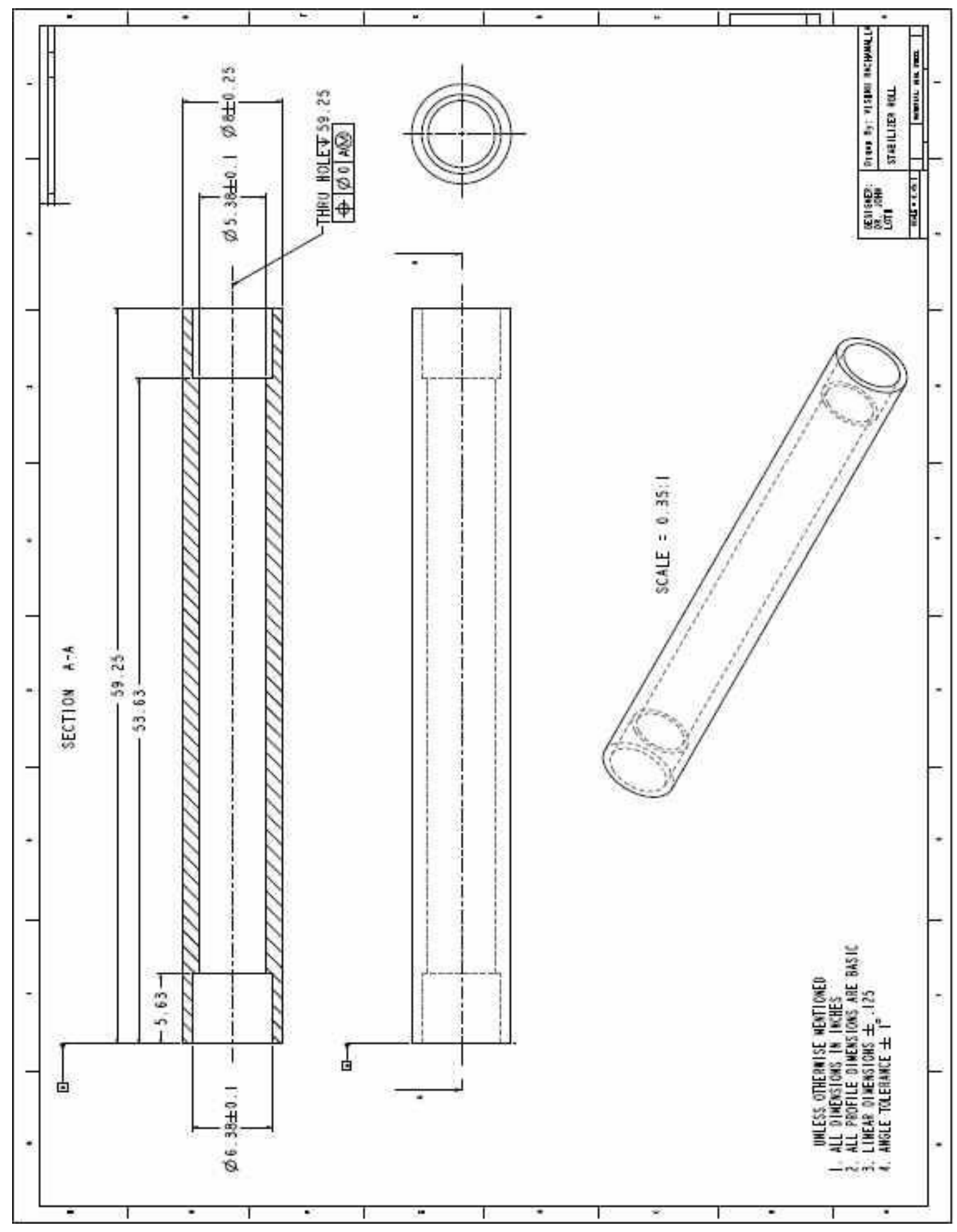

Fig: 3.26 Stabilizer Roller 


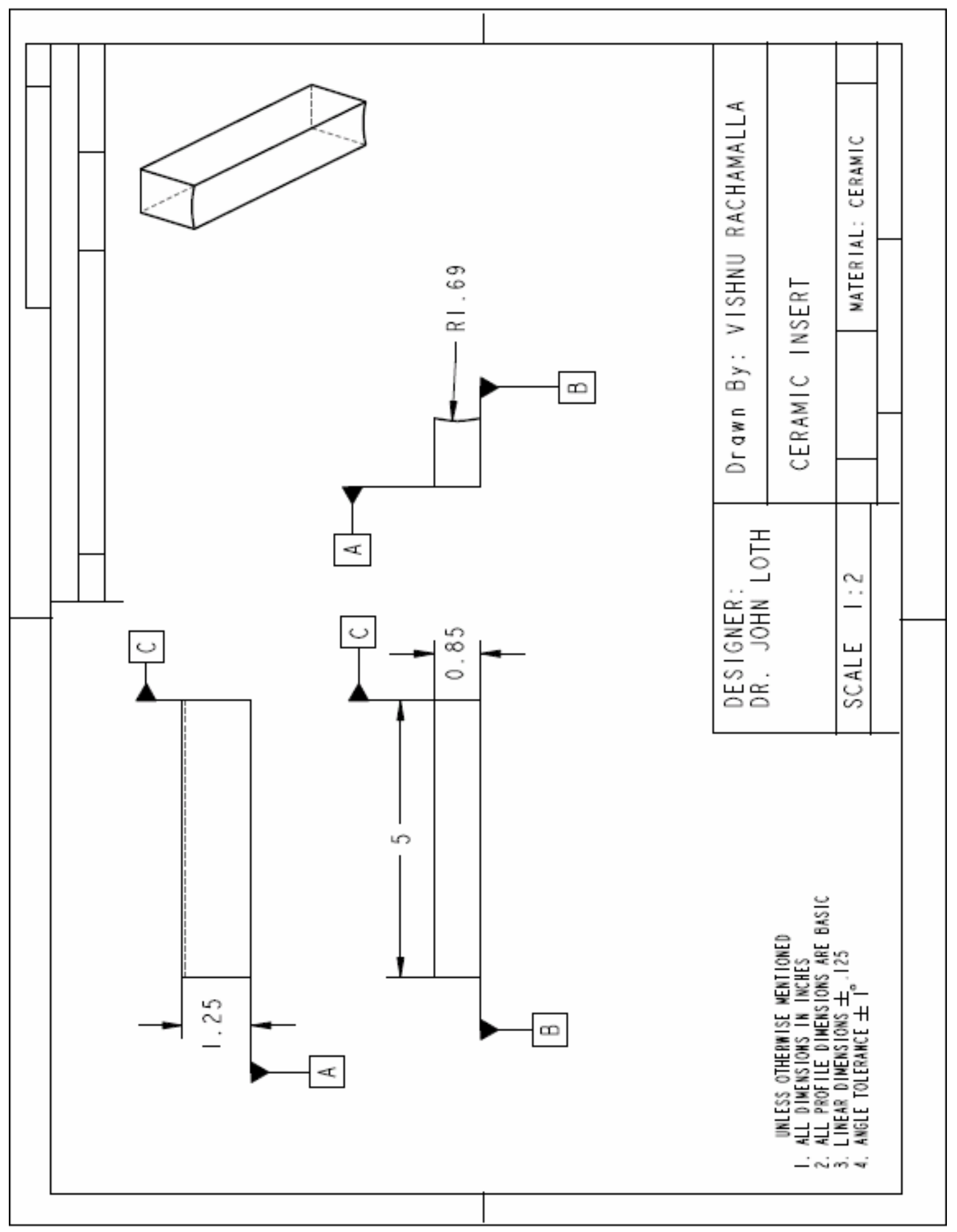

Fig: 3.27 Ceramic Insert 


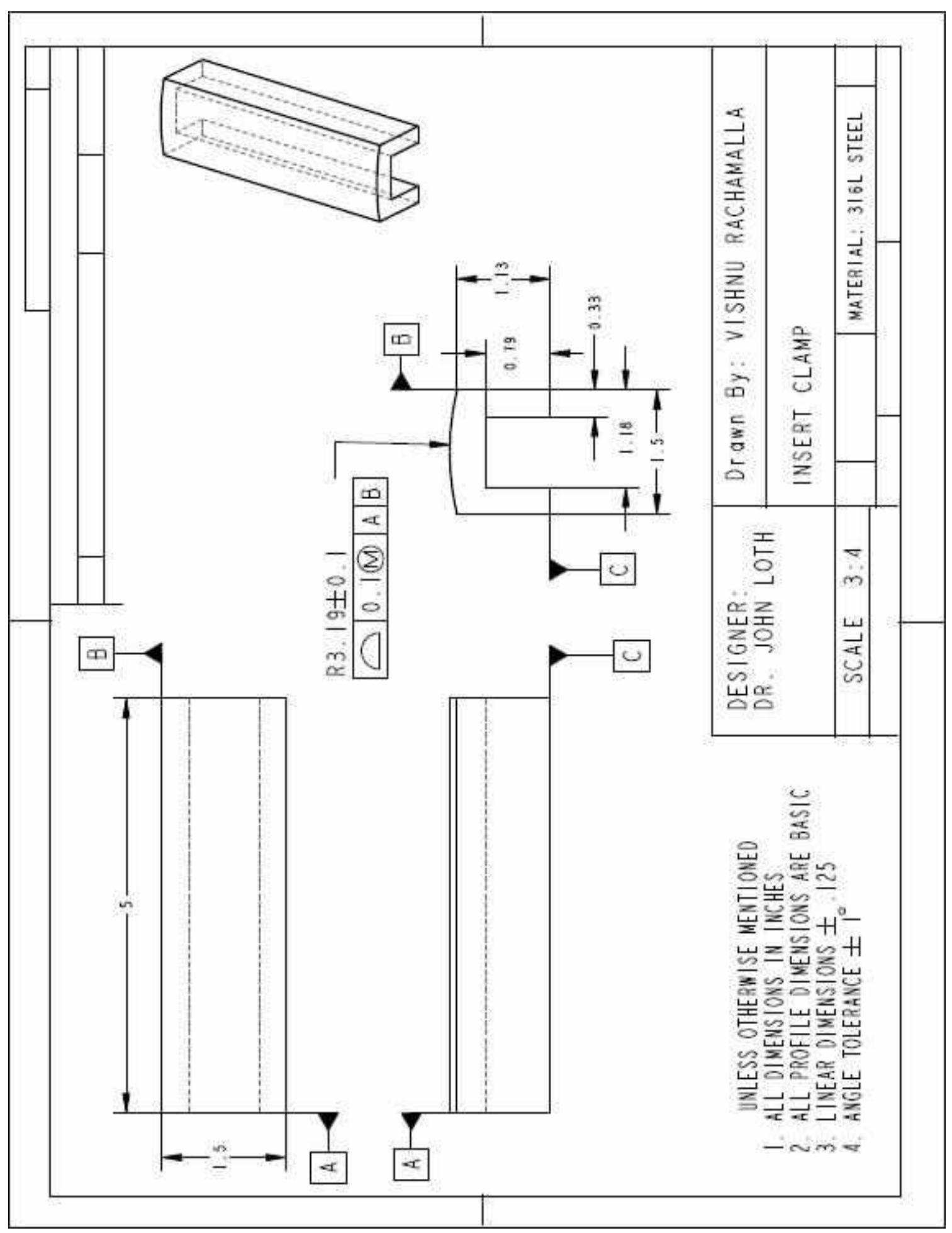

Fig: 3.28 Insert Clamp 


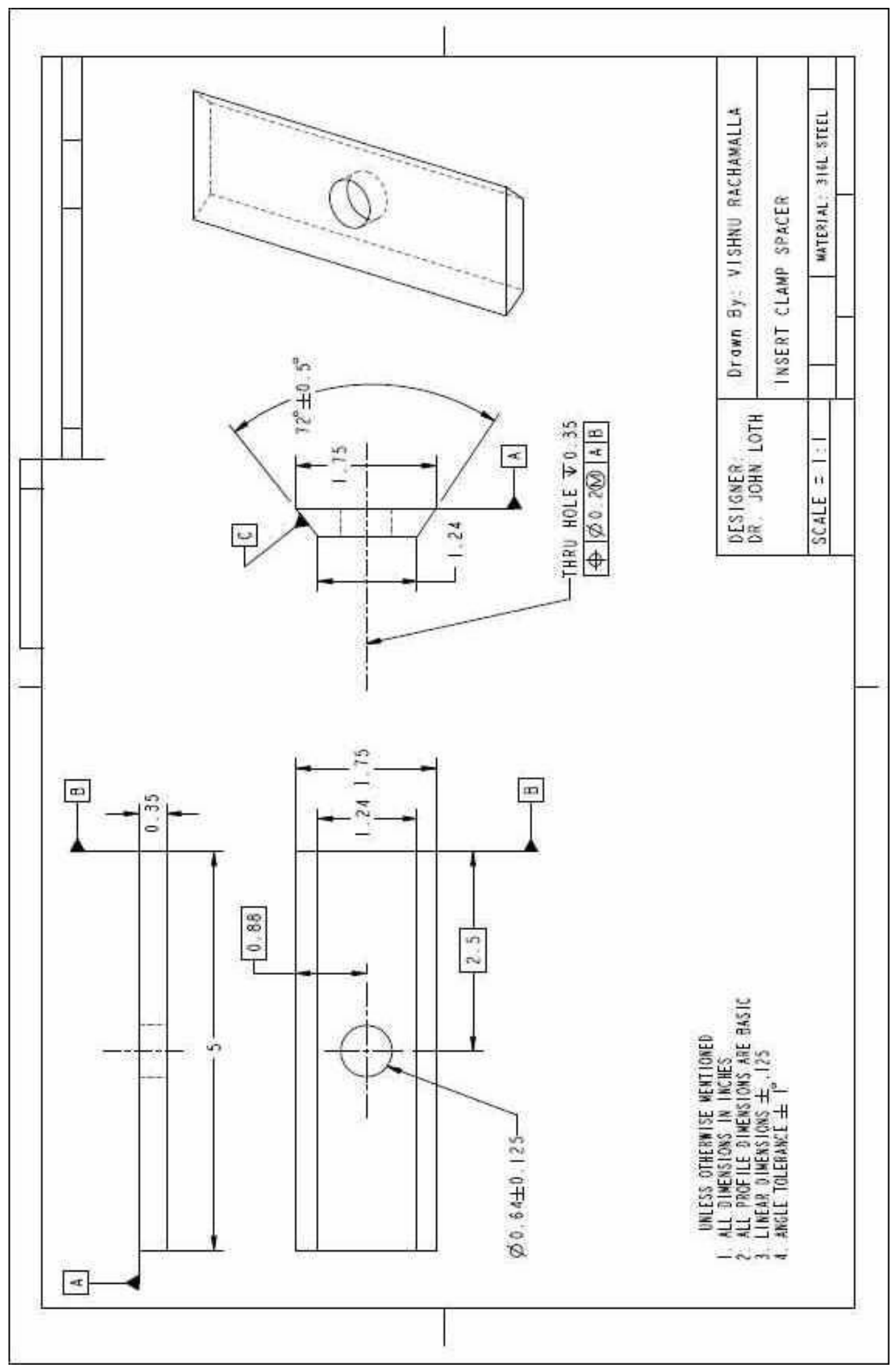

Fig: 3.29 Insert Clamp Spacer 


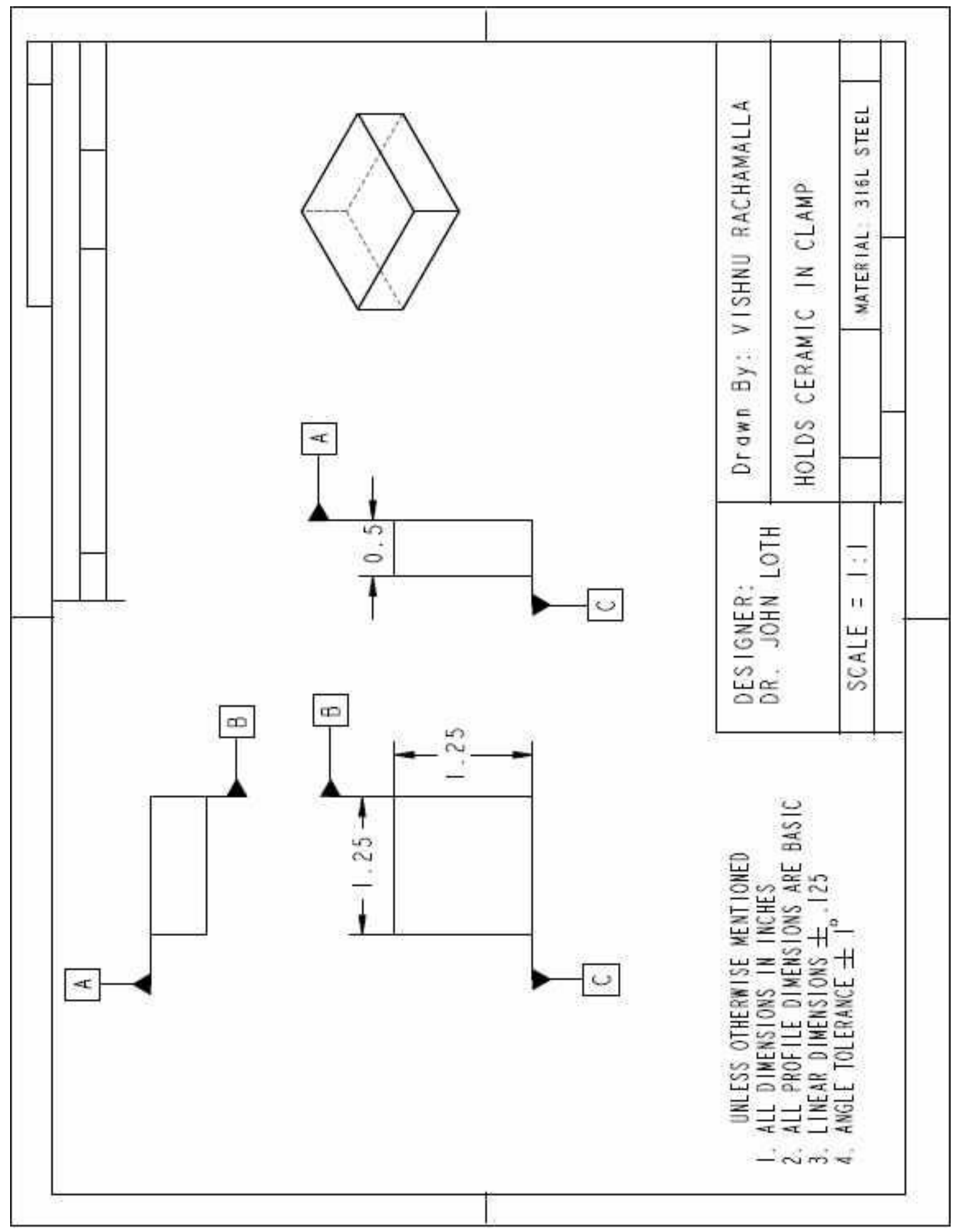

Fig: 3.30 Holds Ceramic in Clamp 


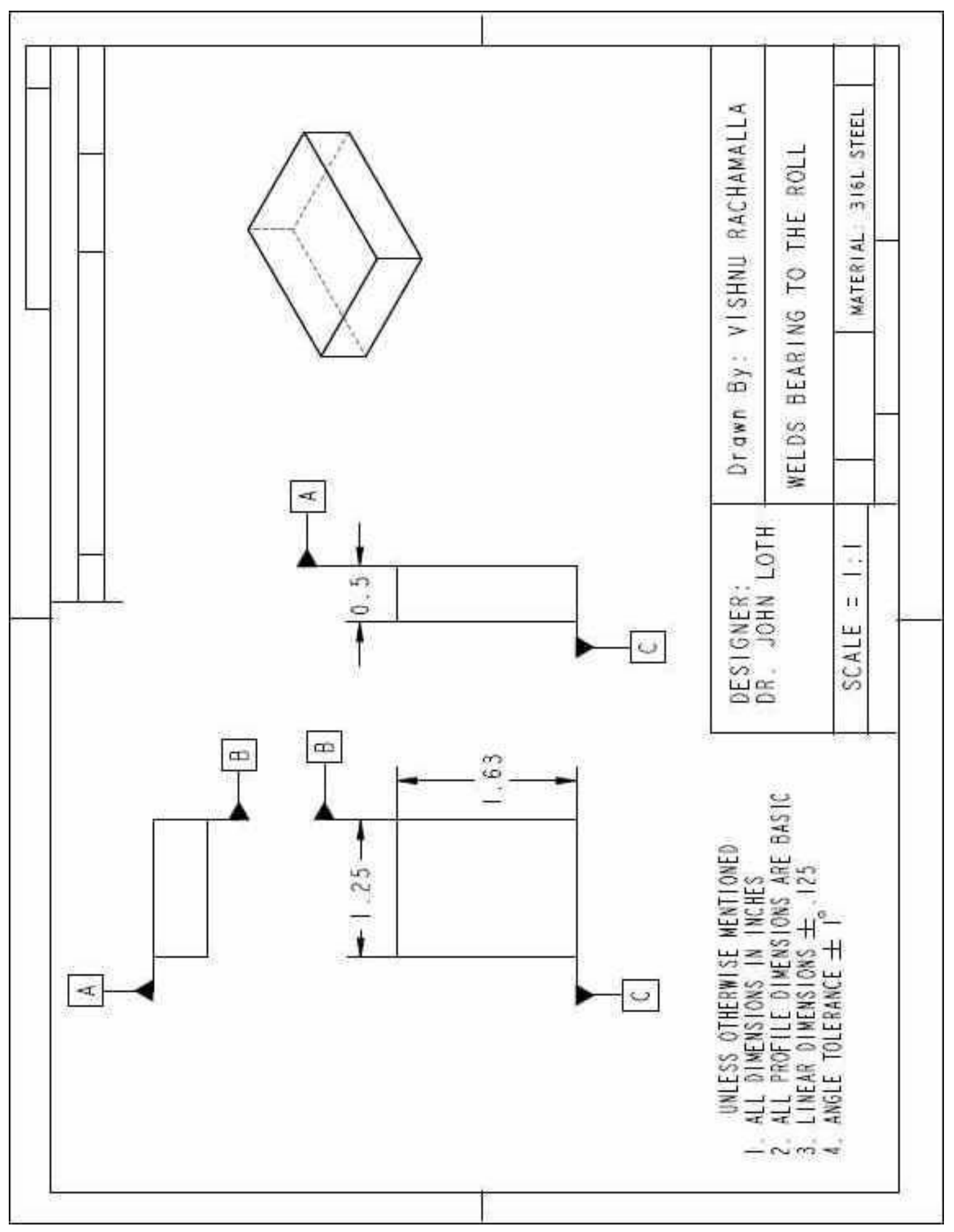

Fig: 3.31 Welds bearing to the roll 


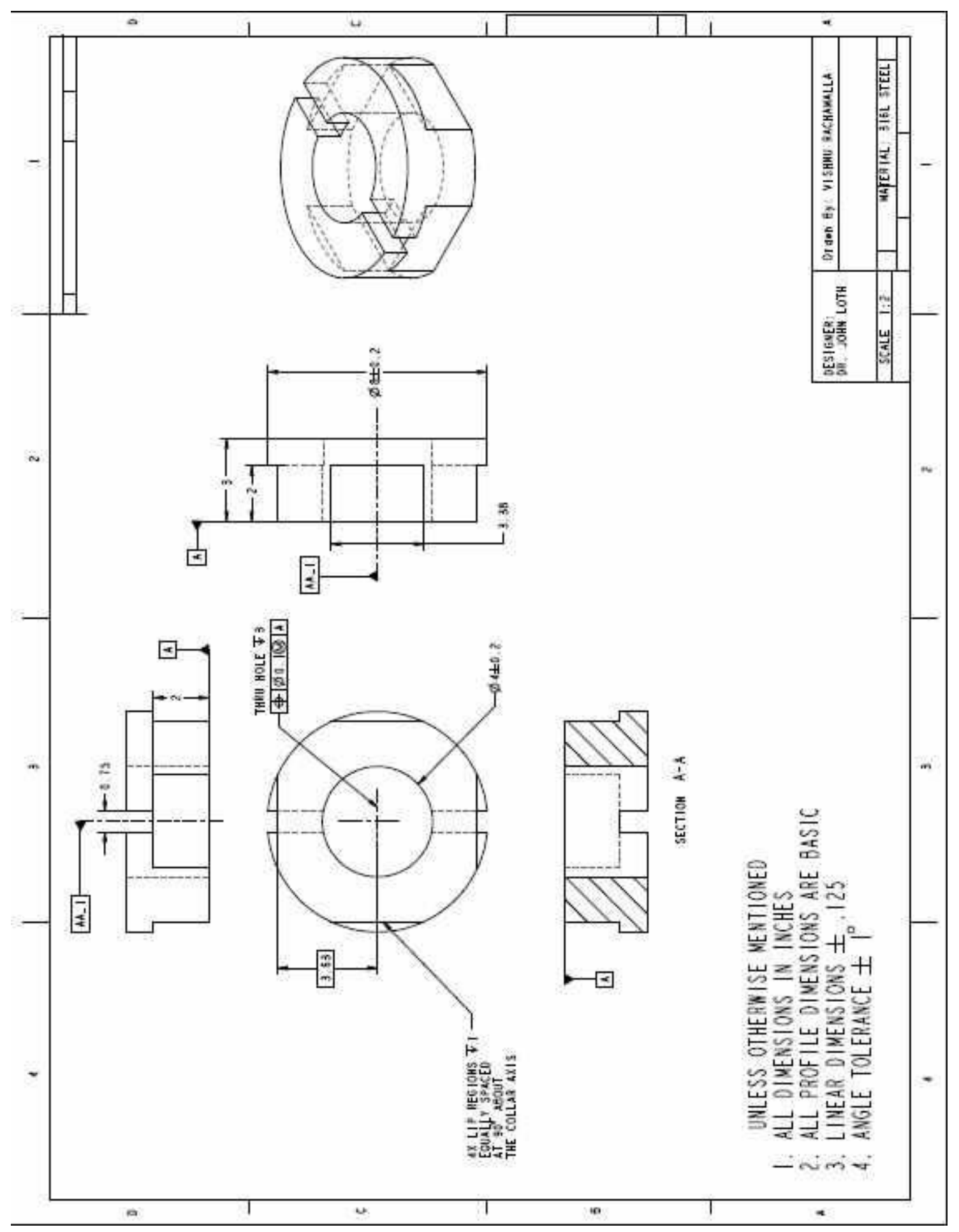

Fig: 3.32 Collar to fit Hangar 




Fig: 3.33 Tapered Key 


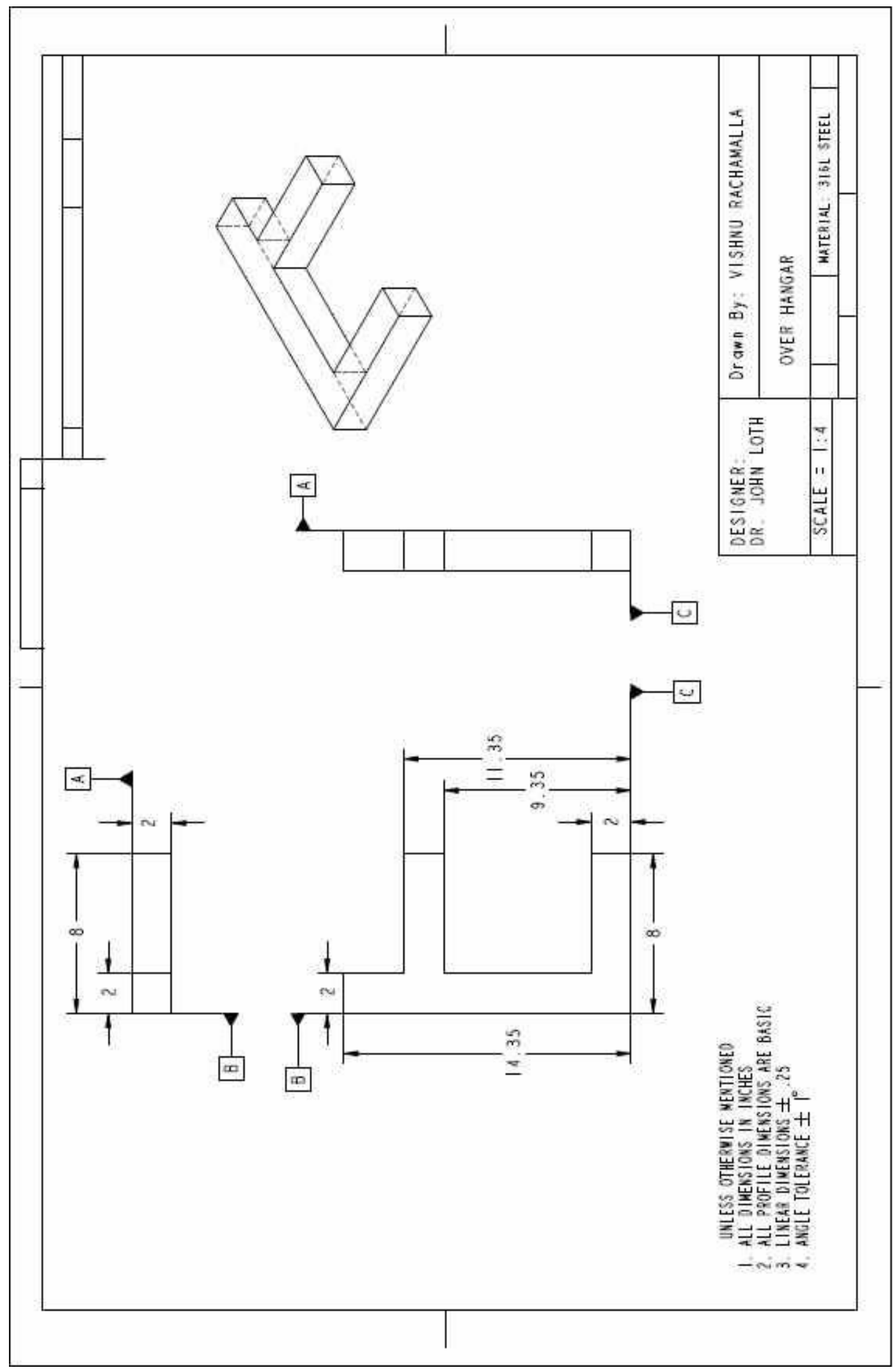

Fig: 3.34 Hangar 


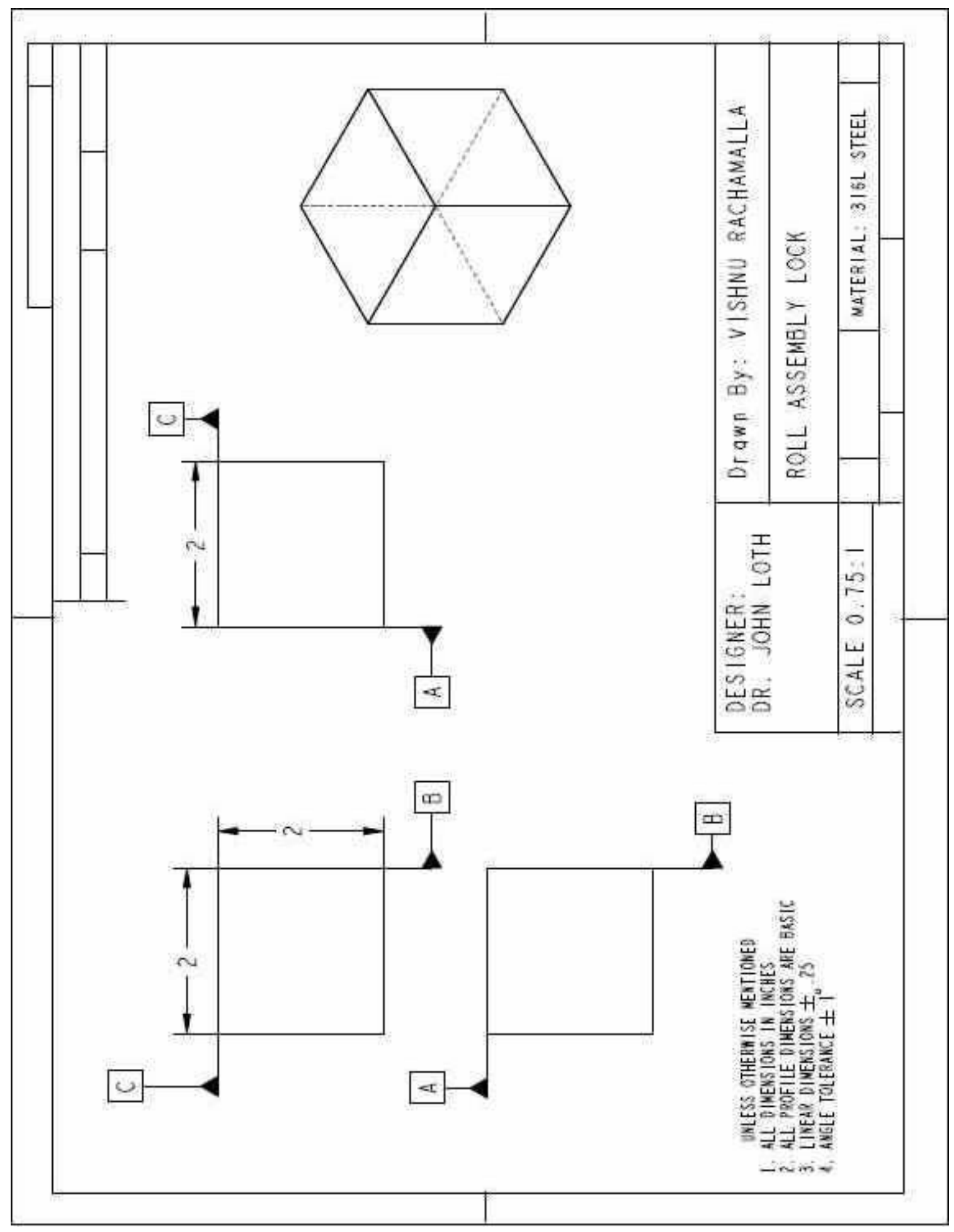

Fig: 3.35 Roll Assembly Lock 


\subsection{DISCUSSION OF THE DESIGN}

Through extensive testing of many bearing materials such as 316L Stainless steel, Stellite, and many other materials provided by the steel vendors, it is determined that the bearing wear rate is proportional to the bearing contact pressure to the power ranging from 1.6 to 2 . The new bearing housing is built inside the rollers, and then rotates with it. Thus both roller and bearing housings rotate about a stationary shaft clamped at each end to the roll supporting bridle. The bearing length now can be tripled without increased in bending moment as compared to the conventional roller. Also, with the rotating ceramic inserts being welded to the end of the roll, perfect bearing alignment can be ensured. Finally, the drastic reduction in the bearing contact pressure could increase the bearing life by at least five fold. 


\section{CHAPTER 4 - SUMMARY AND RECOMMENDATIONS}

Due to bankruptcy of Weirton Steel and sale of the company in 2005, the on-line testing for the herein described bearing life extender is not assured. Through the cooperative efforts between the following parties the cost of a line trial would be shared by all. Weirton Steel intended to provide the roll castings and perform the line trials; Vesuvius-Mc Danel supplied the $5 \times 1 \frac{1}{2}$ inch size ceramic bearing inserts; Praxair Surface technologies volunteered the bearing surface coatings with a 0.05 " and 0.005 " layer of laser clad tungsten carbide on the inner and outer shells of the roll respectively. Petitto Mine Equipment intends to make a reasonable bid for the roll manufacturing. The stabilizer roll provided by Weirton steel is 8-inch in diameter. It rotates on a 4inch diameter stationary shaft. In the region of the two bearings, the shaft is tapered down to 3 -inch in diameter at the ends. The ends are rigidly clamped in collars welded to the arms of the roll support bridle. Each bearing sleeve will have five inserts $72^{\circ}$ apart. The bearing sleeves are attached to the roller and thus rotate with it. The $1 / 2$-inch step between the 3 -inch bearing and the 4 -inch shaft provides sufficient surface for the ACD Wearguard inserts to ride on, thereby forming a thrust bearing. For the first line-trial, neither the bearing length nor its diameter has been increased over that of the conventional roll. The anticipated increase in bearing life will depend on: 1) Reduced shaft deflection and thus more uniform loading, 2) Assured bearing alignment during steering and thus more uniform loading, 3) Improved thrust bearing performance. Future tests 
may use double the length of the bearing areas to demonstrate the advantage of reducing bearing contact pressure.

The anticipated drawbacks of the fixed shaft design are: a) the need to drain all the zinc from the inside of the roll when it is removed from the zinc-pot otherwise it may solidify permanently within the shaft inside. b) The presence of a stationary shaft inside the roller adds friction and may affect roller stopping torque. West Virginia University is hopeful that the advantages listed above will overshadow its shortcomings and the fixed shaft configuration may significantly increase the time between overhauls. ${ }^{5}$ 


\section{REFERENCES}

1. Galvinfo Center Rev 2.1 August 2003, International Lead Zinc Research Organization (ILZRO), details included in the Internet posting www.steelmillsoftheworld.com/activities/datacenter.

2. Society of Automotive Engineers, Matzelle, Albert J, "Examination of stress in sleeve bearing backs", July 1981.

3. Don Renner, "Hands-On-Maintenance for Water, Wastewater Equipment" October 1, 1998.

4. 316 Stainless Steel Data Sheet, details included in the Internet posting www.aksteel.com/pdf/markets_products/stainless/austenitic/316_316L_Da ta_Sheet.pdf.

5. Dr. John Loth, "Zinc-Pot Roll Bearing Design Modification for Increased Life”, Galvatech 04' Conference, April 4-7 2004. (Also in "Materials Characterization "WIT Press 2004, ISBN: 1-85312-988-7).

6. Dr. James Snider II, "Zinc Pot Material Wear and Corrosion Characterization", PhD Dissertation, West Virginia University, WV USA, December 2004. 
7. Ryan Ware, "Design and construction of a Zinc Pot Bearing Material Wearing Tester", April 1, 2001 - March 31, 2002.

8. V.Parthasarathy,"'Long term Performance of Pot Hardware in Continuous Galvanizing Lines", Master's Thesis, West Virginia University, 2003.

9. Teck Cominco Metals Ltd, "Effects of bearing design on the wear of a journal bearing sliding in the molten zinc", $44^{\text {th }}$ MWSP Conference Proceedings, Vol.XL, pp 1285-1297, 02. 


\section{APPENDIX}

Consider a stabilizer roll under a 500 pound load with bearings located at the end of the tube, forming the roller surface. The roll acts like a beam with uniformly distributed load with the supports not at the end, but as shown in the Fig 3.36. The length over which the bearing supports the roll is $5 \frac{5}{8}$ ". Hence, the deflection can be calculated assuming the supports at $L=$ half of $5 \frac{5}{8}$ ". This gives a more appropriate estimate of the deflection.

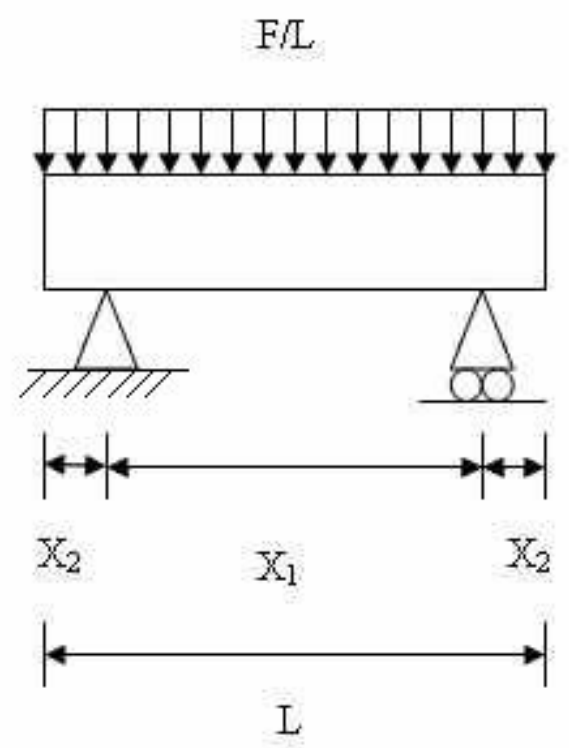

Fig: 3.36 Uniform Load acting on the Stabilizer Roll 


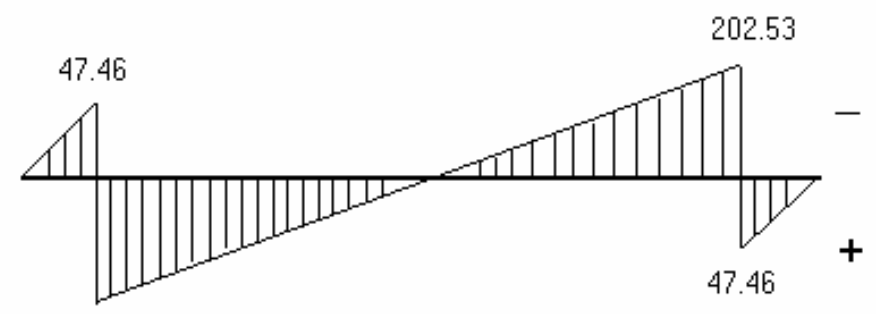

$202.53 \quad$ Shear force (lb) variation
over the span of the roll

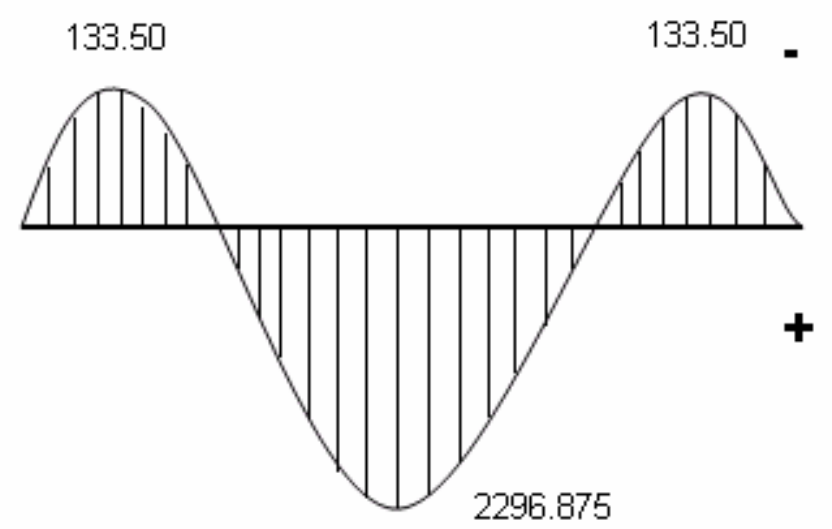

Bending Moment (lbf-in) variation over the span of the roll

Fig: 3.37 Free body Diagram (Shear Force \& Bending Moment Diagram)

The free body diagram of the roll is shown in Fig 3.37. The moment equation can be written as

$M_{A}=(F / 2){ }^{*}<X-X_{2}>+(F / 2) *<X-X_{2}-X_{1}>-(F / 2 L){ }^{*} X^{2}$

Where $<\mathrm{X}-\mathrm{X}_{2}>=0$ if $\mathrm{X}-\mathrm{X}_{2}<0$;

$<\mathrm{X}-\mathrm{X}_{2}-\mathrm{X}_{1}>=0$ if $\mathrm{X}-\mathrm{X}_{2}-\mathrm{X}_{1}<0$; 
For $F=500 \mathrm{lbf}, L=59^{1} / 8^{\prime \prime}, X_{1}=48^{\prime \prime}, X_{2}=5^{5} / 8^{\prime \prime}$,

The value of the maximum shear force is

$\mathrm{F}^{*} \mathrm{X}_{1} /\left(2^{*} \mathrm{~L}\right)=202.53 \mathrm{lbf}$

Due to the overhang, the negative shear force component is

$\mathrm{F}^{*} \mathrm{X}_{2} / \mathrm{L}=47.46 \mathrm{lbf}$

The maximum bending moment occurs at the centre

$\mathrm{F}^{*}\left(\mathrm{X}_{1}^{2}-4 \mathrm{X}_{2}^{2}\right) /\left(8^{*} \mathrm{~L}\right)=2296.875 \mathrm{lbf}-\mathrm{in}$

At the supports it is

$\left(F^{*} X_{2}^{2}\right) /(2 * L)=133.50$ lbf-in.

\section{To find the maximum deflection for varying value of $X_{2}$ (bearing length):}

According to beam bending theory,

$$
\left.E^{*}\right|^{*}\left(d^{2} y / d x^{2}\right)=-M_{A}=(F / 2 L){ }^{*} X^{2}-(F / 2){ }^{*}\left\langle X-X_{2}\right\rangle-(F / 2){ }^{*}\left\langle X-X_{2}-X_{1}\right\rangle
$$

Where $\mathrm{X}=0$ to $\mathrm{L}$

$\left.\mathrm{E}^{*}\right|^{*}(\mathrm{dy} / \mathrm{dx})=(\mathrm{F} / 2 \mathrm{~L}){ }^{*}\left(\mathrm{X}^{3} / 3\right)-(\mathrm{F} / 4){ }^{*}<\mathrm{X}_{1}-\mathrm{X}_{2}>^{2}-(\mathrm{F} / 4)^{*}<\mathrm{X}-\mathrm{X}_{2}-\mathrm{X}_{1}>^{2}+\mathrm{C}_{1}$

$\left.E^{*}\right|^{*} y=(F / 24 L){ }^{*} X^{4}-(F / 12){ }^{*}<X-X_{2}>^{3}-(F / 12){ }^{*}<X-X_{2}-X_{1}>^{3}+C_{1} X+C_{2}$

At $X=L / 2=\left(X_{1} / 2+X_{2}\right), d y / d x=0 ;$ solve for $C_{1}$

At $X=X_{2} ; y=0$; solve for $C_{2}$

At $X=L / 2 ; y=y_{\max }$

The final equation after including the obtained values of $C_{1}$ and $C_{2}$ is 


$$
\begin{aligned}
& \mathrm{E} \times \mathrm{I} \times \mathrm{y}_{\max }=\left[\left\{\left(\frac{\mathrm{F}}{2 \mathrm{~L}}\right) \times\left(\frac{\left(\left(\mathrm{x}_{1}+2 \times \mathrm{x}_{2}\right)^{4}\right)}{192}\right)\right\}-\left\{\left(\frac{\mathrm{F}}{96}\right) \times \mathrm{x}_{1}^{3}\right\}+\right. \\
& +\left\{\left(\frac{\mathrm{F}}{4}\right) \times\left(\mathrm{x}_{1}+2 \times \mathrm{x}_{2}\right) \times\left\{\left(\frac{\mathrm{x}_{1}^{2}}{8}\right)-\left\{\left(\frac{1}{3 \mathrm{~L}}\right) \times\left(\left(\frac{\mathrm{x}_{1}^{3}}{8}\right)+\mathrm{x}_{2}^{3}+\left(\frac{3}{4} \times \mathrm{x}_{1} \times \mathrm{x}_{2} \times\left(\mathrm{x}_{1}+2 \times \mathrm{x}_{2}\right)\right)\right)\right\}\right\}\right\}- \\
& \left.\left.-\left\{\left(\frac{\mathrm{F}}{24 \mathrm{~L}}\right) \times\left(\mathrm{x}_{2}^{4}\right)\right\}-\left\{\left(\frac{1}{2} \times \mathrm{F} \times \mathrm{x}_{2}\right) \times\left\{\left(\frac{\mathrm{x}_{1}^{2}}{8}\right)-\left\{\left(\frac{1}{3 \mathrm{~L}}\right) \times\left(\left(\frac{\mathrm{x}_{1}^{3}}{8}\right)+\mathrm{x}_{2}^{3}+\left(\left(\frac{3}{4} \times \mathrm{x}_{1} \times \mathrm{x}_{2}\right) \times\left(\mathrm{x}_{1}+2 \times \mathrm{x}_{2}\right)\right)\right)\right\}\right\}\right\}\right\}\right]
\end{aligned}
$$

Substituting $\mathrm{X}_{2}=0$, we get $\mathrm{X}_{1}=\mathrm{L}$ and $\mathrm{y}_{\max }=\left(5^{*} \mathrm{~F}^{*} \mathrm{~L}^{3}\right) /\left(384^{*} \mathrm{E}^{*} \mathrm{l}\right)$

which is the maximum deflection for a simply supported beam with a uniformly distributed load. Hence this equation is verified.

At values of $X_{2}=0,1.125,2.5,2.8125,3.375,5.625$, the deflection ' $\mathrm{y}_{\max }$ ' is measured and a graph is plotted for the deflection $\mathrm{y}_{\max }$ and $\mathrm{X}_{2}$. The value of the deflection decreases as $X_{2}$ increases or $X_{1}$ decreases (see Fig. 3.38).

The theoretical values display the maximum deflection at the centre for considering the beam section of the roll. A similar ANSYS simulation is performed to calculate the maximum deflection at the centre. A Beam element (Beam 4) is used for meshing. The constraints are placed at $X_{2}=0$ and the deflection value obtained is $y_{\max }=0.0064 \mathrm{~mm}=2 \frac{5}{8}$ approx (see Fig 3.39) which is equal to the maximum theoretical deflection at the centre. 
The results of the maximum deflection values for $X_{2}=0,1.40625,2.8125$, $4.21875,5.625$ for the roll obtained from ANSYS simulation \& theoretical equation are plotted in the graph (see Fig 3.41). The roll is meshed using the 3D beam element Beam4. The deflection values from the ANSYS simulation can be compared to that obtained on the roll experimentally.

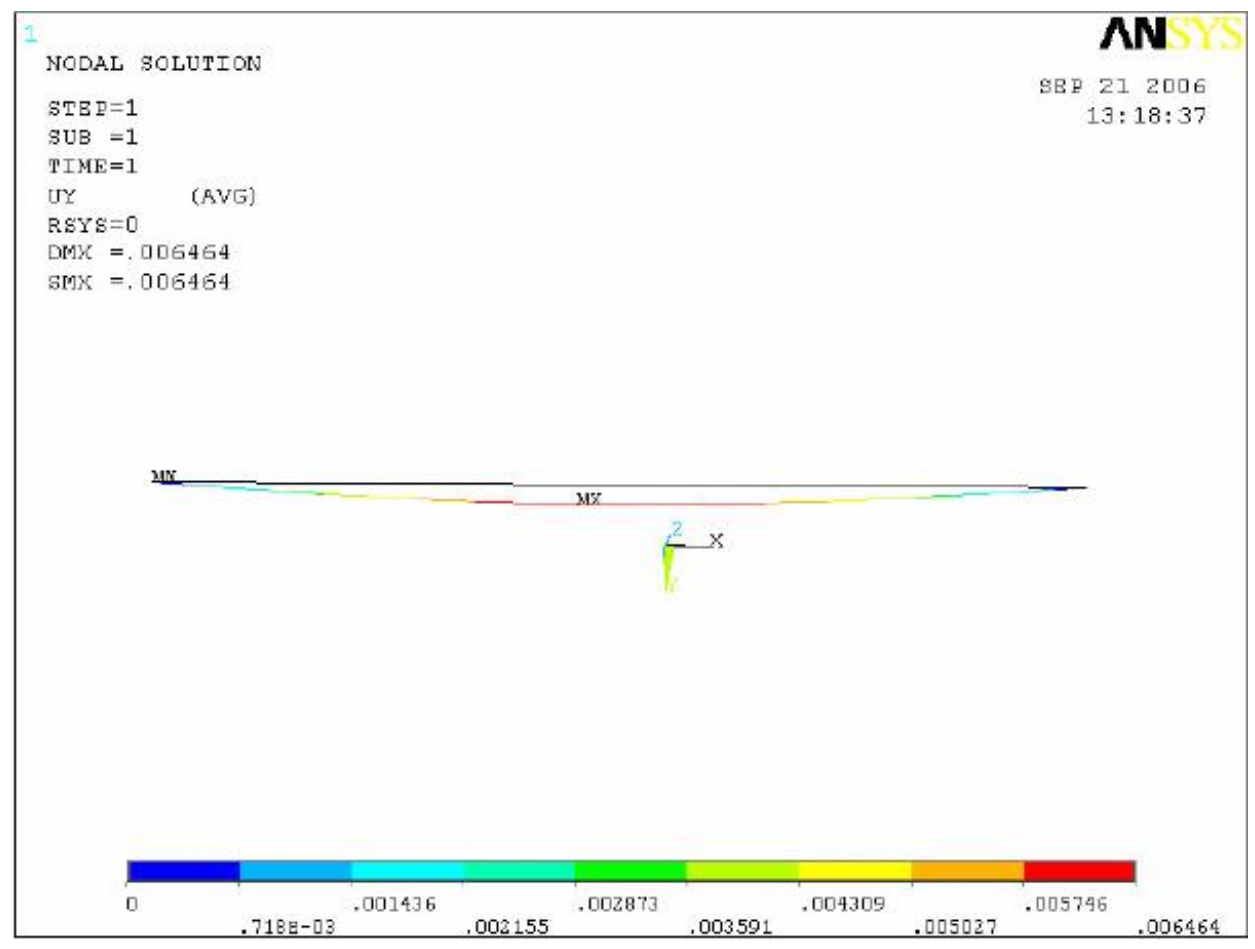

Fig: 3.39 Maximum deflection in ANSYS (beam elements) at $\mathrm{X}_{2}=0$ (in $\mathrm{mm}$ ) 


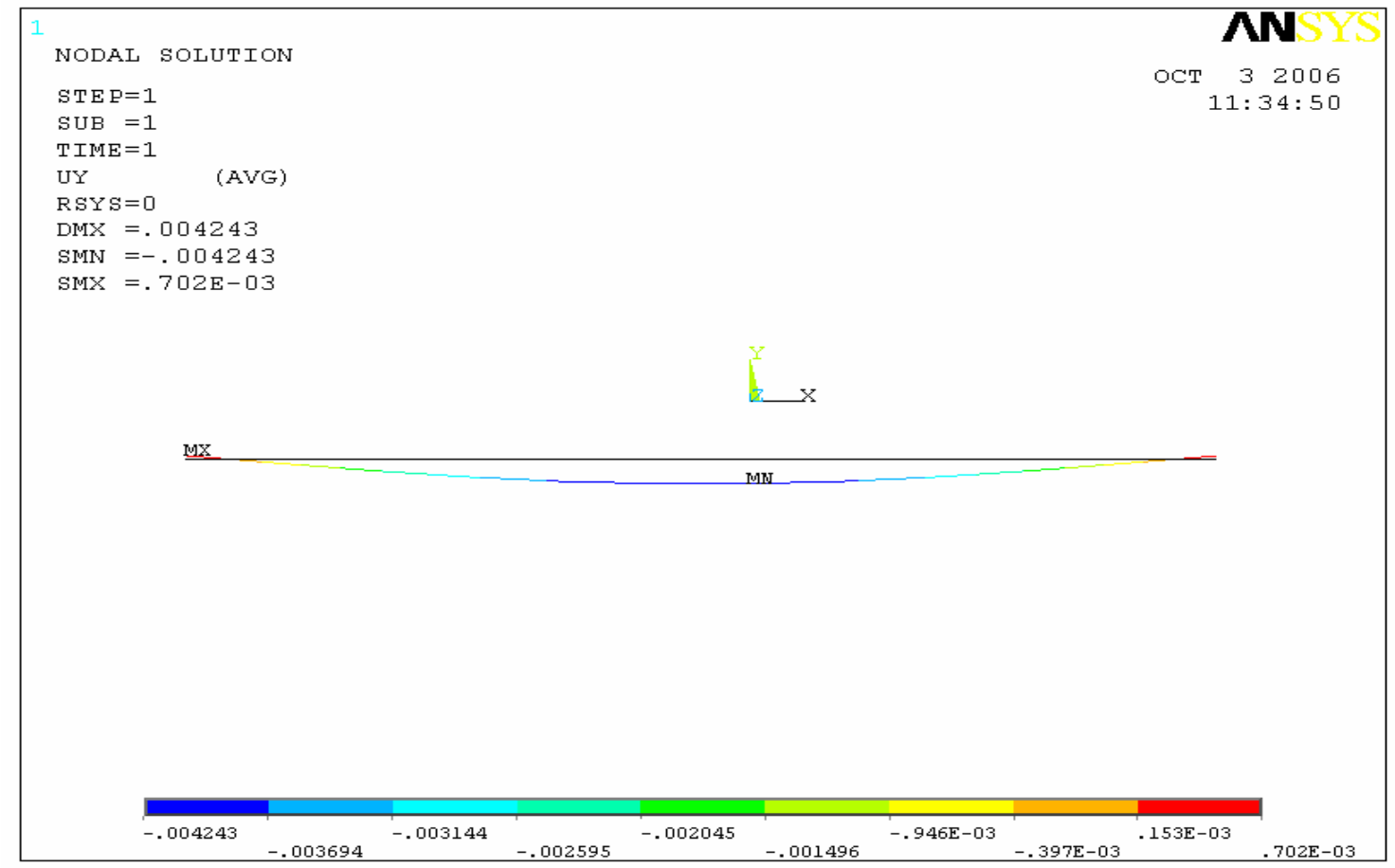

Fig: 3.40 Maximum deflection in ANSYS (beam elements) at $\mathrm{X}_{2}=5.625$ (in mm)

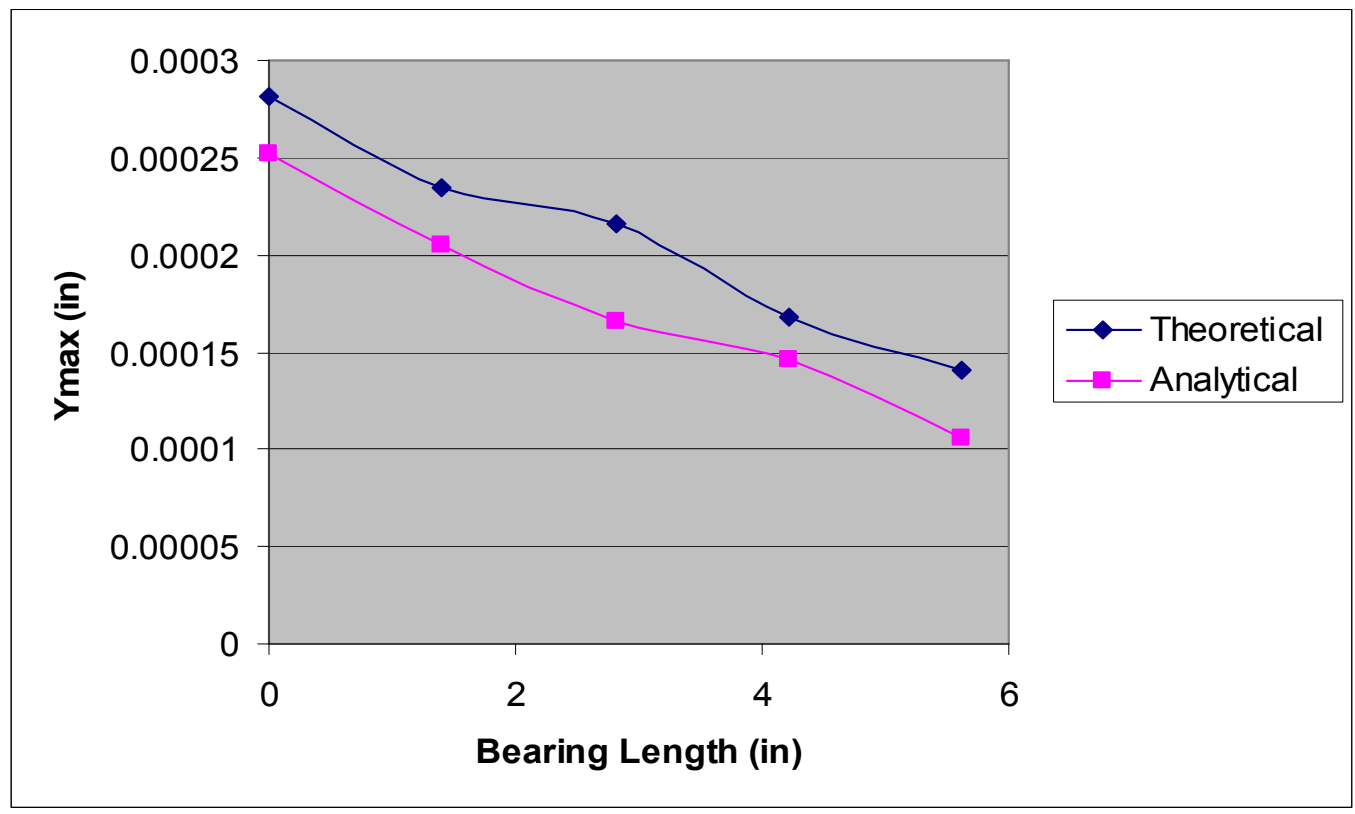

Fig: 3.41 Comparison of Maximum Deflection values in ANSYS \& Theoretical Equation (in inches) 


\section{Critical Speed of the Stabilizer Roll}

It is the speed at which the roll would become dynamically unstable resulting in strong vibrations. The critical speed of the Stabilizer roll can be calculated as:

$\omega_{c}=\left(p i / X_{1}\right)^{2 *}(D / 4) *\left(g^{*} E / \rho\right)^{0.5}$

Where,

$\omega_{c}=$ Critical Speed

$\mathrm{X}_{1}=$ Distance between the bearings $=48 \mathrm{in}$.

$\mathrm{D}=$ Diameter of the roller $=8 \mathrm{in}$.

$\mathrm{g}=$ Acceleration due to gravity $=9.8 \mathrm{~ms}^{-2}=385.8 \mathrm{in} / \mathrm{sec}^{2}$

$\mathrm{E}=$ Modulus of Elasticity $=30 \mathrm{E} 6 \mathrm{lb} / \mathrm{in}^{2}$

$\rho=$ Density of $316 \mathrm{~L}$ Stainless Steel $=0.282 \mathrm{lb} / \mathrm{in}^{3}$

The value of the critical speed is obtained as $8792 \mathrm{rad} / \mathrm{sec}$.

Hence the critical velocity would be $V=r{ }^{*} \omega_{c}=35168 \mathrm{in} / \mathrm{sec}$, where $r=$ radius of the roll (4 in.)

The maximum sheet velocity is $110 \mathrm{in} / \mathrm{sec}$ (see Fig 1.2) for Line \# 5 at Weirton Steel. Even if the roll rotates about the same speed as the sheet, it is much lower than the critical speed. 